\title{
Wind Climate Analyses for SRTC's Central Climatology Site
}

A. H. Weber, R. L. Buckley, and R. J. Kurzeja

Westinghouse Savannah River Company Aiken, SC 29808 
This document was prepared in conjunction with work accomplished under Contract No. DE-AC09-96SR18500 with the U. S. Department of Energy.

\section{DISCLAIMER}

This report was prepared as an account of work sponsored by an agency of the United States Government. Neither the United States Government nor any agency thereof, nor any of their employees, makes any warranty, express or implied, or assumes any legal liability or responsibility for the accuracy, completeness, or usefulness of any information, apparatus, product or process disclosed, or represents that its use would not infringe privately owned rights. Reference herein to any specific commercial product, process or service by trade name, trademark, manufacturer, or otherwise does not necessarily constitute or imply its endorsement, recommendation, or favoring by the United States Government or any agency thereof. The views and opinions of authors expressed herein do not necessarily state or reflect those of the United States Government or any agency thereof.

This report has been reproduced directly from the best available copy.

Available for sale to the public, in paper, from: U.S. Department of Commerce, National Technical Information Service, 5285 Port Royal Road, Springfield, VA 22161, phone: (800) 553-6847, fax: (703) 605-6900

email: orders@ntis.fedworld.gov

online ordering: http://www.ntis.gov/help/index.asp

Available electronically at http://www.osti.gov/bridge

Available for a processing fee to U.S. Department of Energy and its contractors, in paper, from: U.S. Department of Energy, Office of Scientific and Technical Information, P.O. Box 62, Oak Ridge, TN 37831-0062,

phone: (865)576-8401,

fax: (865)576-5728

email: $\underline{\text { reports@ adonis.osti.gov }}$ 


\section{Wind Climate Analyses for SRTC's Central Climatology Tower}

\section{Executive Summary}

This report was written to present climatological summaries of the wind data at the Central Climatology (CC) tower in a convenient format and to point out some features of the wind speed and direction that have not been widely appreciated in the past. Short-term (two-week) wind roses provide a means to demonstrate the temporal and spatial relationships that wind speed and direction undergo using a ten-year database from the $\mathrm{CC}$ tower. These relationships are best demonstrated by examining the figures provided in this report or looking at loops of computergenerated images provided by the authors.

As is true for the National Weather Service (NWS) surface stations in the Southeast, the Appalachian Mountains and the Atlantic Ocean are major influences of wind direction for the $\mathrm{CC}$ Tower. Terrain steering of the wind from these influences is suggested in the seasonal and diurnal patterns of the wind. The CC Tower is strongly influenced by sea breezes in the evening hours (mainly in the spring and summer seasons) that penetrate from the coast up the Savannah River channel. In autumn all levels of the CC Tower are subject to northeasterly winds that arise from high-pressure systems to the north and northwest.

Wind roses can be used to aid wind direction forecasting at the Savannah River Site (SRS), particularly when computer models predict light wind speeds. Also, in cases when numerical models disagree on wind direction forecasts it is advisable to consider the $\mathrm{CC}$ tower wind roses.

Subjective comparisons between the annual wind roses for Columbia, South Carolina (CAE) and Augusta, Georgia (AGS) with the CC tower showed that the top three tower levels resembled CAE whereas the bottom level resembled AGS. On shorter time scales, the results of a subjective comparison showed that the $\mathrm{CC}$ tower roses resembled an average of the two wind roses for AGS and CAE. Neither AGS nor CAE were consistently similar to the lower two CC levels for shorter time scales (e.g., two-weeks). This conclusion emphasizes the need for on-site wind measurements at SRS.

Statistical correlation between CC's 61-m wind speed and El Niño/La Niña conditions was very low. Furthermore, a significant statistical correlation between CC's 61-m wind speed and the North Atlantic Oscillation (NAO) index was not found.

The mean wind speeds for the ten-year period were determined by hour, two-week period and year. The highest mean wind speed was seen at night at the top tower level. The lowest mean wind speed was found during the night at the lowest tower level. The maximum mean wind speed during the twenty-four hour period was $4.39 \mathrm{~m} / \mathrm{sec}$ at the $61-\mathrm{m}$ level at 22:00 EST. The minimum mean wind speed during the twenty-four hour period was $1.28 \mathrm{~m} / \mathrm{sec}$ at the $4-\mathrm{m}$ level at 04:00 EST. 
The mean wind speeds for twenty-six two-week periods showed that the highest wind speeds $(4.77 \mathrm{~m} / \mathrm{sec})$ are achieved during in late February-early March at the 61-m tower level. The lowest wind speeds $(1.53 \mathrm{~m} / \mathrm{sec})$ are found during mid-August at the $4-\mathrm{m}$ tower level.

The mean wind speeds for each year over the ten-year period showed that the highest wind speed was achieved during 1996 at the top tower level. The lowest wind speed was found during 1991 at the lowest tower level (which was 2-m at this time). The maximum mean wind speed during the ten-year period was $4.19 \mathrm{~m} / \mathrm{sec}$ at the $61-\mathrm{m}$ level in 1996 . The minimum mean wind speed during the ten-year period was $1.62 \mathrm{~m} / \mathrm{sec}$ at the $2-\mathrm{m}$ level in 1991 .

\section{Introduction}

The Savannah River Technology Center's (SRTC) Atmospheric Technologies Group (ATG) has operated the CC tower near the center of the Savannah River Site (SRS) since 1985. Data from the weather instruments on this tower have provided answers to questions involving risk analyses, dose studies, weather forecast verifications, and wind/temperature conditions during extreme events and planned tests. Most recently these data are being used for initial and boundary conditions for computationally intensive numerical simulations using mesoscale forecasting models that are run on a three-hourly basis by ATG for SRS and the surrounding vicinity.

Weber et al. (2002a) found that a series of wind roses based on relatively short time scales (from two weeks to one hour) were a convenient method to depict the predominant wind speeds and directions at anemometer sites in the Southeast operated by the NWS. That report also revealed some interesting spatial and temporal relationships among thirteen NWS stations in the Carolinas, Georgia, and Florida. Our study here will focus on the $\mathrm{CC}$ tower to show changes in the wind speed and direction distributions with height during diurnal and annual cycles. This study will concentrate on mean wind speed and direction measurements since wind gusts and turbulence were covered in an earlier publication (Weber et. al., 2002b). The results in this report may also be useful for assessing the potential for wind turbine generators at the SRS.

\section{Wind Instrumentation and Changes in Measurement Height}

Parker and Addis (1993) described the siting and instrumentation on the CC tower. The tower is located at north latitude 33 degrees 14 minutes 43 seconds, and west longitude 81 degrees 39 minutes 0 seconds in N-Area near the center of the SRS (labeled CLM in Fig. 1). The tower stands in a flat area surrounded by grass out to about $83 \mathrm{~m}(272 \mathrm{ft})$ followed by a low-profile (< $1.5 \mathrm{~m}$ or $5 \mathrm{ft}$ high) storage yard/buildings, railroad, and scattered stands of pine trees. The pine tree stands begin about $152 \mathrm{~m}(500 \mathrm{ft})$ from the tower. Beyond the isolated pine tree stands are areas of denser forest and cleared areas for roads, production sites, railroads, fields and streams.

Parker and Addis (1993) also described the cup anemometers and wind vanes mounted on the $\mathrm{CC}$ tower. The wind instruments consist of Teledyne-Geotech model 1585 bivanes and model 1564B cup anemometers that have been operated and calibrated on a regular basis since 1985. 
There has been one change in measurement height of the wind instrumentation at the lowest level of the tower. In May 1993 the anemometer and bivane were moved from 2-m to 4-m to avoid the wake effect of an instrumentation box mounted on a tower leg.

\section{Wind Speed and Direction Data}

Data from the first half of the 20-year period of CC's operation could not be copied from magnetic tape storage media to disk so our effort in this study used the more recent data from the CC Tower's records. The wind speed and direction data for use in this study were obtained for the four tower measurement levels $(2-4,18,32$, and 61-m) for a ten-year period spanning January 1, 1991 to December 31, 2000. These data are 15-minute scalar averages of wind speed and vector averages of wind direction. Four fifteen-minute records beginning on each hour were combined to obtain one-hour averages of the wind speed (scalar average) and wind direction (vector average).

In order to show the wind speed and direction data at a given level for all 10 years on a single wind rose plot it is necessary to convert the wind directions into 16-point compass-sector wind directions, since the original winds were reported to the nearest degree. This was accomplished by rounding the wind direction to the nearest of sixteen 22.5-degree compass sectors (centered on N, NNE, etc.) No bias is introduced in the wind direction sectors using this process (as would be the case for NWS stations that report to the nearest 10 degrees).

Using our 10-year data interval it was possible to average the wind rose plots over different time periods to examine climatic changes over a typical year. In this report the data were categorized using twenty-six two-week periods covering a typical year. (Each year has 364 days, the remaining 1-2 days of each year were dropped). There were six 4-hr time periods covering the diurnal cycle. The six 4-hr time periods selected were (midnight, 00:00-03:00 LST; pre-rise, 04:00-07:00; post-rise, 08:00-11:00; afternoon, 12:00-15:00; early evening, 16:00-19:00; late evening, 20:00-23:00 LST). For the CC Tower during January 1, 1991 to December 31, 2000 (10 years) there are 87,672 hourly observations (350,688 fifteen-minute observations). For the 26 two-week periods and six 4-hr periods spanning a day (averaged over the 10-year data set) there are $\sim 560$ hours of data from the $\mathrm{CC}$ Tower represented in each individual wind rose plot. A complete set of $156(26 \times 6)$ wind roses will be available on the Internet at an address provided by the author (allen.weber@srs.gov). The Internet is being used to present the wind roses since there are such a large number of color figures that need to be displayed at full scale. In this report we will reduce the size of the figures representing the 26 two-week periods and the six periods of the day so that each two-week period will fit on a single page.

\section{Geographical Features and Observed Annual and Seasonal Changes in Wind Direction}

The Appalachian Mountains' and the Atlantic Coast's effect on the windroses for NWS's Southeast stations was noted in the earlier report (Weber et al., 2002a). The Appalachians help force storm tracks farther south into northern Georgia and the coastline's temperature gradient from land to sea induces land and sea breezes, particularly in the spring and summer. The CC's location, $\sim 65 \mathrm{~km}$ from the NWS station near Augusta, Georgia (AGS) and $\sim 105 \mathrm{~km}$ from the 
NWS station in Columbia, South Carolina (CAE) suggests that CC's wind roses should have some similarities. Of course, there are local terrain features that can affect winds so that the overall wind pattern will be a result of local and large-scale interactions. The large-scale terrainslope (few 10s of kilometers) near the CC site is basically from the NW to the SE (Fig. 1). The small-scale terrain slope near the tower is small enough to neglect for most purposes.

The annual wind rose (Fig. 2) for the CC site for the ten-year period has a degree of isotropy at the lowest tower level. Winds from the north through northwest sector are noticeably infrequent at all heights. Winds from the east-southeast and southeast are infrequent at the top three levels. The top three levels of the CC tower's annual-averaged wind roses differ by only minor percentages for each of the sixteen direction sectors. In fact, overlaying transparent cutouts of the wind roses of the top three levels shows no discernable differences. This similarity is rather striking considering the height differences among the top levels. The similarity of the wind roses for the top three CC tower levels is a fairly common condition throughout the year. The contrast of the top three levels with the bottom level will be considered in more detail later in this report.

\section{Observed Two-Week and 4-hour Changes in Wind Direction for the Afternoon Period}

Figures 3 through 28 show the breakdown for the two-week periods for the six periods of the day. The afternoon period is emphasized in the following discussion since outdoor work is more likely to be performed at SRS in the afternoon than other periods of the day. The afternoon winds in early January (Fig. 3) indicate that climatologically speaking, well-mixed conditions exist throughout the CC Tower levels including the 4-m level. All of the CC winds for this time period resemble the AGS wind rose for the same time period with a strong mode from the west and a secondary mode from the east-northeast. This wind rose appearance reflects the influence of mid-latitude cyclones and cold air damming, a common winter weather phenomenon in South Carolina. In late January (Fig. 4) the wind speeds increase and the wind direction frequencies become slightly more often out of the northwest (perhaps because of a greater frequency of storm systems).

In early February (Fig. 5) the wind directions remain essentially the same but the wind speeds in the $12 \mathrm{~m} / \mathrm{s}$ bin increase. In mid-February (Fig. 6) there is a slight direction shift to the west and southwest with a secondary mode from the east. In late February-early March (Fig. 7) the mode from the east disappears and shifts to the south-southeast. In mid-March (Fig. 8) the direction modes return to the mid-February pattern with westerlies and east-northeasterlies, except that speeds are stronger out of the west than in mid-February. The reasons behind this return to the previous pattern or "pulsing" behavior is not yet understood, but the phenomenon will be shown again later in this report.

In late March-early April (Fig. 9) the primary modes are from the northwest, southwest and south. The primary mode shifts to southwest during mid-April (Fig. 10) with a low frequency winds from northwest clockwise through southeast, reflecting fewer mid-latitude cyclones. In late April-early May (Fig. 11) the majority of the wind directions shift to the three westerly modes (west-southwest, west, and west-northwest). There are still very few winds from northwest to southeast (in a clockwise rotation sense). In mid-May (Fig. 12) there is a noticeable 
lack of east-southeast winds but northeast winds become more prevalent. In late May-early June (Fig. 13) the primary and secondary modes shift to west and east, and there is a distinct lack of northerly winds. This behavior may reflect the tendency for the Bermuda high pressure system to influence winds during the late spring and summer seasons. In mid-June (Fig. 14) there is a rotation of the former wind rose pattern to west-southwest and east-northeast. In late June (Fig. 15) there is a shift to the southwest and a diminishing number of east-northeast winds.

In early July (Fig. 16) the shift to the southwest with diminishing east-northeast is continued. By late July (Fig. 17) this same trend continues and northwest through southeast (clockwise) are mainly absent. In early August (Fig. 18) the main mode is west-southwest but east-northeast picks up again. By mid-August (Fig. 19) the predominant mode shifts to east-northeast. In late August-early September east-northeast and northeast (Fig. 20) are predominant due to frequent high-pressure systems over the Appalachians. There are also more wind directions from the north and south at the three lower levels, a noticeable lack of northwest winds, and speed increases over the previous two-weeks, especially at the higher levels. In mid-September (Fig. 21) there are more west-northwest and east-southeast modes along with the northeast mode. In late Septearly Oct. (Fig. 22) northeast winds are dominant. In mid-October (Fig. 23) west-northwest winds once again gain strength so that the pattern more strongly resembles mid-September. By late Oct-early November (Fig. 24) there are more west and west-southwest winds reflecting more frequent mid-latitude cyclones. In mid-November (Fig. 25) there are more west-northwest and east-northeast winds. In late November (Fig. 26) there are more northeast winds. In early December (Fig. 27) there is a shift to west and fewer northeast winds. In late December (Fig. 28) there are more west-southwest and northeast winds.

As mentioned earlier, there seems to be a fairly coherent pattern of wind direction patterns reflected in the wind roses repeated from the bottom to the top of the $\mathrm{CC}$ tower. The reasons for the short term shifts are not as apparent as the longer term shifts that are discussed in the earlier report on the Southeastern NWS stations, namely the subtropical high pressure system in the summer months and the high pressure system over the Appalachians in the autumn. Rather than discuss each four-hour period in the detail as in the paragraphs above, we decided to summarize the important features of each period separately in Fig. 29.

Fig. 29 shows three wind direction modes for each of the 6 periods of the day over an entire year (26 two-week periods). The modes plotted in the figure are (1) primary mode: the most frequent wind direction for the upper three levels of the tower, (2) secondary mode: the second most frequent wind direction for the upper three levels of the tower, and (3) surface mode: the most frequent wind direction for the lowest tower level.

The figure shows some of the striking short-term changes in the primary wind direction mode which occur (in a climatological sense) over the two-week periods. In some cases these shortterm fluctuations seem to suggest that the winds "overshoot" and oscillate about some mean wind direction. This can be seen best in the figures for post-sunrise, early evening, and presunrise. These oscillations seem to contain one-month and two-month periods in the wind direction within the annual cycle. The lowest tower level often shows a predominant wind direction that is quite different from the higher tower levels, especially for late evening, midnight 
and pre-sunrise. It is worth emphasizing that these are climatologically averaged wind directions and so to speak as if the winds necessarily exhibit strong wind shear on any given day could be misleading. Nevertheless, there ought to be occasions when the actual tower winds behave in this manner. Katabatic winds below 18 meters could cause such behavior.

\section{Highlights of Wind Roses for All Periods of the Day}

The following sub-sections summarize highlights of the annual pattern of wind roses from the $\mathrm{CC}$ tower for the six 4-hr periods of the day.

\section{Afternoon:}

- The east-northeasterly and easterly winds mostly disappear in the late February-early March period (Fig. 7, when south-southeast winds become active) only to re-establish themselves two weeks later in mid-March (Fig. 8) then mostly disappear in the late March-early April period (Fig. 9), then resurge again in mid-May and early June through late June (Figs. 1215). The northeasterlies are gone in late July (Fig. 17), but return in August (Fig. 18) and continue through the remainder of the year.

- Westerly winds never really disappear during the year but are steadiest in late July (Fig. 17) when the west through south sectors account for the vast majority of wind directions. The westerlies are at their minimum during late September-early October (Fig. 22).

- Northerlies are found least often in mid April, mid June, and late July (Figs. 10, 14, and 17) and most often in mid November through December (Figs. 25-28). After a bit of a hiatus in January, the north winds return quite strongly again in early February (Fig. 5).

- Successive two-week periods that show considerable contrast are (1) late July (westsouthwest) to early August (Figs. 17-18), (2) mid February (east) to late February-early March (SSE) (Figs. 6-7), and (3) late March-early April (west-northwest) to mid April (westsouthwest) (Figs. 9-10).

\section{Early Evening:}

- Successive two-week periods that show considerable contrast are (1) late January (westnorthwest) to early February (southwest) (Figs. 4-5), and (2) mid May (south) to late Mayearly June (west and east-southeast) (Figs. 12-13), and (3) late May-early June (west and east-southeast) to mid June (south-southeast) (Figs. 13-14).

- Sea breeze effects (or perhaps preferential channeling near the Savannah River) are manifested from late March-early April to late April-early May (Figs. 9-11), then mid June through late October-early November (Figs. 14-24).

\section{Late Evening:}

- Sea breeze effects (or perhaps preferential channeling near the Savannah River) are manifested from mid February (at the lowest level) or mid April (all levels) to mid September (Figs. 6-21). 
- Striking sea breezes occur during mid April through late June (Figs. 10-15) then mid August to mid September (Figs. 19-21). These nocturnal sea breezes were studied in detail by Buckley and Kurzeja (1997) during the Stable Atmospheric Boundary Layer Experiment (STABLE).

- Great contrast from the bottom of the CC Tower to the top occurs during late October-early November (Fig. 24). (East-southeast at the lowest level to West or east-northeast at the higher levels.)

\section{Midnight:}

- Significant changes for (1) mid October (north-northeast) to late October-early November (west) (Figs. 23-24) and (2) mid November (northeast) to late November (west) (Figs. 2526).

- Great contrast from top to bottom of tower late October-early November (low northeasterly, high westerly) (Fig. 24).

- The most isotropic wind roses for all the tower levels seem to be in mid February (Figs. 6).

- Significant are (1) southerly winds from mid April to late June (Figs. 10-15), (2) northeasterly winds from late August-early September (Fig. 20), pulsing in late Septemberearly October (Fig. 22) and again in mid November (Fig. 25).

\section{Pre Sunrise:}

- Significant changes are found for (1) late February-early March (west) mid March (northeast) (Figs. 7-8), (2) late July (southwest) early August (northeast) (Figs. 17-18).

- Large contrast is found from top to bottom of tower late February-early March (low south southeast, high west) (Fig. 7).

- Most isotropic is mid February, late March-early April through late April-early May (Figs. 6, 9-11).

- Significant wind roses are for (1) southerly winds from mid April to late June (Figs. 10-15), (2) northeasterly winds from late August-early September, pulsing in late September-early October and again in mid November (Figs. 20, 22, and 25).

\section{Post Sunrise:}

- Significant regimes are from early July (Fig. 16) (mostly westerlies) to early August when the mode becomes bimodal (west-southwest \& east-northeast) (Fig. 18).

- Significant wind rose is found for early February, mid May, early December, and late December (no south-southeasterlies or southeasterlies) (Figs. 5, 12, 27, and 28). 
- Significant wind rose for mid April (mostly west-northwest to south-southwest) (Fig. 10).

- Significant wind roses are found for northeasterly winds from late August-early September pulsing in late September-early October and again in mid November (Figs. 20, 22, and 25).

\section{Examples of Wind Rose Use}

The wind roses can be used to aid wind direction forecasting as the following case illustrates. The SRS fire weather forecast is issued twice per day at the Weather Center (WC) using NWS and Regional Atmospheric Modeling System (RAMS) models. On March 11, 2003, the forecaster consulted model results that suggested westerly winds would blow all day into the late evening due to westerly winds aloft. On the other hand, a large surface high-pressure system centered over western New York implied easterly surface winds at night after decoupling with the westerlies aloft. The wind rose for this time of year (Fig. 8) shows that while westerlies are very common in the afternoon, by early evening the 4-m winds have an increasing tendency for a SSE direction. This tendency becomes strongest in late evening and weakens around midnight. The actual winds are shown in Fig. 30. It can be seen that the results from the wind rose could have given a reason to question the forecast produced by numerical models in this case, especially since light wind speeds were forecast. This example shows the value of consulting the wind roses for a given two-week period. Not every situation will result in better forecasts by using these two-week wind roses, but for situations when numerical models disagree or forecast light winds, it would be prudent to consider the dominant modes of the wind rose.

Another example from the mid-April period is shown in Fig. 10. The wind roses show that westerly winds are very common during the afternoon. By early evening a transition begins with the dominant mode from the south then by late evening the lowest level of the tower has switched to southeast winds. This information could be quite useful to the United States Forest Service for predicting a smoke plume's path (from smoldering embers) after a controlled burn is extinguished at the working day's end.

A final example is shown in Fig. 20. In late August-early September the afternoon winds come from a variety of directions but the strongest mode is from the ENE. By early evening the strongest mode is from the SSE and this persists through late evening. In the midnight and early morning hours however, the predominant wind direction switches to northeast.

\section{Similarity of Wind Roses between CC and AGS or CAE}

In some situations it would be helpful to be able to provide information on the similarity of wind roses between CC lower tower levels and the National Weather Service stations at AGS or CAE. Unfortunately, the measurement levels at AGS have been changed (14-10 m) while CAE's have remained at $10 \mathrm{~m}$ during the ten-year period from 1991-2000. CC's lower 2 levels have been at 2 (or 4 since May 1993) and 18-m, so AGS and CAE's measurement heights are about midway between the lower two CC instruments. These differences make it difficult to compare the distributions in a statistically rigorous manner. 
Subjectively comparing the annual wind rose for CAE and AGS with the CC tower shows that the top three tower levels resemble CAE whereas the bottom level resembles AGS. On shorter time scales, the results of a subjective comparison are that the CC tower is usually resemble an average of the wind roses for AGS and CAE. Neither AGS nor CAE are consistently similar to the lower two CC levels for shorter time scales (e.g., two-weeks). This conclusion emphasizes the need for on-site wind measurements at SRS.

\section{El Niño's Lack of Influence on CC Winds}

\section{a. ENSO Index}

The El Niño/Southern Oscillation's (ENSO) influence on rainfall in the Southeast U.S. is now becoming more appreciated. (See Wolter, 1987 and Wolter and Timlin, 1993 and 1998, or the web site designed by the Southeast Regional Climate Center.) One might hope that the various ENSO indexes are related to the wind speed and/or direction preferences in the Southeast and that effect would be reflected in the wind data collected at the $\mathrm{CC}$ tower site. In order to investigate this possibility we chose to use an index called the "multivariate ENSO index (MEI)" since it contains additional parameters (related to climate) that the ENSO index alone doesn't contain (Wolter and Timlin, 1993). (A scatter plot of the MEI versus the usual ENSO index (based on pressure differences) in Fig. 31 shows a good correlation between the two indexes.) The MEI values were merged to the wind speed and direction data from the 10-years of CC data, and wind roses were computed for three subsets: El Niño (MEI > 0.1), La Niña (MEI < -0.1), and neutral $(-0.1<\mathrm{MEI}<0.1)$. These results are shown in Figs. 32-34. These figures show little if any correlation between the wind direction and the MEI.

The results of computing simple statistics for the wind speed at $61 \mathrm{~m}$ for El Niño (MEI > 0.1), La Niña (MEI < -0.1), and neutral $(-0.1<$ MEI < 0.1) are shown in Table 1 . The mean speed for the El Niño case is 3.92 versus 4.08 in the La Niña case. This is a relatively small percentage difference in speed; it is one that is statistically significant because of the large number of observations in the 10 -year period. There are also small statistically significant changes in the $u$ and v-components (east-west and north-south components) of the wind vector.

Table 1. Simple statistics for the CC's 61-m wind speed based on the MEI index, i.e., El Niño (MEI > 0.1), La Niña (MEI < -0.1), and neutral $(-0.1<$ MEI $<0.1)$. The statistics are the mean of the variable, standard deviation, minimum and maximum of the variable, respectively.

\begin{tabular}{lllllll}
\hline Subset & Variable & No. of observations & Mean & Std. Dev. & Minimum & Maximum \\
\hline \multirow{2}{*}{ El Niño } & SPD_MS & 48,502 & 3.92 & 1.74 & 0.0165 & 30.83 \\
& U_COMP & 47,966 & 0.26 & 3.32 & & \\
& V_COMP & 47,966 & 0.24 & 2.82 & & \\
La Niña & SPD_MS & 31,932 & 4.08 & 1.71 & 0.0583 & 14.06 \\
& U_COMP & 31,840 & 0.225 & 3.39 & & \\
& V_COMP & 31,840 & 0.164 & 2.93 & & \\
Neutral & SPD_MS & 1973 & 3.86 & 1.42 & 0.201 & 9.081 \\
& U_COMP & 1964 & -0.287 & 3.12 & & \\
& V_COMP & 1964 & 0.800 & 2.66 & & \\
\hline
\end{tabular}




\section{b. NAO Index and CC Windroses}

The NAO index is a measure of atmospheric pressure patterns in the North Atlantic. The National Weather Service Climate Predictions Center's web site (no author listed, http://www.cpc.ncep.noaa.gov/data/teledoc/nao.html) describes the NAO as follows:

The positive phase of the NAO reflects below-normal heights and pressure across the high latitudes of the North Atlantic and above-normal heights and pressure over the central North Atlantic, the eastern United States and Western Europe. The negative phase reflects an opposite pattern of height and pressure anomalies over these regions. Both phases of the NAO are associated with basin-wide changes in the intensity and location of the North Atlantic jet stream and storm track, and in large-scale modulations of the normal patterns of zonal and meridional heat and moisture transport (Hurrell 1995). This in turn results in changes in temperature and precipitation patterns often extending from eastern North America to western and central Europe.

The NAO index and the MEI are have no real correlation as can be seen in the scatter plot of NAO versus MEI (Fig. 35).

The relationship between the NAO index and $\mathrm{CC}$ winds was explored by categorizing the NAO into three subsets similar to the MEI, i.e., NAOo (NAO > 0.1), NAOa (NAO <-0.1), and NAOn $(-0.1<\mathrm{NAO}<0.1)$. These results are shown in Figs. 36-38.

Slightly fewer westerlies and southerlies, and slightly more northeasterlies and westsouthwesterlies characterize the NAOo phase (Fig. 36) than the NAOa (Fig. 37) phase. The NAOn (Fig. 38, neutral phase) is characterized by more frequent southerlies than either the NAOo or NAOa phase.

The results of examining subsets of the wind speed data are shown in Table 2. The mean speed for the case of NAOo is 4.00 versus 3.94 in the NAOa case. As in the comparison with the MEI index, this is a fairly insignificant percentage change in speed but one that is statistically significant because of the large number of observations in the 10-year period. There is a larger percentage change in the v-component (north-south component) of the wind. For the NAOo case the v-component is $0.17 \mathrm{~m} / \mathrm{s}$ while for the NAOa case the $\mathrm{v}$-component is $0.25 \mathrm{~m} / \mathrm{s}$.

Table 2. Simple statistics for the CC's 61-m wind speed based on the NAO index, i.e., NAOo $(\mathrm{NAO}>0.1)$, NAOa $(\mathrm{NAO}<-0.1)$, and neutral $(-0.1<\mathrm{MEI}<0.1)$. The statistics are the mean of the variable, standard deviation, minimum and maximum of the variable, respectively.

\begin{tabular}{lllllll}
\hline Subset & Variable & No. of observations & Mean & Std. Dev. & Minimum & Maximum \\
\hline NAOo & SPD_MS & 39,320 & 4.00 & 1.74 & 0.0165 & 16.295 \\
& U_COMP & 38,929 & 0.29 & 3.36 & & \\
& V_COMP & 38,929 & 0.17 & 2.88 & & \\
NAOa & SPD_MS & 30,875 & 3.94 & 1.72 & 0.0405 & 30.832 \\
& U_COMP & 30,686 & 0.25 & 3.33 & & \\
& V_COMP & 30,686 & 0.25 & 2.83 & & \\
NAOn & SPD_MS & 12,212 & 4.00 & 1.68 & 0.1296 & 12.455 \\
& U_COMP & 12,155 & 0.008 & 3.33 & & \\
& V_COMP & 12,155 & 0.322 & 2.87 & & \\
\hline
\end{tabular}




\section{Mean Wind speeds by Hour, Two-Week Period, and Year}

The mean wind speeds for the ten-year period were determined by hour, two-week period and year. The results of plotting the mean speeds versus the hour of the day (Eastern Standard Time) for the four levels are shown in Fig. 39. This figure shows the expected change of speed with height and time of day. The highest wind speeds are achieved at night at the top tower level. The lowest wind speed is found during the night at the lowest tower level. The maximum mean wind speed during the twenty-four hour period is $4.39 \mathrm{~m} / \mathrm{sec}$ at the $61-\mathrm{m}$ level at 22:00 EST. The minimum mean wind speed during the twenty-four hour period is $1.28 \mathrm{~m} / \mathrm{sec}$ at the $4-\mathrm{m}$ level at 04:00 EST. The speeds are shown in Table 3.

Table 3. Wind speeds averaged by LST hour for the entire 10-year data set (1991-2000) for the 2-4, 18, 36 and 61-m levels of the CC tower. (The minimum and maximum speeds for each level are italicized).

\begin{tabular}{|c|c|c|c|c|}
\hline LST Hour & $\begin{array}{l}\text { 2-4-meter } \\
\text { level speed } \\
(\mathrm{m} / \mathrm{s})\end{array}$ & $\begin{array}{l}\text { 18-meter } \\
\text { level speed } \\
(\mathrm{m} / \mathrm{s})\end{array}$ & $\begin{array}{l}36-\text { meter } \\
\text { level speed } \\
(\mathrm{m} / \mathrm{s})\end{array}$ & $\begin{array}{l}\text { 61-meter } \\
\text { level speed } \\
(\mathrm{m} / \mathrm{s})\end{array}$ \\
\hline 0 & 1.351 & 2.084 & 3.067 & 4.280 \\
\hline 1 & 1.311 & 2.020 & 2.984 & 4.188 \\
\hline 2 & 1.292 & 1.989 & 2.936 & 4.110 \\
\hline 3 & 1.293 & 1.974 & 2.911 & 4.073 \\
\hline 4 & 1.285 & 1.957 & 2.889 & 4.035 \\
\hline 5 & 1.289 & 1.954 & 2.865 & 4.007 \\
\hline 6 & 1.389 & 2.025 & 2.832 & 3.913 \\
\hline 7 & 1.701 & 2.300 & 2.884 & 3.704 \\
\hline 8 & 2.090 & 2.691 & 3.086 & 3.591 \\
\hline 9 & 2.342 & 2.956 & 3.278 & 3.614 \\
\hline 10 & 2.461 & 3.086 & 3.391 & 3.695 \\
\hline 11 & 2.519 & 3.163 & 3.458 & 3.768 \\
\hline 12 & 2.553 & 3.204 & 3.510 & 3.821 \\
\hline 13 & 2.582 & 3.243 & 3.564 & 3.889 \\
\hline 14 & 2.585 & 3.260 & 3.597 & 3.947 \\
\hline 15 & 2.494 & 3.173 & 3.536 & 3.915 \\
\hline 16 & 2.261 & 2.918 & 3.354 & 3.797 \\
\hline 17 & 1.837 & 2.496 & 3.092 & 3.728 \\
\hline 18 & 1.472 & 2.159 & 2.981 & 3.849 \\
\hline 19 & 1.366 & 2.101 & 3.076 & 4.127 \\
\hline 20 & 1.402 & 2.164 & 3.176 & 4.323 \\
\hline 21 & 1.427 & 2.193 & 3.200 & 4.386 \\
\hline 22 & 1.427 & 2.183 & 3.183 & 4.393 \\
\hline 23 & 1.393 & 2.146 & 3.143 & 4.354 \\
\hline
\end{tabular}

The mean wind speeds for the twenty-six two-week periods were determined in a similar manner. The results of plotting these mean speeds versus the two-week period (\#1 is the first two weeks of January, \#2 is the following two weeks of January, etc.) for the four levels are shown in Fig. 40. This figure shows the expected change of speed with height and two-week period. The highest wind speeds are achieved during period \#5 (mid-February) at the top tower level. The 
lowest wind speed is found during period \#17 (mid-August) at the lowest tower level. The maximum mean wind speed during the year is $4.77 \mathrm{~m} / \mathrm{sec}$ at the $61-\mathrm{m}$ level in late February-early March. The minimum mean wind speed during the year is $1.53 \mathrm{~m} / \mathrm{sec}$ at the $4-\mathrm{m}$ level in mid August.

Fig. 40 also shows the pulsing of the wind speed mentioned in an earlier section of this report for two-week periods \#2 (mid January) through \#8 (mid April). Period \#8 is followed by a marked decrease in the wind speed over the following four weeks to \#10 (mid-May). After the summer lull in wind speed two secondary maxima are achieved in periods \#20 $(4.17 \mathrm{~m} / \mathrm{sec}$ in late September-early October) and \#24 (4.19 m/sec in late November). The mean wind speeds for the twenty-six two-week periods are shown in Table 4.

Table 4. Wind speeds averaged by two-week period for the entire 10-year data set (1991-2000) for the 2-4, 18, 36 and 61-m levels of the CC tower. (The minimum and maximum speeds for each level are italicized).

\begin{tabular}{cllll}
\hline $\begin{array}{l}\text { Two-week } \\
\text { designator }\end{array}$ & $\begin{array}{l}2-4-\mathrm{m} \\
\text { level speed } \\
(\mathrm{m} / \mathrm{s})\end{array}$ & $\begin{array}{l}18-\mathrm{m} \\
\text { level speed } \\
(\mathrm{m} / \mathrm{s})\end{array}$ & $\begin{array}{l}36-\mathrm{m} \\
\text { level speed } \\
(\mathrm{m} / \mathrm{s})\end{array}$ & $\begin{array}{l}61-\mathrm{m} \\
\text { level speed } \\
(\mathrm{m} / \mathrm{s})\end{array}$ \\
\hline 1 & 1.894 & 2.714 & 3.484 & 4.292 \\
2 & 2.090 & 2.965 & 3.775 & 4.574 \\
3 & 1.925 & 2.748 & 3.565 & 4.378 \\
4 & 2.000 & 2.823 & 3.607 & 4.374 \\
5 & 2.175 & $\mathbf{3 . 0 8 0}$ & $\mathbf{3 . 8 8 3}$ & $\mathbf{4 . 7 7 3}$ \\
6 & 2.147 & 3.069 & 3.760 & 4.761 \\
7 & 2.014 & 2.816 & 3.464 & 4.450 \\
8 & 2.144 & 2.981 & 3.758 & 4.724 \\
9 & 1.911 & 2.621 & 3.282 & 4.179 \\
10 & 1.879 & 2.402 & 2.911 & 3.711 \\
11 & 1.857 & 2.441 & 2.950 & 3.717 \\
12 & 1.747 & 2.247 & 2.724 & 3.455 \\
13 & 1.661 & 2.214 & 2.699 & 3.404 \\
14 & 1.627 & 2.199 & 2.692 & 3.404 \\
15 & 1.586 & 2.099 & 2.561 & 3.246 \\
16 & 1.567 & 2.051 & 2.646 & 3.264 \\
17 & $\mathbf{1 . 5 3 4}$ & 2.022 & 2.547 & 3.155 \\
18 & 1.567 & 2.134 & 2.828 & 3.591 \\
19 & 1.573 & 2.124 & 2.853 & 3.617 \\
20 & 1.796 & 2.478 & 3.288 & 4.168 \\
21 & 1.653 & 2.291 & 3.117 & 3.966 \\
22 & 1.550 & 2.224 & 3.056 & 3.979 \\
23 & 1.667 & 2.226 & 2.923 & 3.689 \\
24 & 1.616 & 2.339 & 3.170 & 4.193 \\
25 & 1.768 & 2.488 & 3.316 & 4.173 \\
26 & 1.802 & 2.570 & 3.353 & 4.164 \\
\hline & & & & \\
\hline
\end{tabular}

The mean wind speeds for each year over the ten-year period were found by computing scalar averages for each year. The results of plotting these mean speeds versus the year for the four 
levels are shown in Fig. 41. The highest wind speed was achieved during 1996 at the top tower level. The lowest wind speed is found during 1991 at the lowest tower level (which was 2-m at this time). The maximum mean wind speed during the ten-year period is $4.19 \mathrm{~m} / \mathrm{sec}$ at the $61-\mathrm{m}$ level in 1996. The minimum mean wind speed during the ten-year period is $1.62 \mathrm{~m} / \mathrm{sec}$ at the 2$\mathrm{m}$ level in 1991. The mean wind speeds for each year are shown in Table 5.

Table 5. Wind speeds averaged for each year of the 10-year data set (1991-2000) for the 2-4, 18, 36 and 61-m levels of the $\mathrm{CC}$ tower. (The minimum and maximum speeds for each level are italicized).

\begin{tabular}{lllll}
\hline Year & $\begin{array}{l}2-4-\mathrm{m} \\
\text { level speed } \\
(\mathrm{m} / \mathrm{s})\end{array}$ & $\begin{array}{l}18-\mathrm{m} \\
\text { level speed } \\
(\mathrm{m} / \mathrm{s})\end{array}$ & $\begin{array}{l}36-\mathrm{m} \\
\text { level speed } \\
(\mathrm{m} / \mathrm{s})\end{array}$ & $\begin{array}{l}61-\mathrm{m} \\
\text { level speed } \\
(\mathrm{m} / \mathrm{s})\end{array}$ \\
\hline 1991 & $\mathbf{1 . 6 2 1}$ & $\mathbf{2 . 3 2 7}$ & 2.991 & $\mathbf{3 . 6 8 0}$ \\
1992 & 1.636 & 2.485 & 3.208 & 3.975 \\
1993 & 1.808 & 2.471 & 3.145 & 3.908 \\
1994 & 1.892 & 2.567 & $\mathbf{2 . 8 9 8}$ & 4.064 \\
1995 & 1.842 & 2.396 & 3.035 & 3.727 \\
1996 & $\mathbf{1 . 9 3 6}$ & $\mathbf{2 . 6 2 7}$ & $\mathbf{3 . 3 8 1}$ & $\mathbf{4 . 1 9 0}$ \\
1997 & 1.817 & 2.495 & 3.261 & 4.071 \\
1998 & 1.806 & 2.489 & 3.261 & 4.030 \\
1999 & 1.793 & 2.462 & 3.250 & 4.099 \\
2000 & 1.816 & 2.450 & 3.240 & 4.032 \\
\hline
\end{tabular}

\section{Conclusions and Recommendations}

This report has been written to present climatological summaries of the wind data at the CC Tower in a convenient format and to point out some features of the wind speed and direction that have not been widely appreciated in the past. Short-term (two-week) wind roses provide a means to demonstrate the temporal and spatial relationships that wind speed and direction undergo using a ten-year database from the CC Tower. These relationships are best demonstrated by examining the Figures provided in this report or looking at loops of computer-generated images.

As was true for the NWS surface stations in the Southeast, the Appalachian Mountains and the Atlantic Ocean are major influences of wind direction for the CC Tower. Terrain steering of the wind from these influences is suggested in the seasonal and diurnal patterns of the wind. The CC Tower is strongly influenced by sea breezes in the evening hours (mainly in the spring and summer seasons) that penetrate from the coast up the Savannah River channel. In autumn all levels of the CC Tower are subject to northeasterly winds that arise from high-pressure systems to the north and northwest.

Wind roses can be used to aid wind direction forecasting at SRS, particularly when models predict light wind speeds. In cases when numerical models disagree on wind direction forecasts it is advisable to consider the $\mathrm{CC}$ tower wind roses.

Subjectively comparing the annual wind rose for CAE and AGS with the CC tower showed that the top three tower levels resembled CAE whereas the bottom level resembled AGS. On shorter 
time scales, the results of a subjective comparison were that the CC tower usually resembled an average of the two wind roses for AGS and CAE. Neither AGS nor CAE were consistently similar to the lower two CC levels for shorter time scales (e.g., two-weeks). This conclusion emphasizes the need for on-site wind measurements at SRS.

Statistical correlation between CC's 61-m wind speed and El Niño/La Niña conditions was very low. Furthermore, a significant statistical correlation between CC's $61-\mathrm{m}$ wind speed and the NAO index was not found.

The mean wind speeds for the ten-year period were determined by hour, two-week period and year. The highest wind speeds were seen at night at the top tower level. The lowest wind speed was found during the night at the lowest tower level. The maximum mean wind speed during the twenty-four hour period was $4.39 \mathrm{~m} / \mathrm{sec}$ at the $61-\mathrm{m}$ level at 22:00 EST. The minimum mean wind speed during the twenty-four hour period was $1.28 \mathrm{~m} / \mathrm{sec}$ at the $4-\mathrm{m}$ level at 04:00 EST.

The mean wind speeds for the twenty-six two-week periods showed the highest wind speeds $(4.77 \mathrm{~m} / \mathrm{sec})$ are achieved during in late February-early March at the 61-m tower level. The lowest wind speed $(1.53 \mathrm{~m} / \mathrm{sec})$ is found during mid-August at the 4-m tower level.

The mean wind speeds for each year over the ten-year period showed that the highest wind speed was achieved during 1996 at the top tower level. The lowest wind speed was found during 1991 at the lowest tower level (which was 2-m at this time). The maximum mean wind speed during the ten-year period was $4.19 \mathrm{~m} / \mathrm{sec}$ at the $61-\mathrm{m}$ level in 1996. The minimum mean wind speed during the ten-year period was $1.62 \mathrm{~m} / \mathrm{sec}$ at the $2-\mathrm{m}$ level in 1991.

\section{Acknowledgement}

The authors would like to acknowledge the able assistance of L. D. Koffman for his help with the wind rose plots using ArcView GIS. 


\section{References}

Buckley, R. L., and R. J. Kurzeja, 1997: An observational and numerical study of the nocturnal sea breeze. Part I: structure and circulation. J. Appl. Meteor., 36, 1577-1598.

Hurrell, J. W., 1995: Decadal trends in the North Atlantic Oscillation: Regional temperatures and precipitation. Science, 269, 676-679.

Parker, M. J., and R. P. Addis, 1993: Meteorological Monitoring Program(U). WSRC-TR-930106, Westinghouse Savannah River Company, Savannah River Technology Center, Aiken SC. $87 \mathrm{pp}$.

Weber, A. H., R. L. Buckley, and M. J. Parker, 2002a: Wind Climate Analyses for National Weather Service Stations in the Southeast (U). WSRC-TR-2002-00515, Westinghouse Savannah River Company, Savannah River Technology Center, Aiken SC. 60pp.

Weber, A. H., M. J. Parker, and J. H. Weber, 2002b: Surface Wind Gust Statistics at the Savannah River Site. $16^{\text {th }}$ Conference on Probability and Statistics in the Atmospheric Sciences, 13-17 January 2002, Orlando Florida. 120-125.

Wolter, K., 1987: The Southern Oscillation in surface circulation and climate over the tropical Atlantic, Eastern Pacific, and Indian Oceans as captured by cluster analysis. J. Climate Appl. Meteor., 26, 540-558.

Wolter, K., and M.S. Timlin, 1993: Monitoring ENSO in COADS with a seasonally adjusted principal component index. Proc. of the 17th Climate Diagnostics Workshop, Norman, OK, NOAA/N MC/CAC, NSSL, Oklahoma Clim. Survey, CIMMS and the School of Meteor., Univ. of Oklahoma, 52-57.

Wolter, K., and M.S. Timlin, 1998: Measuring the strength of ENSO - how does 1997/98 rank? Weather, 53, 315-324. 


\section{List of Figures}

Fig. 1. Map showing the CC tower's location (labeled CLM) on the Savannah River Site.

Fig. 2. Annual wind rose for the CC tower winds. The six wind speed classes are 0-2, 2-4, 4-6, 6$8,8-12$, and $<12 \mathrm{~m} / \mathrm{s}$. The petals of the rose show the direction from which the wind blows, so a petal drawn from the center toward the north sector indicates winds blowing from the north. The "petal" lengths are all normalized to the $20 \%$ segment shown.

Fig. 3. As in Fig. 2 except for early January (Weeks 1 and 2 of 52). Also, the "petal" lengths are all normalized to the $15 \%$ segment shown.

Fig. 4. As in Fig. 3 except for late January (Weeks 3 and 4 of 52).

Fig. 5. As in Fig. 3 except for early February (Weeks 5 and 6 of 52).

Fig. 6. As in Fig. 3 except for mid February (Weeks 7 and 8 of 52).

Fig. 7. As in Fig. 3 except for late February-early March (Weeks 9 and 10 of 52).

Fig. 8. As in Fig. 3 except for mid March (Weeks 11 and 12 of 52).

Fig. 9. As in Fig. 3 except for late March-early April (Weeks 13 and 14 of 52).

Fig. 10. As in Fig. 3 except for mid April (Weeks 15 and 16 of 52).

Fig. 11. As in Fig. 3 except for late April-early May (Weeks 17 and 18 of 52).

Fig. 12. As in Fig. 3 except for mid May (Weeks 19 and 20 of 52).

Fig. 13. As in Fig. 3 except for late May-early June (Weeks 21 and 22 of 52).

Fig. 14. As in Fig. 3 except for mid June (Weeks 23 and 24 of 52).

Fig. 15. As in Fig. 3 except for late June (Weeks 25 and 26 of 52).

Fig. 16. As in Fig. 3 except for early July (Weeks 27 and 28 of 52).

Fig. 17. As in Fig. 3 except for late July (Weeks 29 and 30 of 52).

Fig. 18. As in Fig. 3 except for early August (Weeks 31 and 32 of 52).

Fig. 19. As in Fig. 3 except for mid August (Weeks 33 and 34 of 52). 
Fig. 20. As in Fig. 3 except for late August-early September (Weeks 35 and 36 of 52).

Fig. 21. As in Fig. 3 except for mid September (Weeks 37 and 38 of 52).

Fig. 22. As in Fig. 3 except for late September-early October (Weeks 39 and 40 of 52).

Fig. 23. As in Fig. 3 except for mid October (Weeks 41 and 42 of 52).

Fig. 24. As in Fig. 3 except for late October-early November (Weeks 43 and 44 of 52).

Fig. 25. As in Fig. 3 except for mid November (Weeks 45 and 46 of 52).

Fig. 26. As in Fig. 3 except for late November (Weeks 47 and 48 of 52).

Fig. 27. As in Fig. 3 except for early December (Weeks 49 and 50 of 52).

Fig. 28. As in Fig. 3 except for late December (Weeks 51 and 52 of 52).

Figs. 29a-f. Wind direction modes for the 6 periods of the day over an entire year. The modes plotted in each figure are (1) primary mode: selected as representing the most frequent wind direction for the upper three levels of the tower, (2) secondary mode: selected as representing the second most frequent wind direction for the upper three levels of the tower, and (3) surface mode: selected as representing the most frequent wind direction for the lowest tower level.

Fig. 30. A plot of the actual wind direction from the 4-m level of the CC Tower on March 11, 2003, during a controlled burn by the United States Forest Service at the SRS. This figure shows the switching of wind directions in light wind conditions from the west to the east-southeast as depicted in the wind rose plot of Fig. 8.

Fig. 31. A scatter plot of the MEI index versus the usual ENSO index (based on pressure differences).

Fig. 32. Wind rose description as in Fig. 2 for an individual level. This wind rose is for El Niño (MEI > 0.1) conditions over the 10-year period.

Fig. 33. As in Fig. 32 except for La Niña (MEI <-0.1) conditions.

Fig. 34. As in Fig. 32 except for neutral $(-0.1<$ MEI < 0.1$)$ conditions.

Fig. 35. A scatter plot of the NAO index versus the usual MEI index.

Fig. 36. As in Fig. 32 except for NAOo (NAO> 0.1) conditions.

Fig. 37. As in Fig. 32 except for NAOa (NAO<-0.1) conditions. 
Fig. 38. As in Fig. 32 except for NAOn $(-0.1<\mathrm{NAO}<0.1)$ conditions.

Fig. 39. Wind speeds averaged by LST hour for the entire 10-year data set (1991-2000) for the 2$4,18,36$ and $61-\mathrm{m}$ levels of the CC tower.

Fig. 40. Wind speeds averaged by two-week period for the entire 10-year data set (1991-2000) for the 2-4, 18, 36 and 61-m levels of the CC tower. (\#1 period is the first two weeks of January, \#2 period is the following two weeks, etc.,).

Fig. 41. Wind speeds averaged for each year of the 10-year data set (1991-2000) for the 2-4, 18, 36 and 61-m levels of the $\mathrm{CC}$ tower.

\section{List of Tables}

Table 1. Simple statistics for the CC's 61-m wind speed based on the MEI index, i.e., El Niño (MEI > 0.1), La Niña (MEI <-0.1), and neutral $(-0.1<$ MEI < 0.1). The statistics are the mean of the variable, standard deviation, minimum and maximum of the variable, respectively.

Table 2. Simple statistics for the CC's 61-m wind speed based on the NAO index, i.e., NAOo $(\mathrm{NAO}>0.1)$, NAOa $(\mathrm{NAO}<-0.1)$, and neutral $(-0.1<\mathrm{MEI}<0.1)$. The statistics are the mean of the variable, standard deviation, minimum and maximum of the variable, respectively.

Table 3. Wind speeds averaged by LST hour for the entire 10-year data set (1991-2000) for the $2-4,18,36$ and $61-\mathrm{m}$ levels of the CC tower. (The minimum and maximum speeds for each level are italicized).

Table 4. Wind speeds averaged by two-week period for the entire 10-year data set (1991-2000) for the 2-4, 18, 36 and 61-m levels of the CC tower. (The minimum and maximum speeds for each level are italicized).

Table 5. Wind speeds averaged for each year of the 10-year data set (1991-2000) for the 2-4, 18, 36 and 61-m levels of the $\mathrm{CC}$ tower. (The minimum and maximum speeds for each level are italicized). 


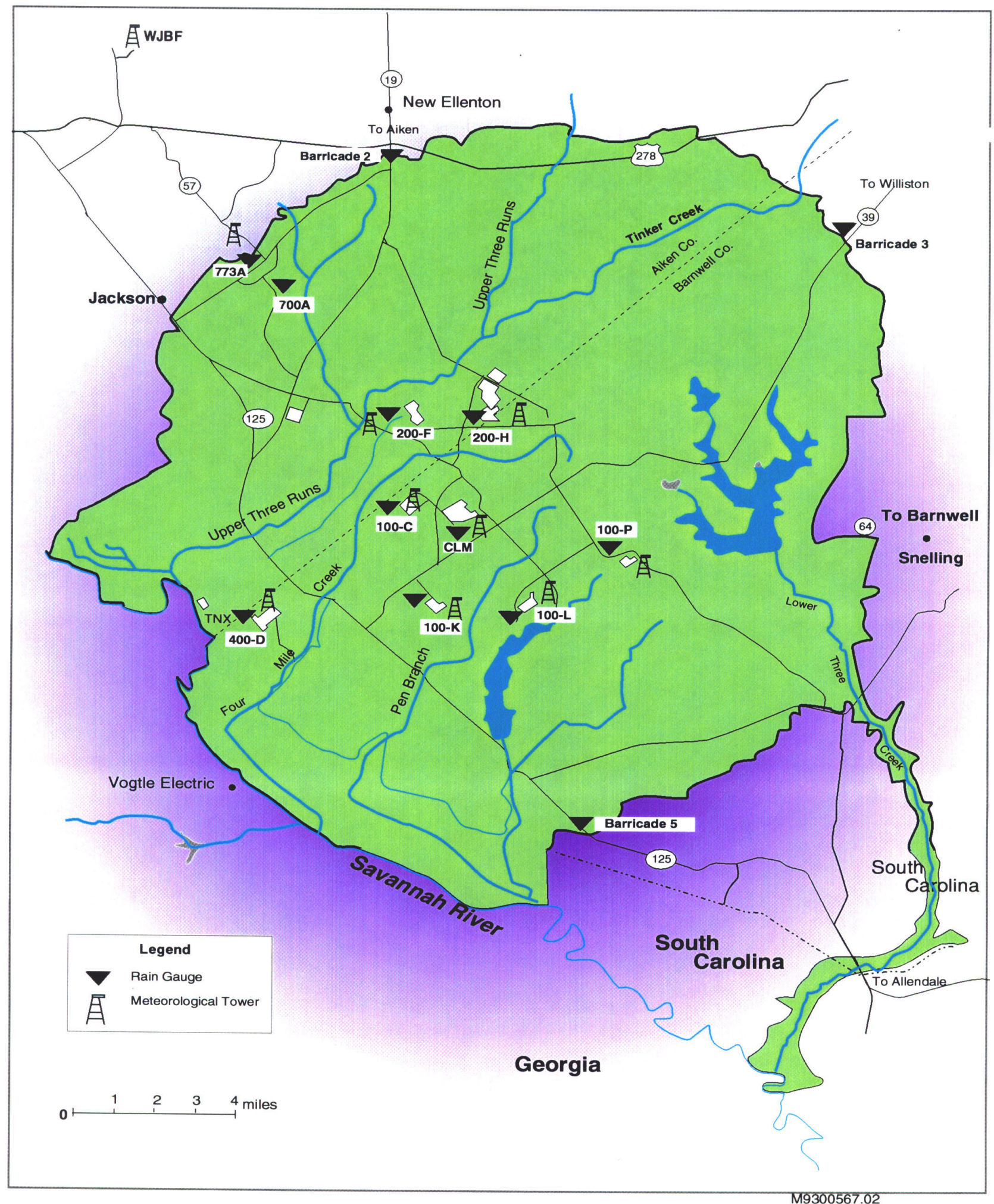

Fig. 1. Map showing the CC tower's location (labeled CLM) on the Savannah River Site. 

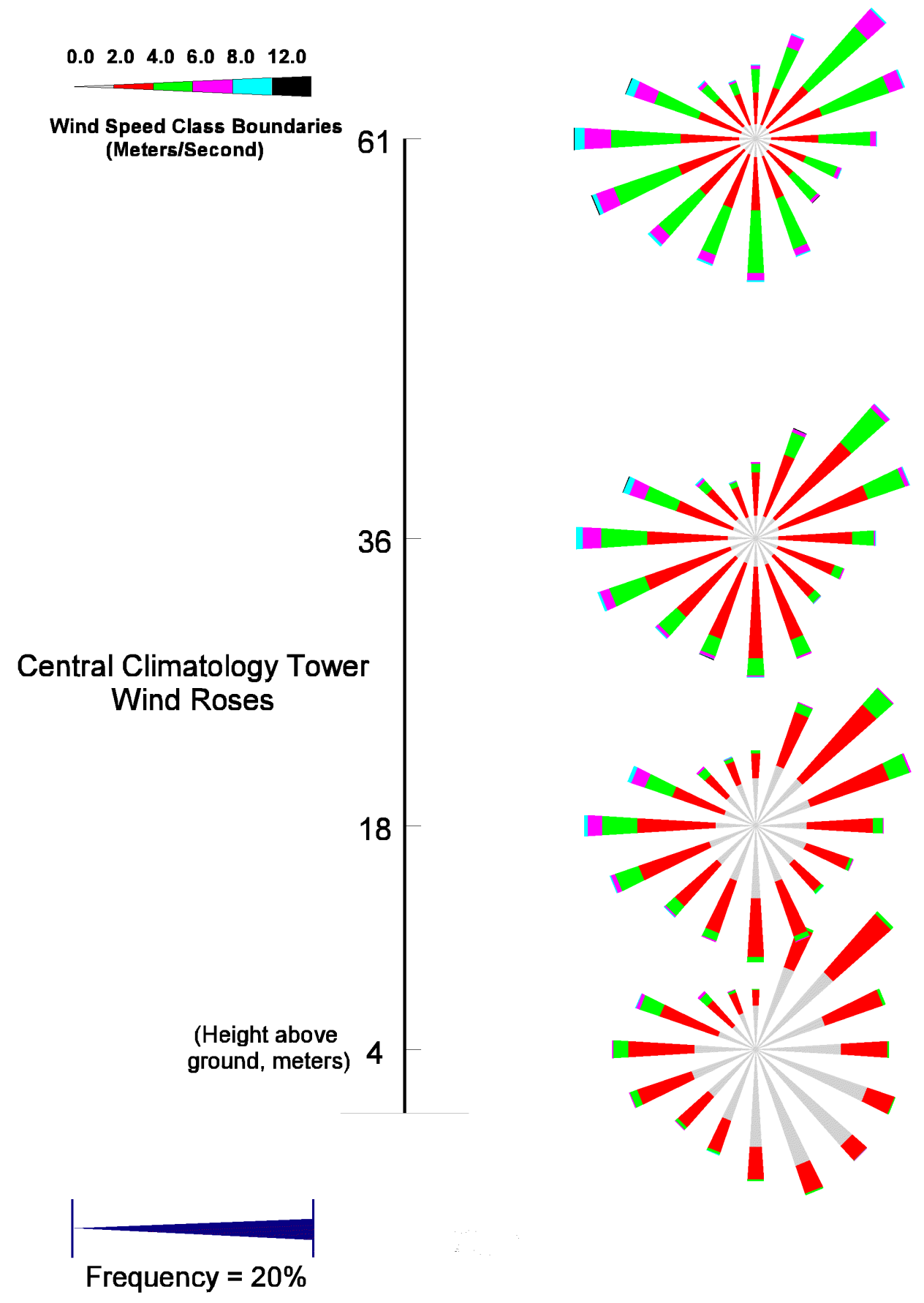

Fig. 2. Annual wind rose for the CC tower winds. The six wind speed classes are 0-2, 2-4, 4-6, 6-8, 8-12, and < $12 \mathrm{~m} / \mathrm{s}$. The petals of the rose show the direction from which the wind blows, so a petal drawn from the center toward the north sector indicates winds blowing from the north. The "petal" lengths are all normalized to the $20 \%$ segment shown. 

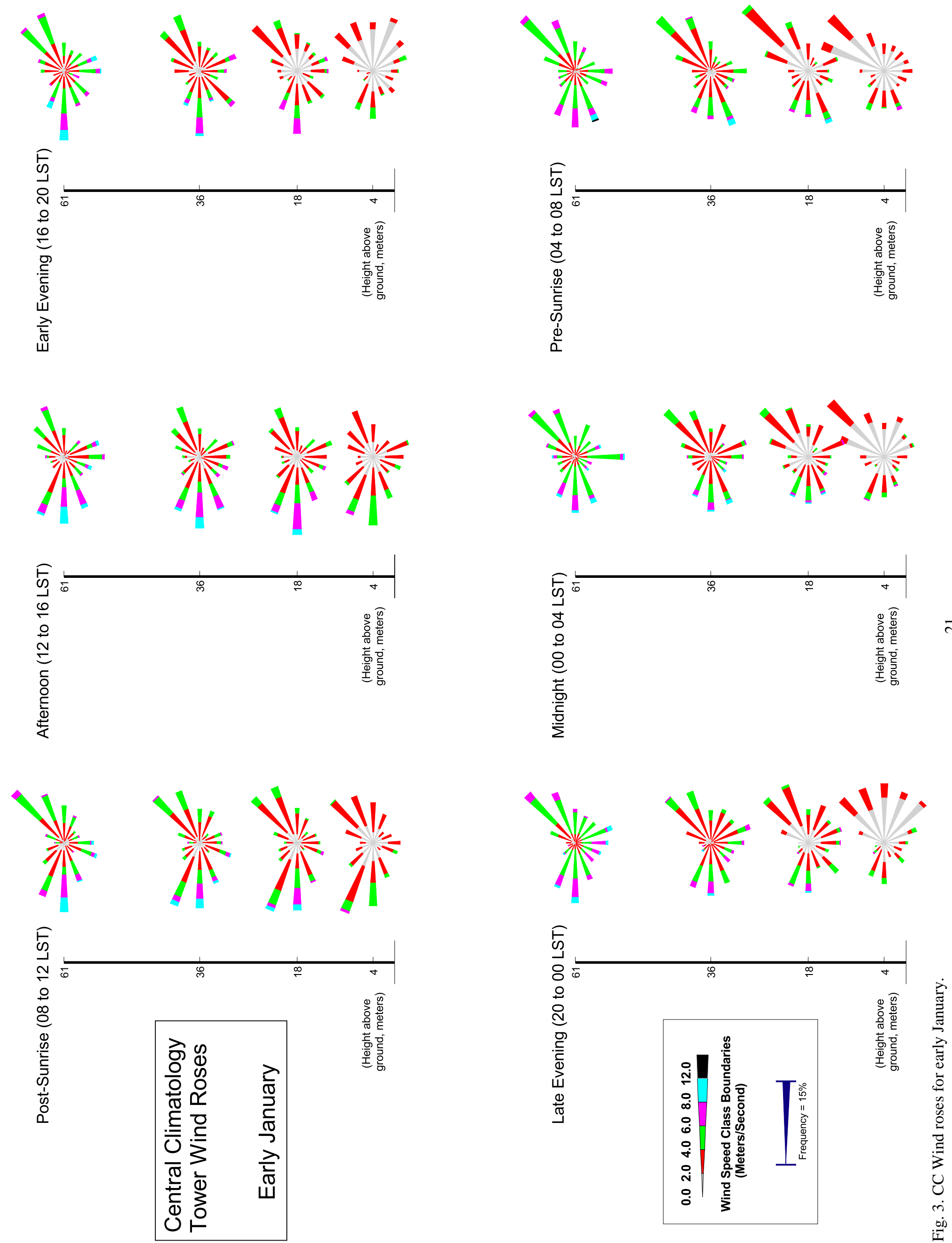

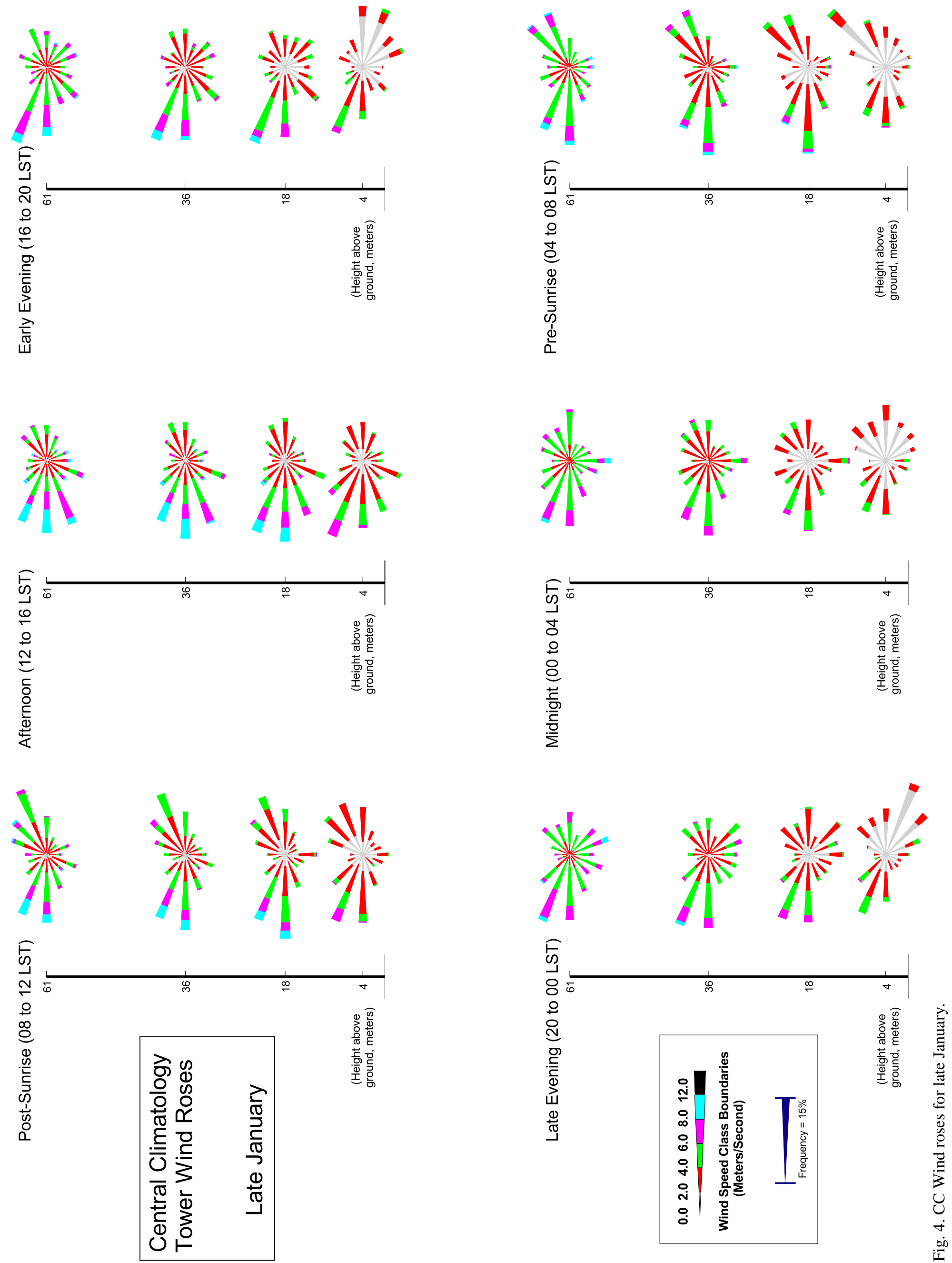

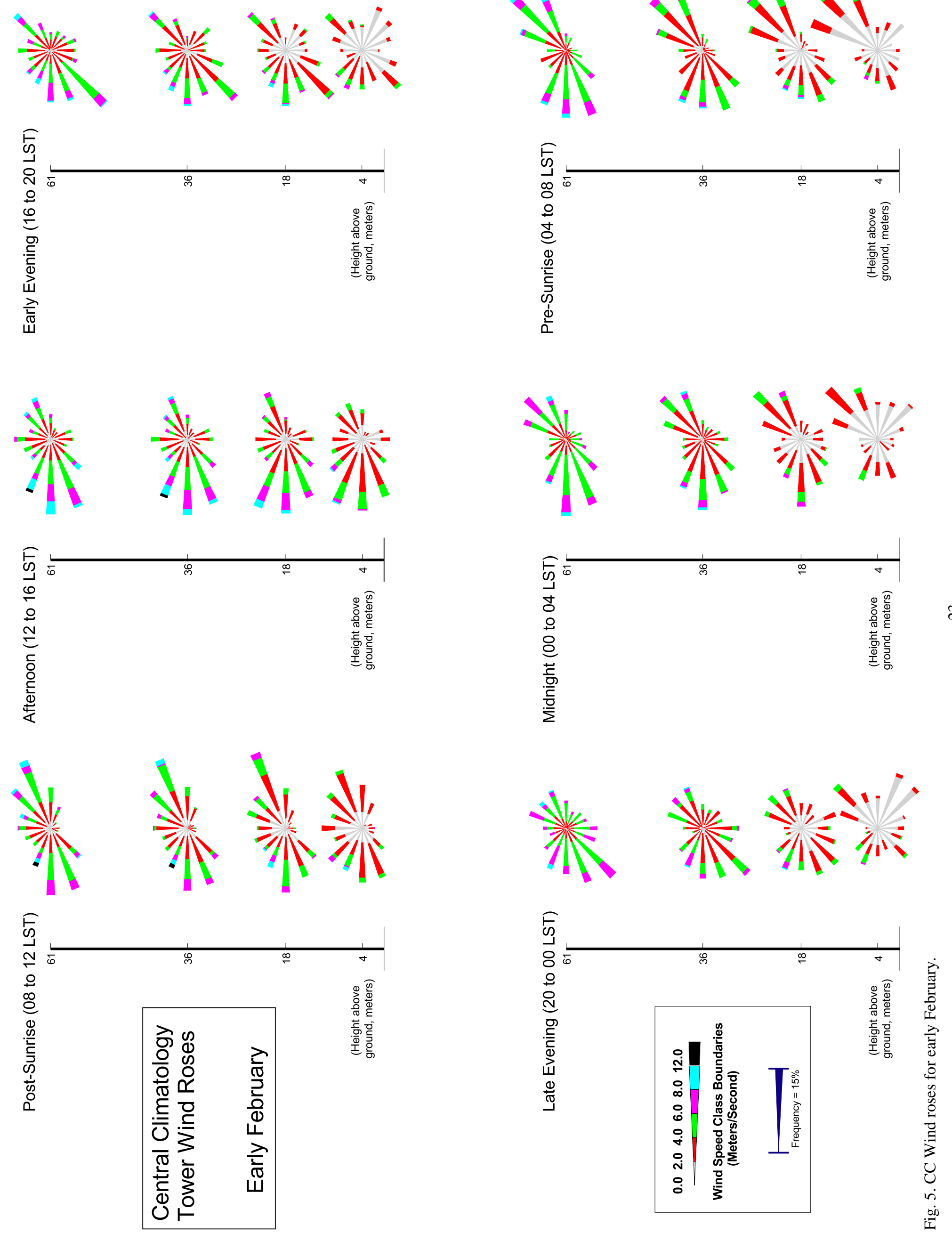

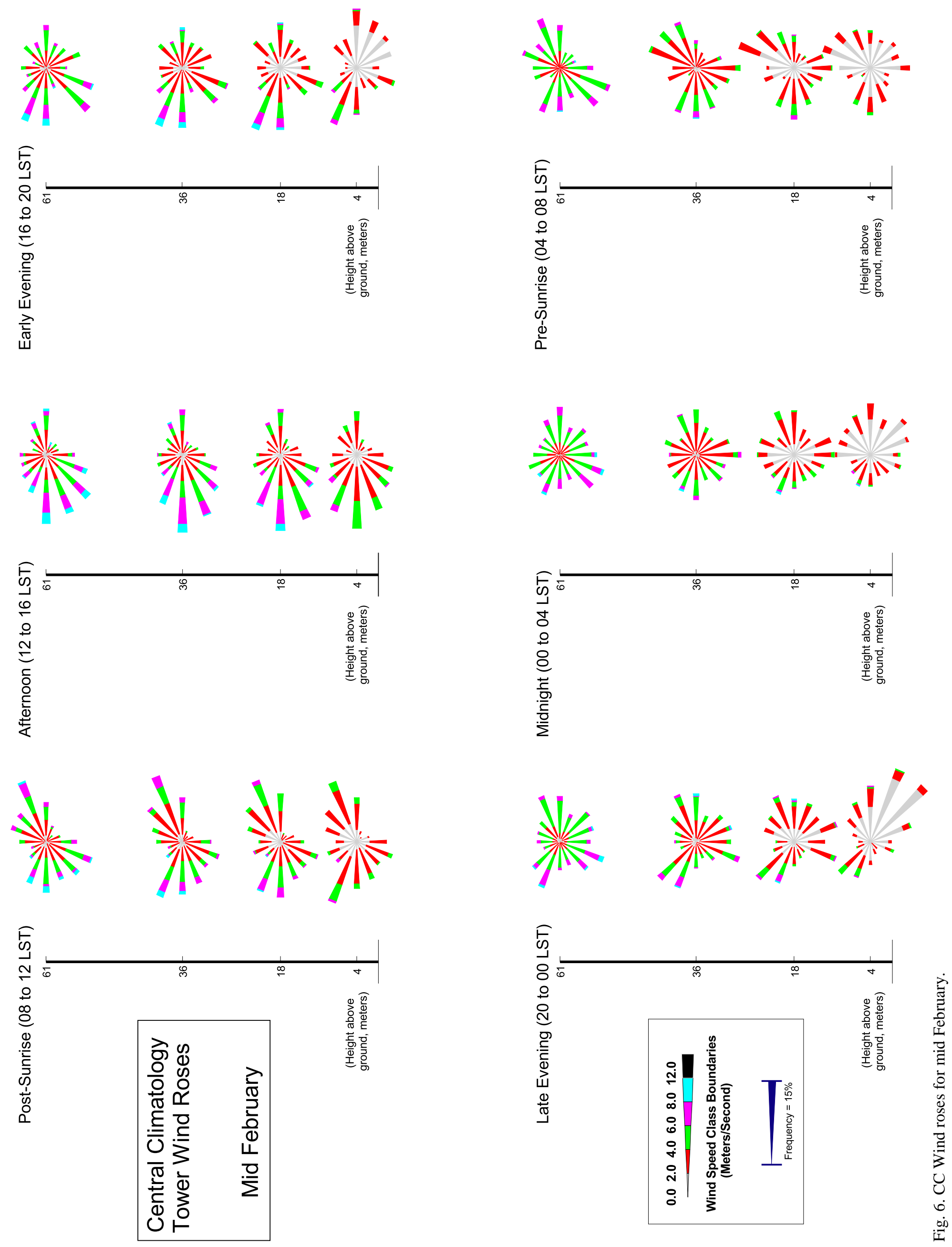

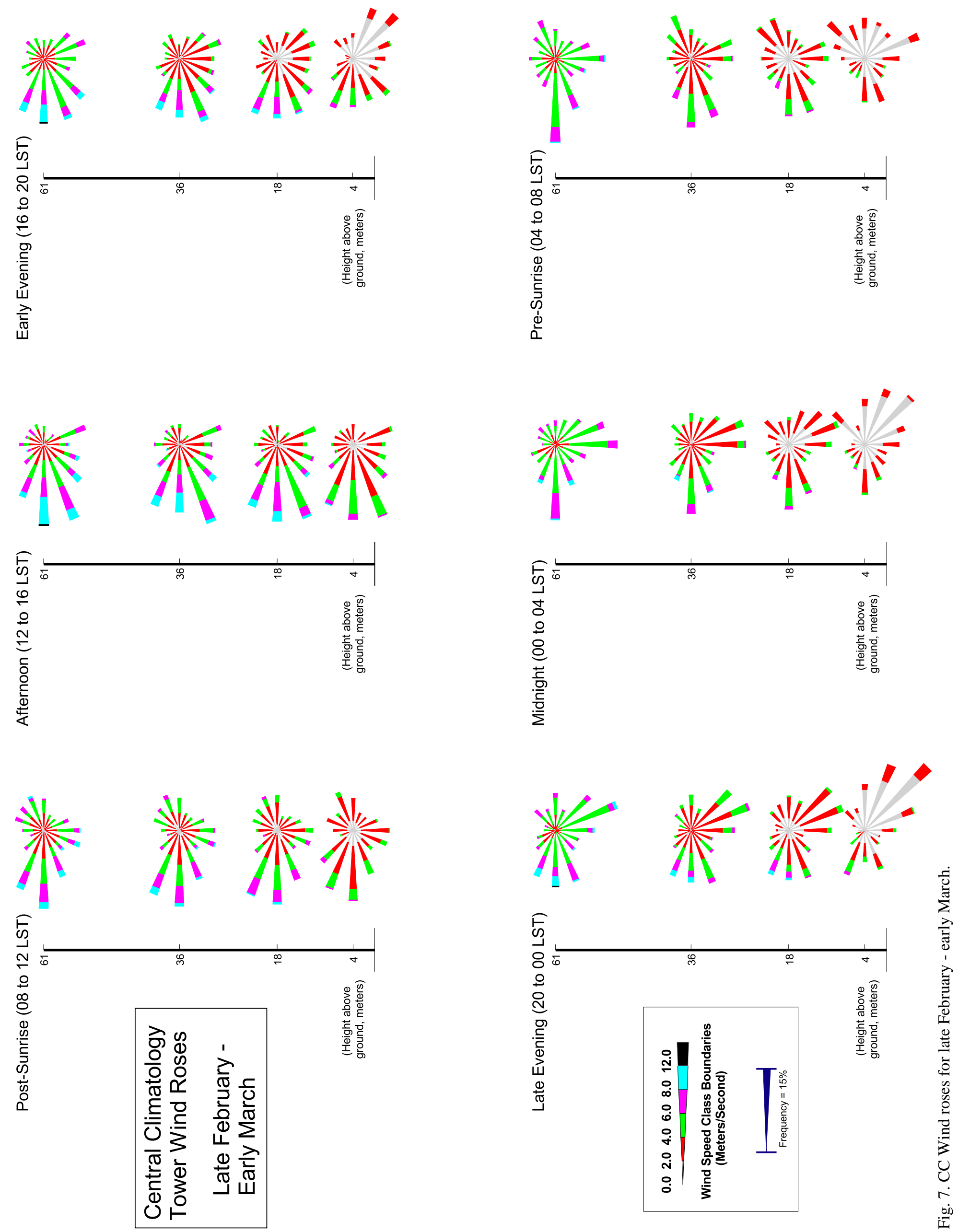

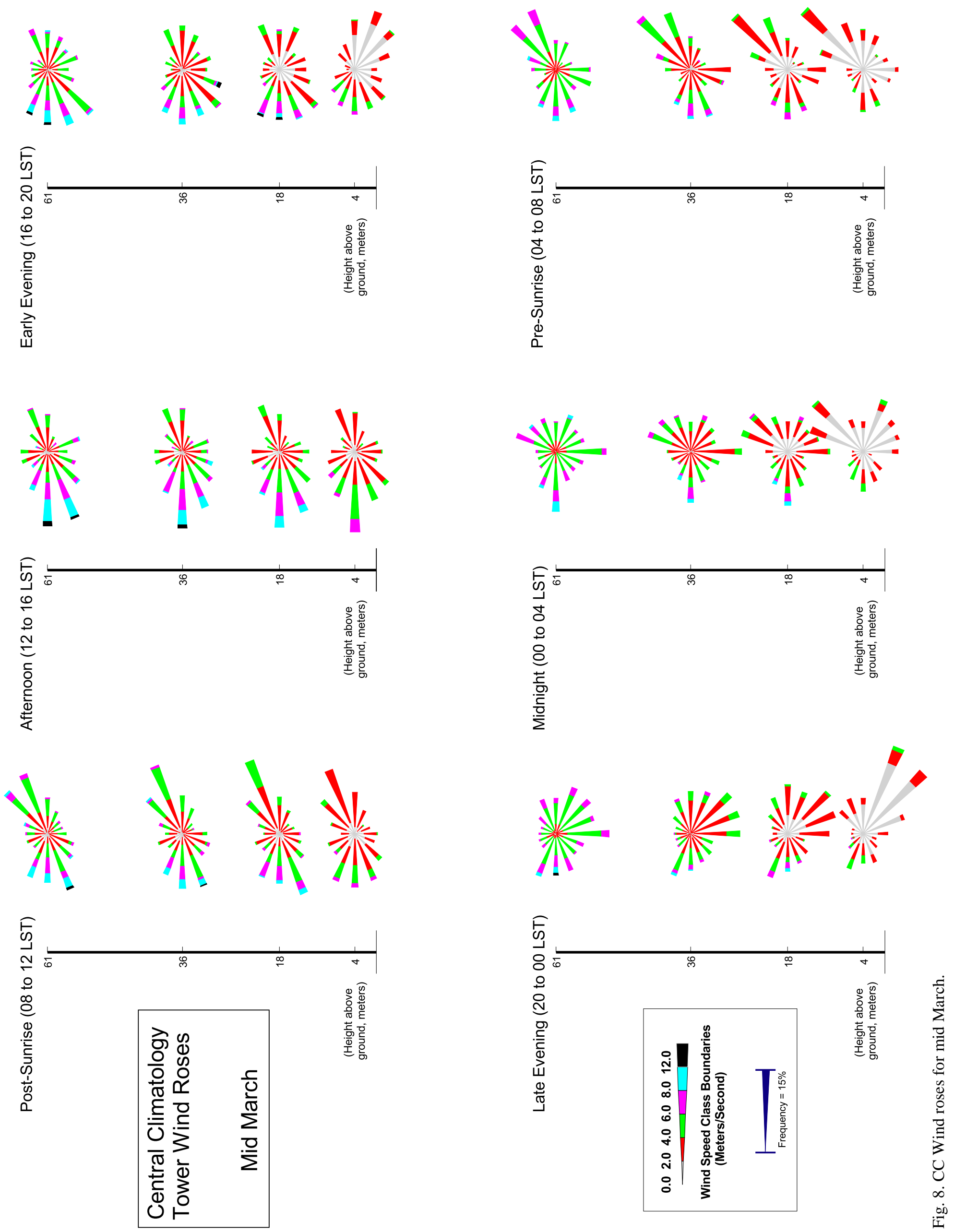

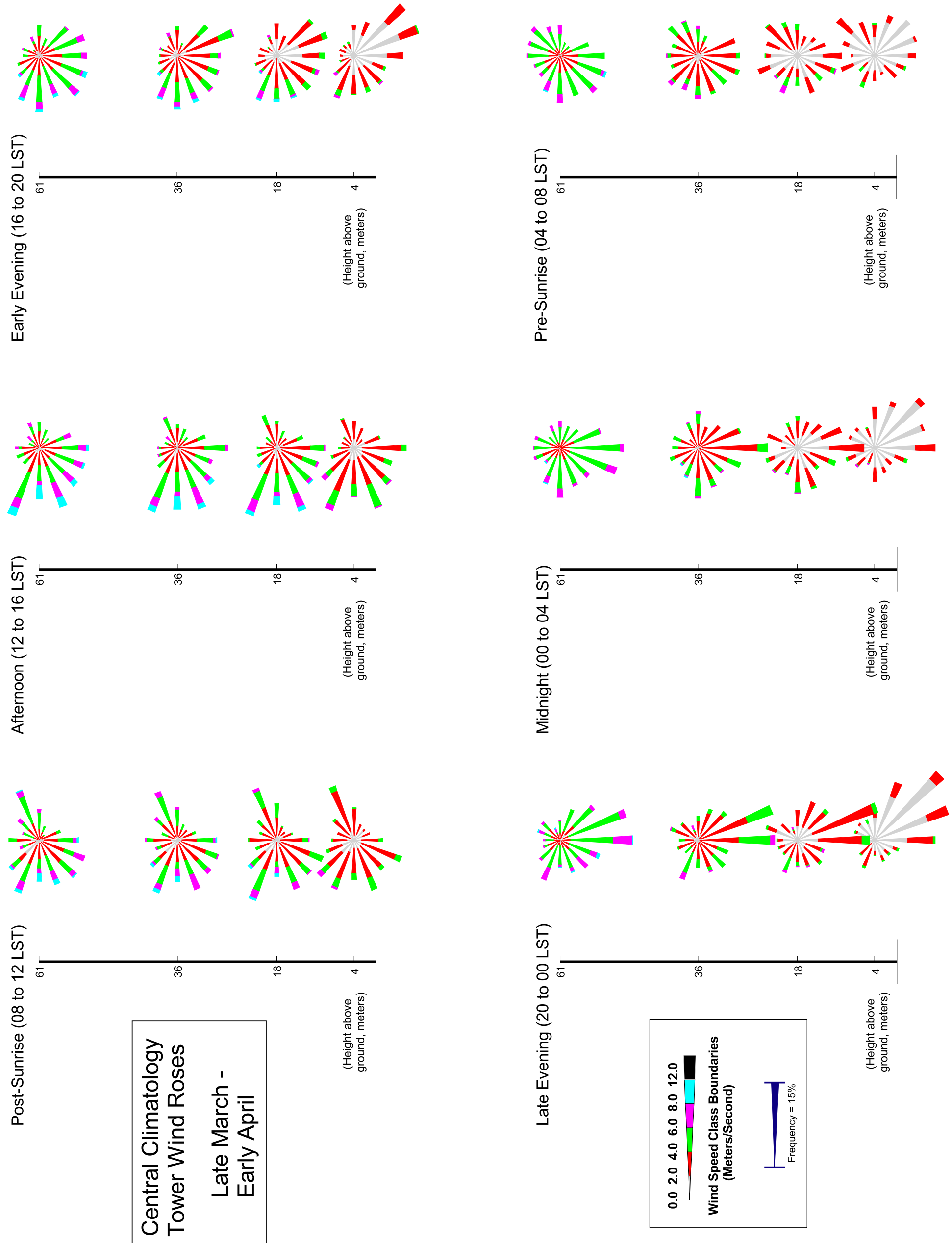

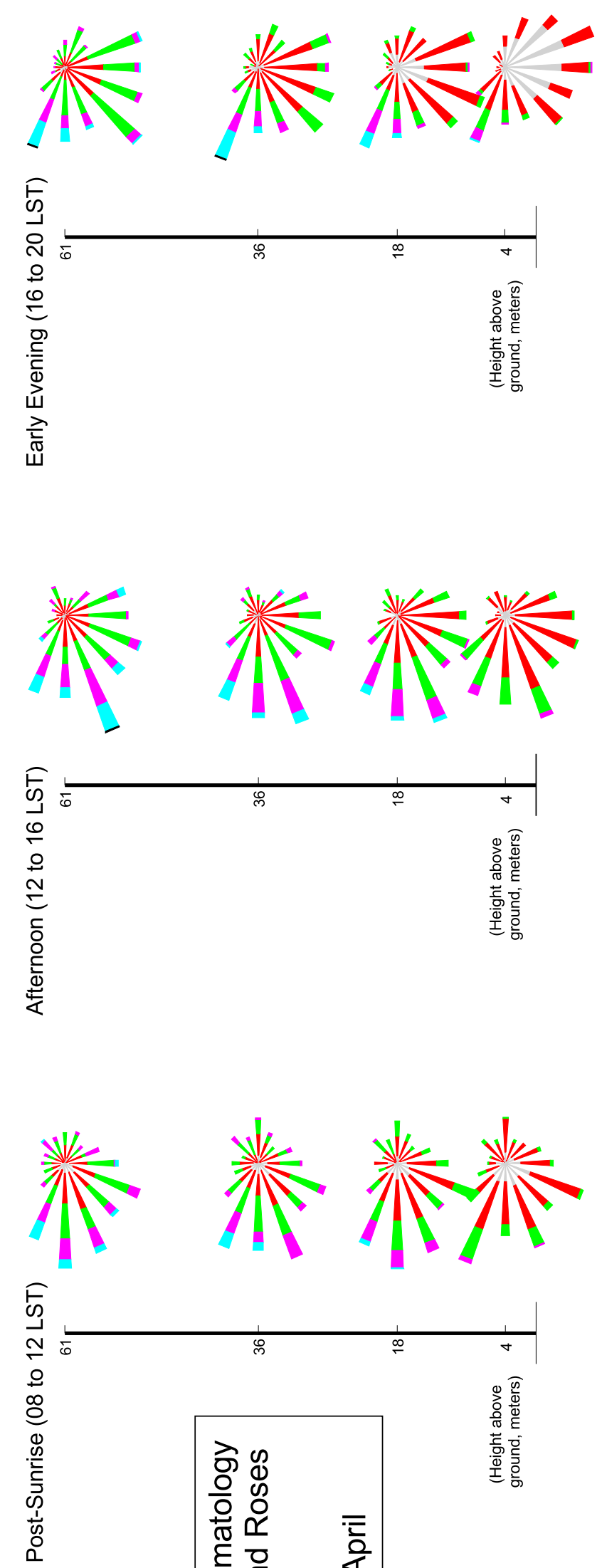
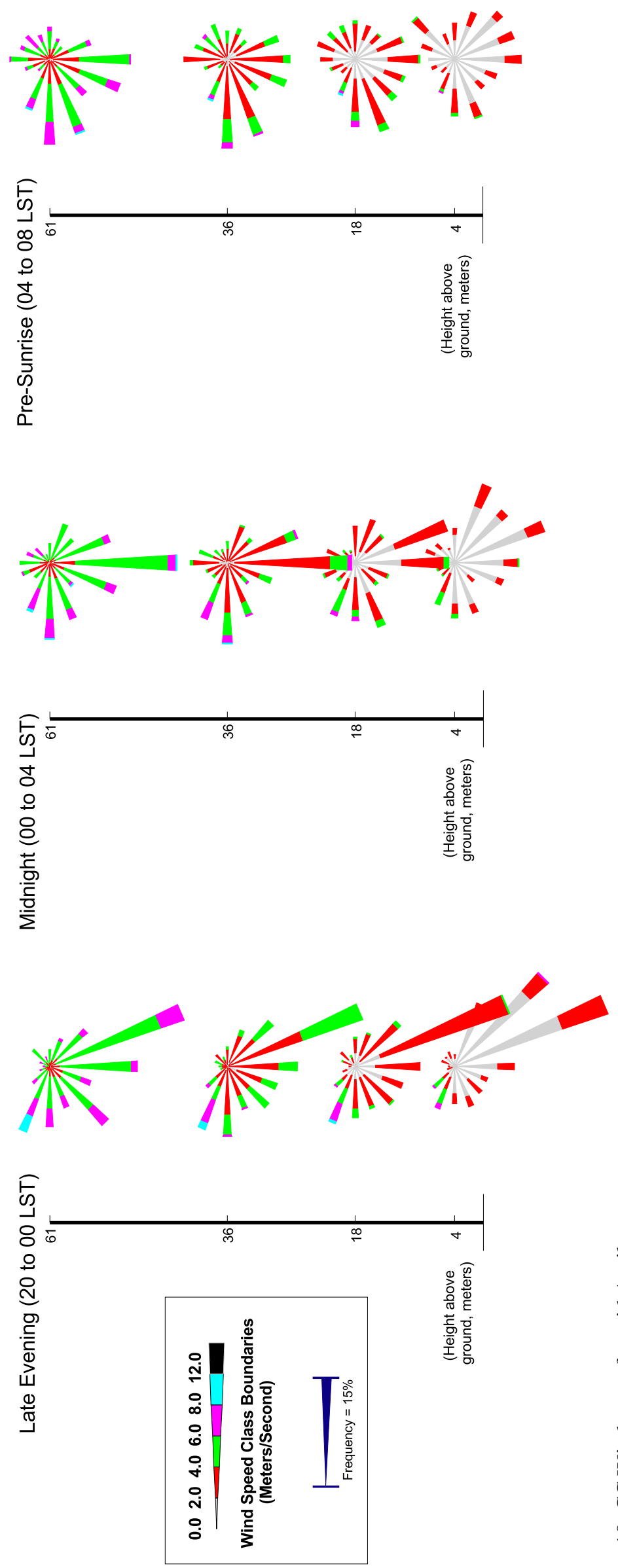

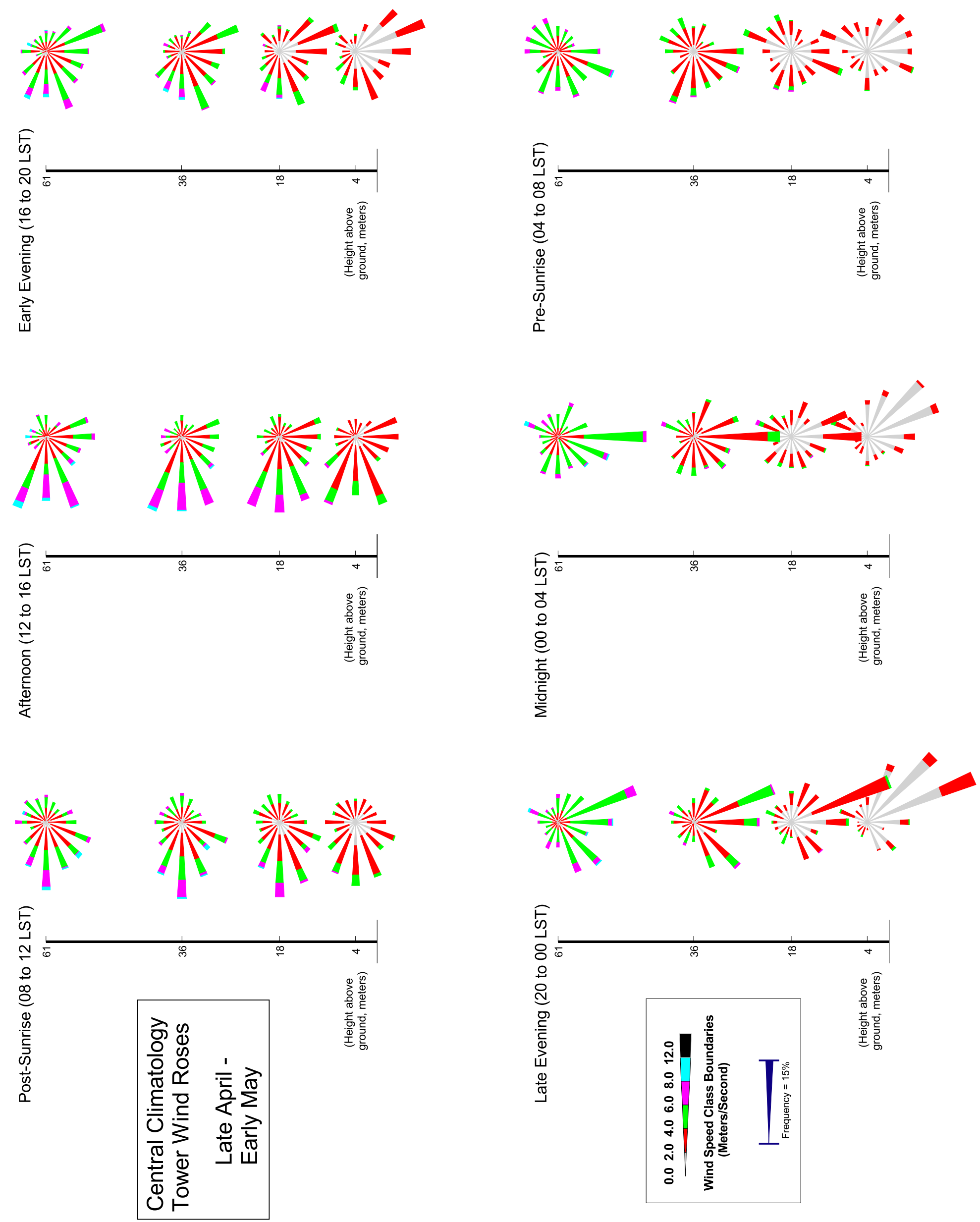

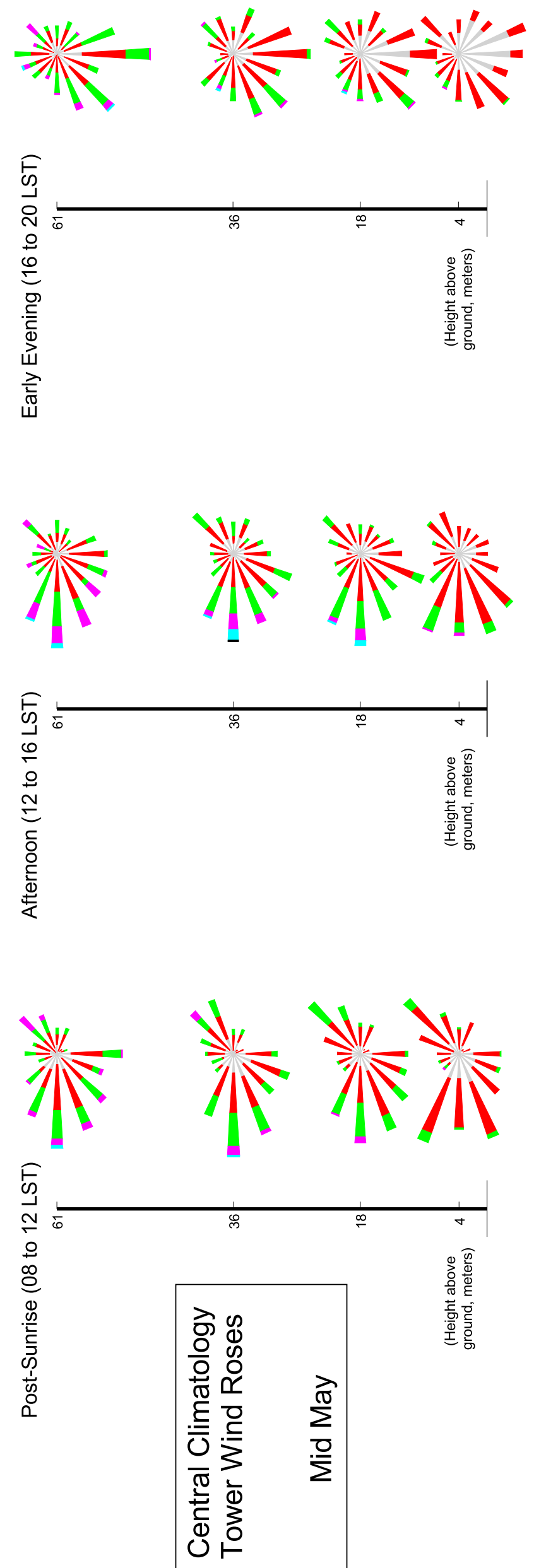
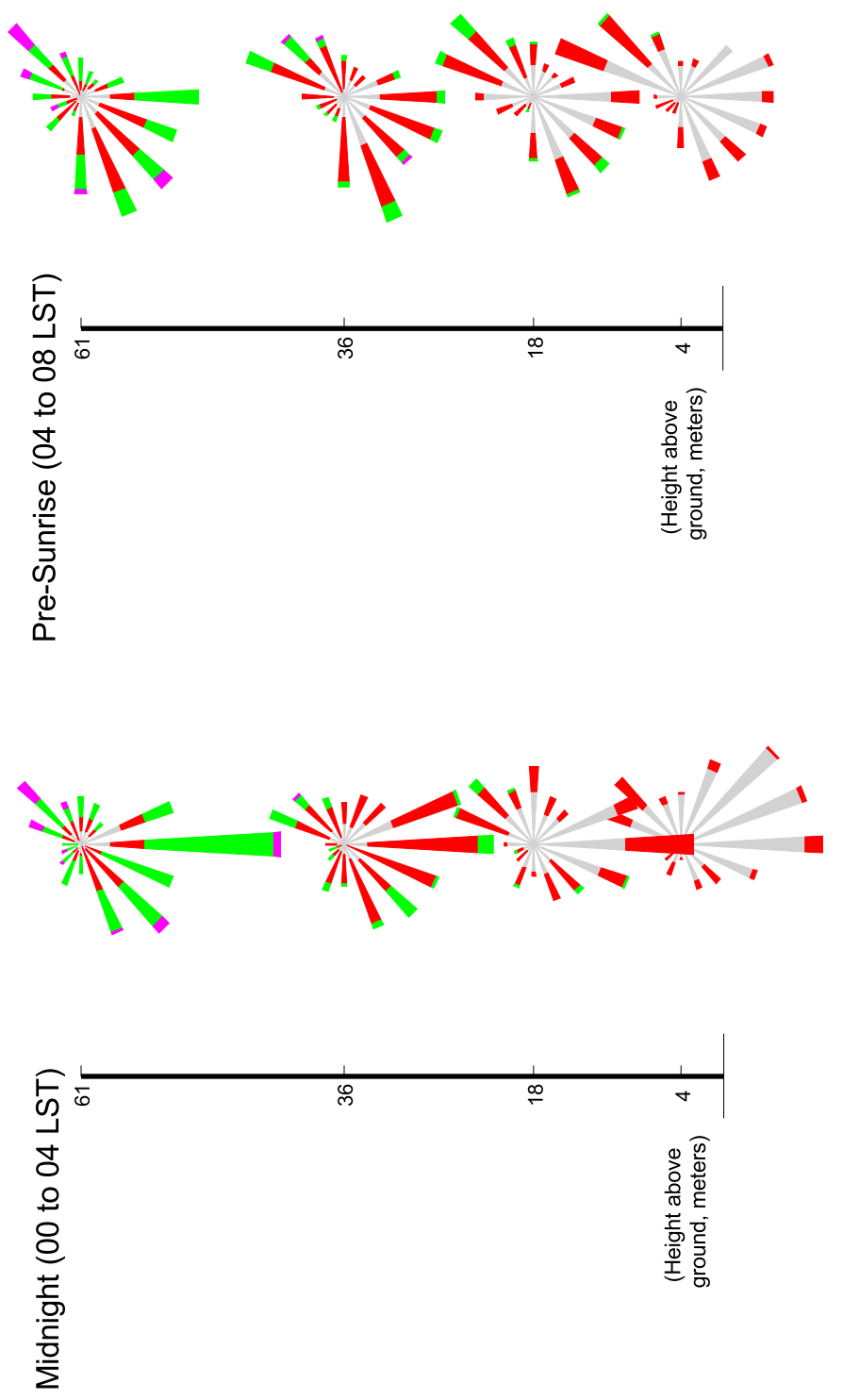

요
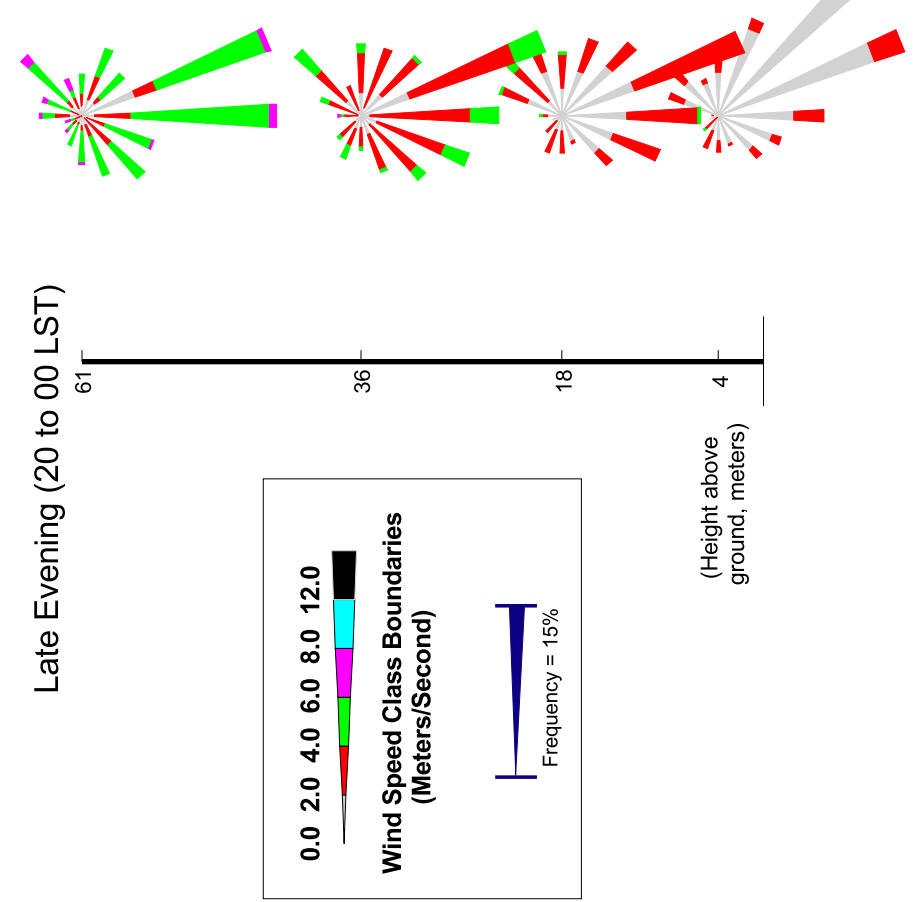

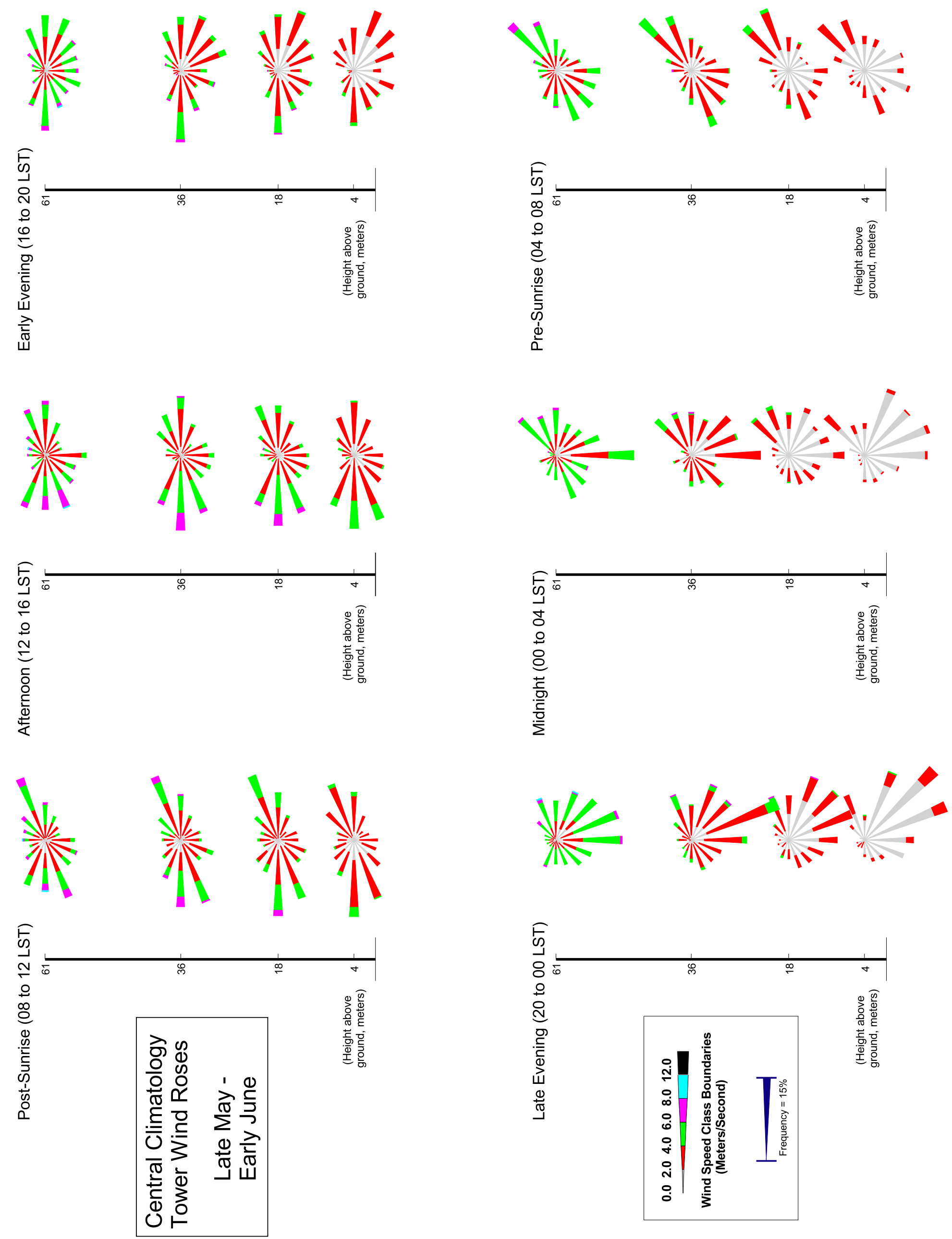

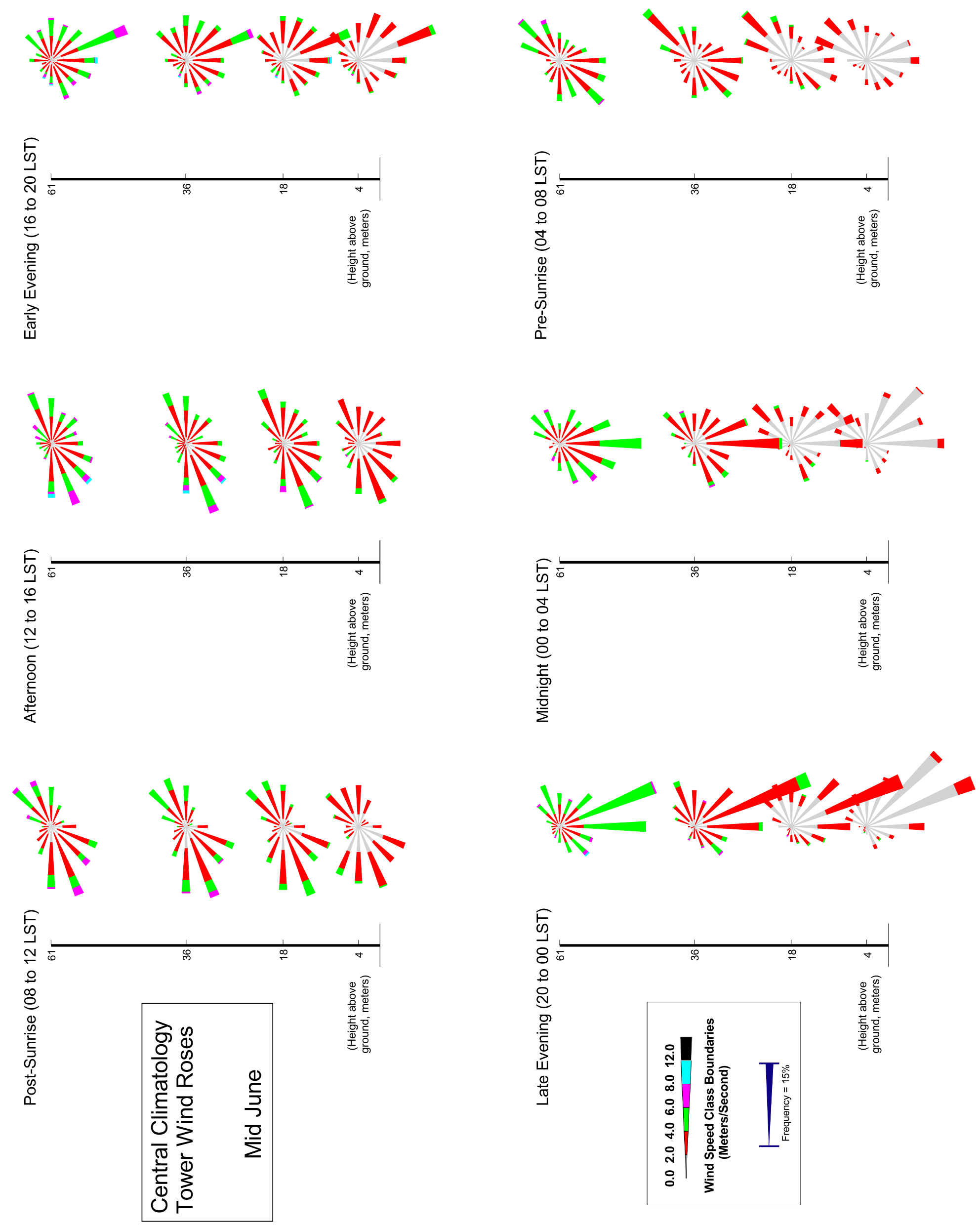

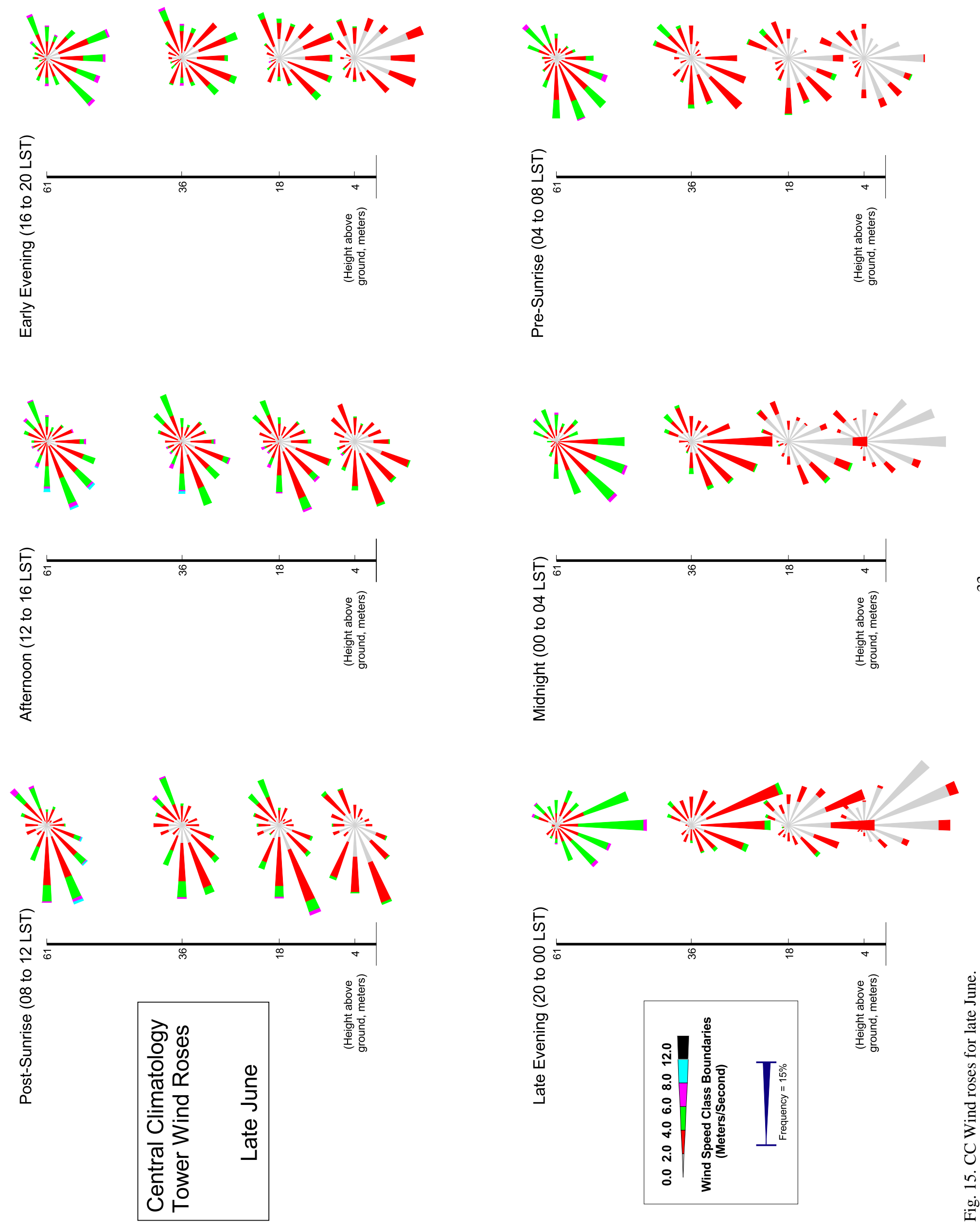

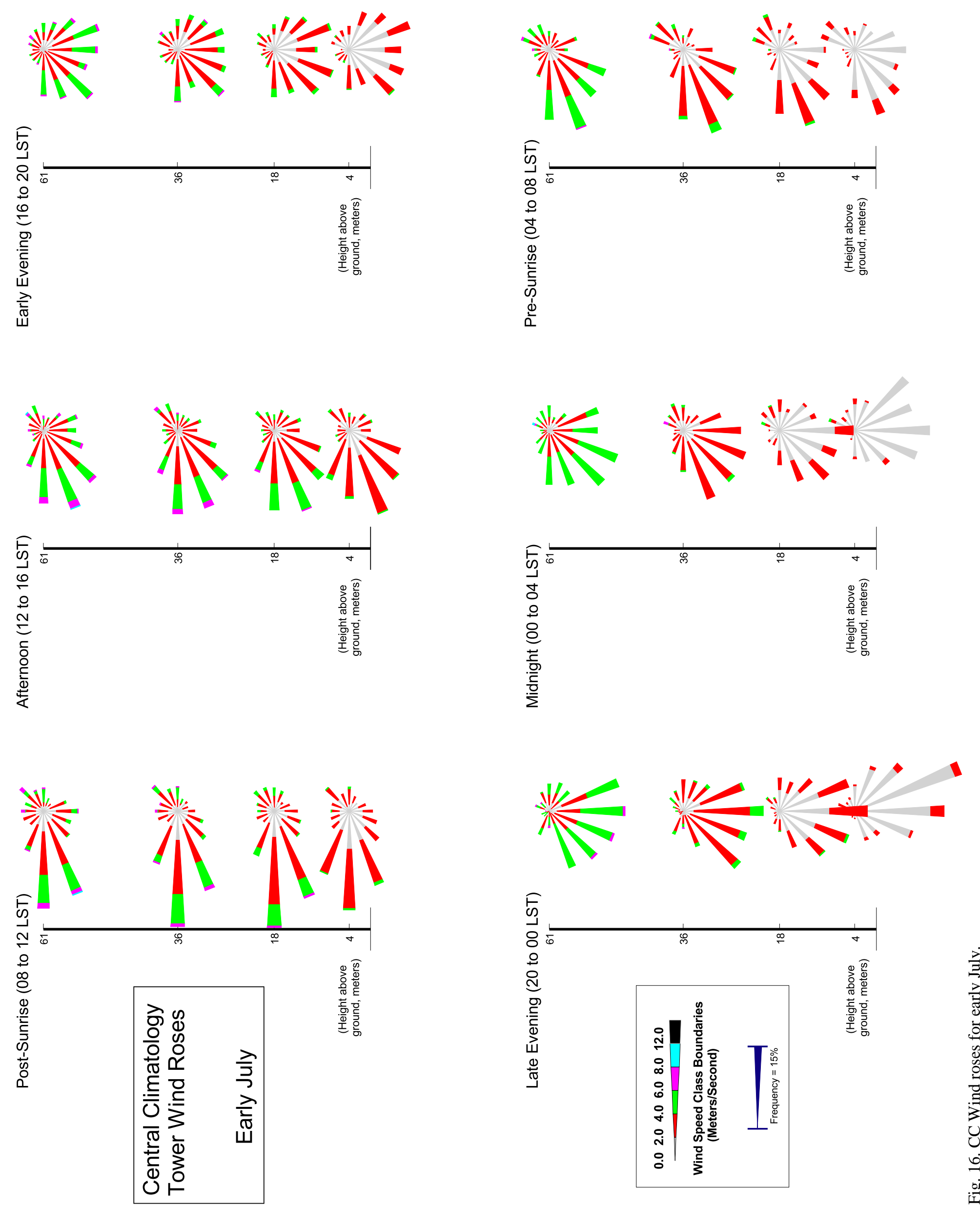

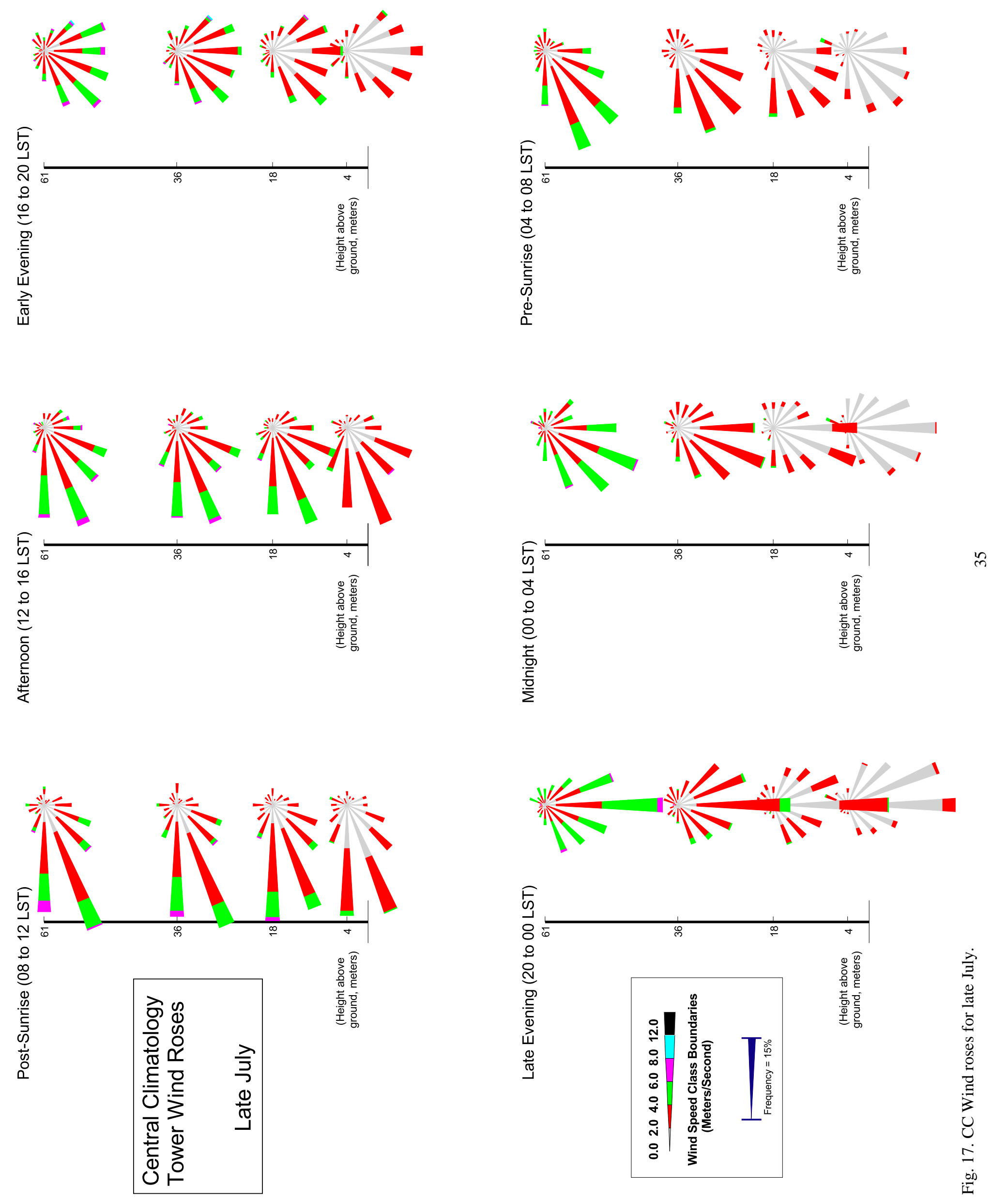


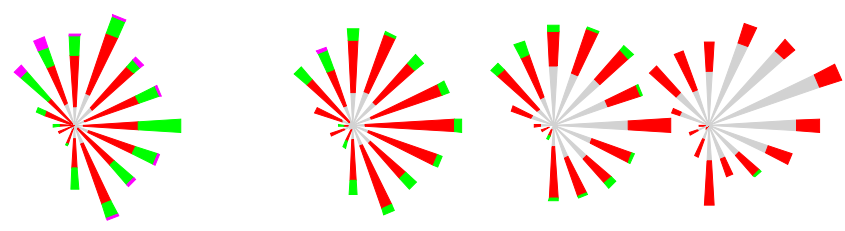
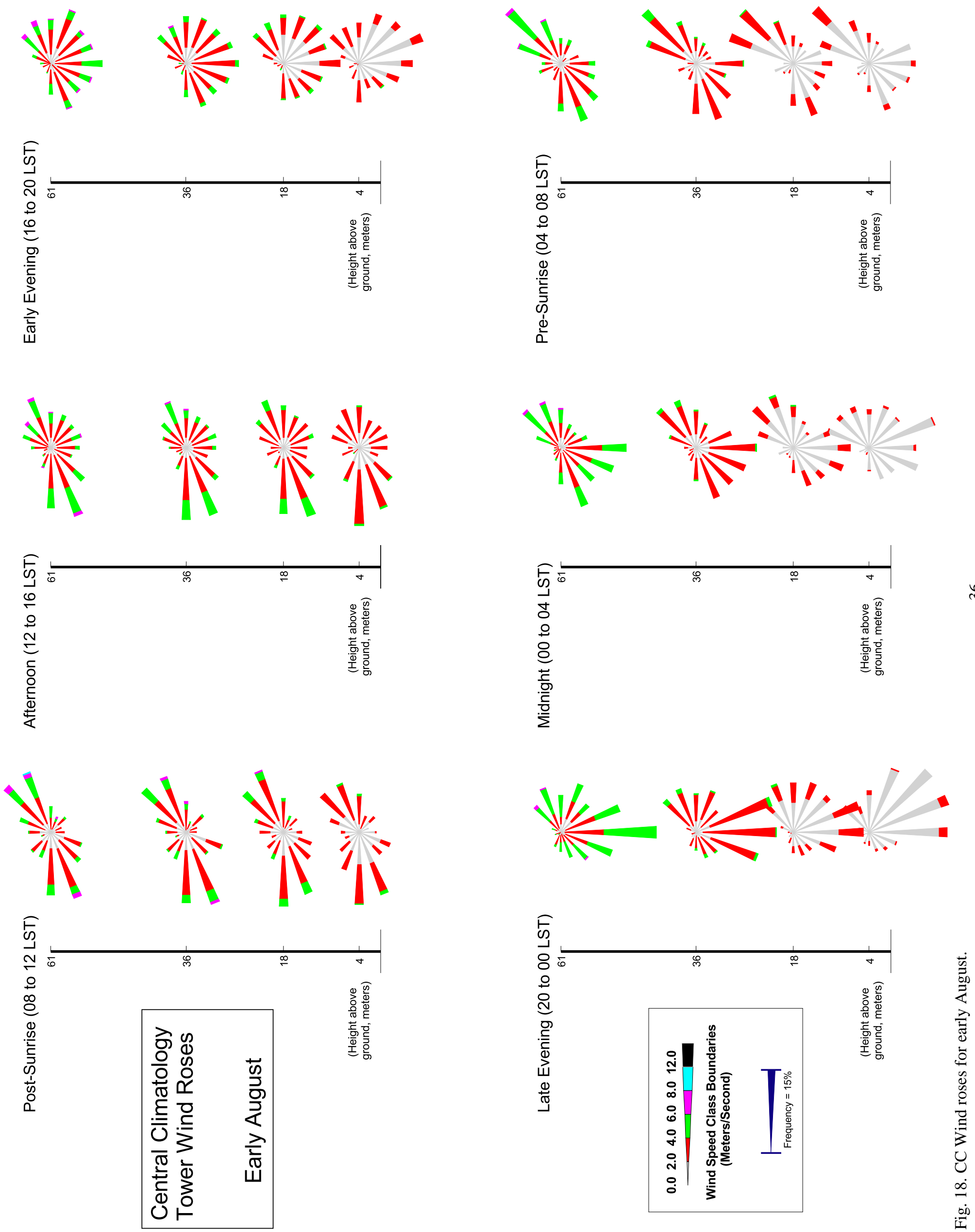


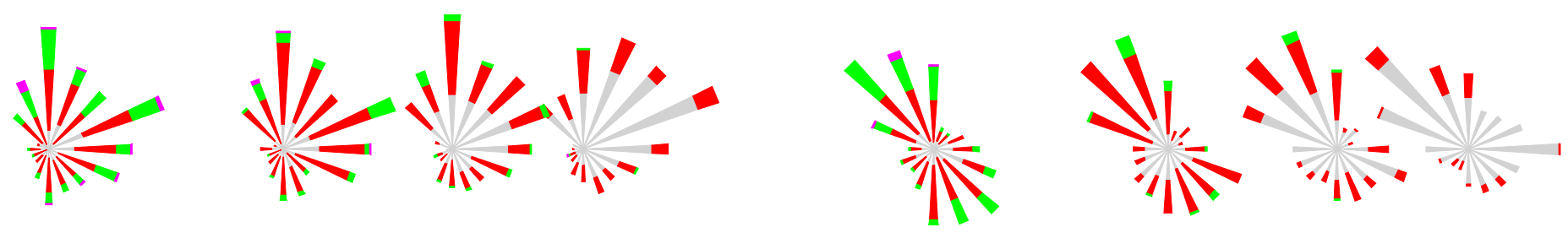
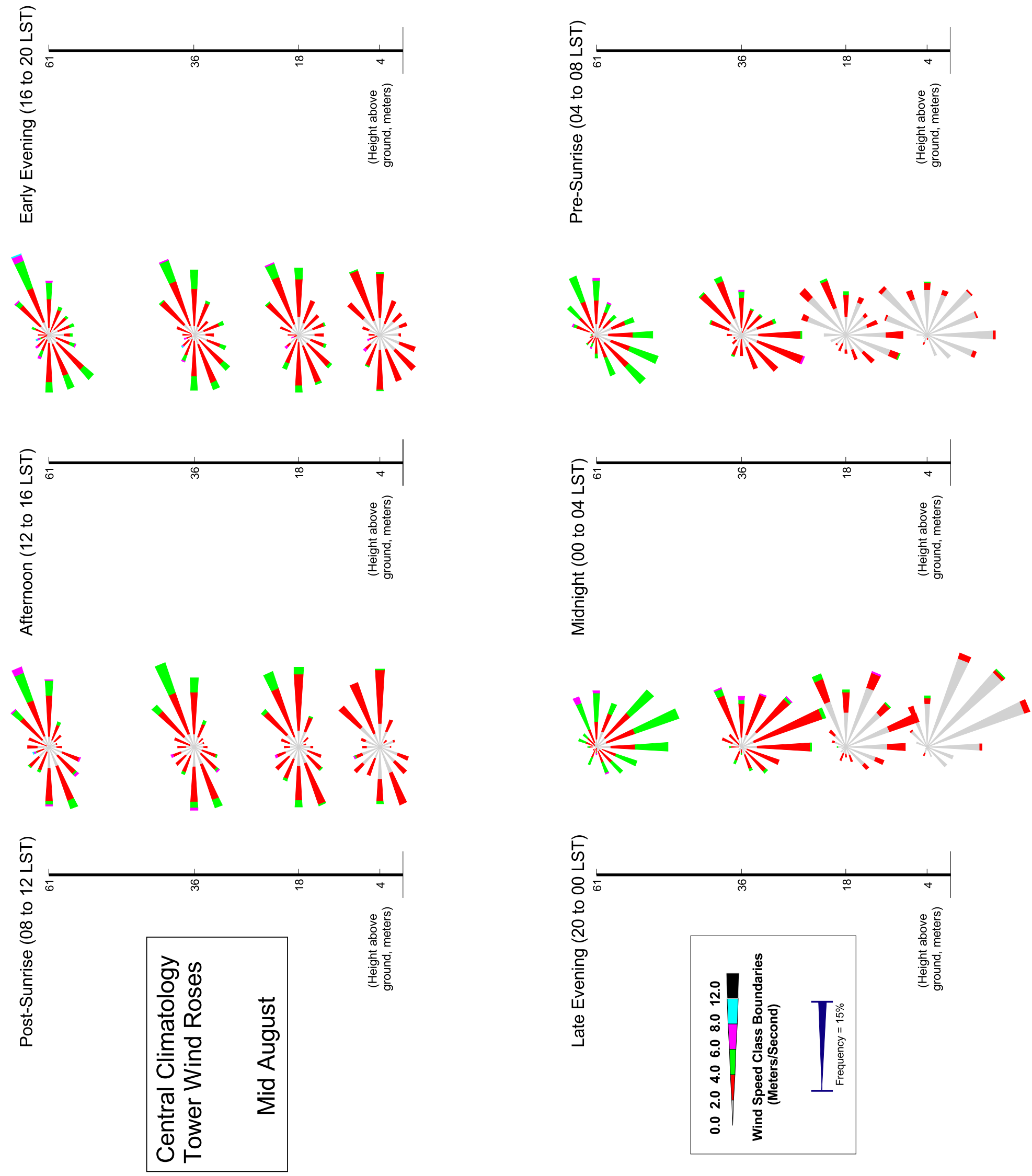
粰
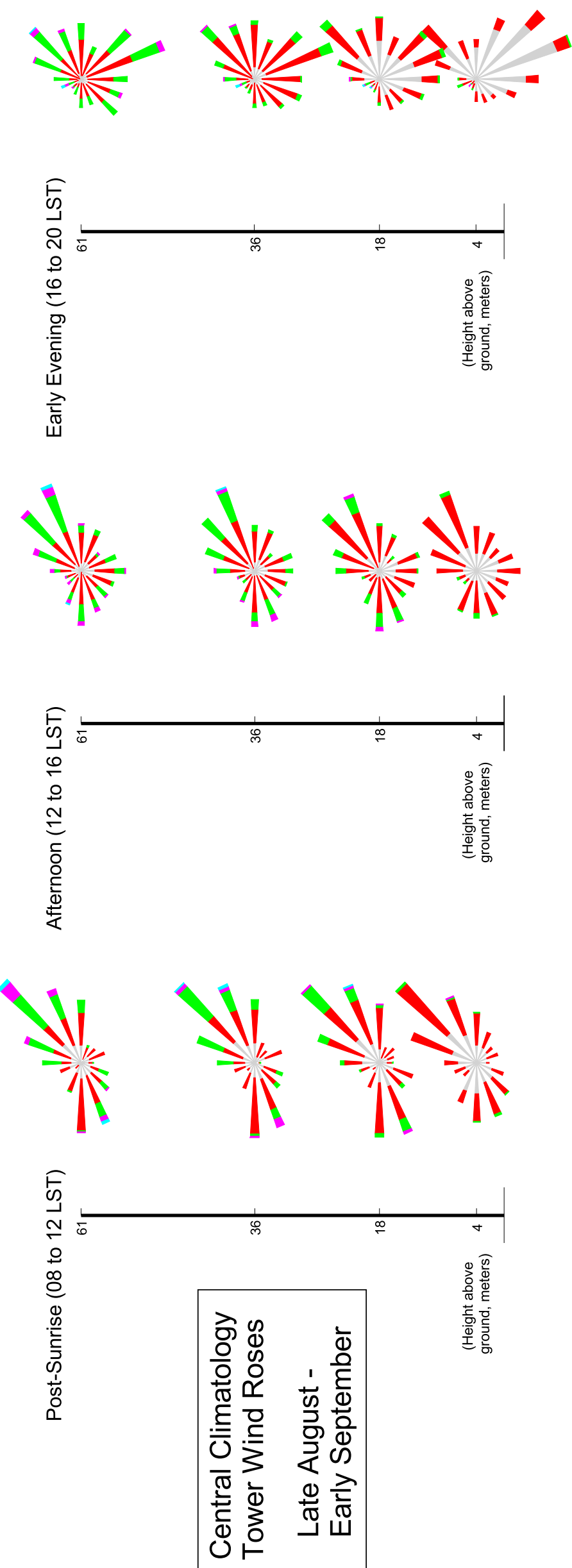
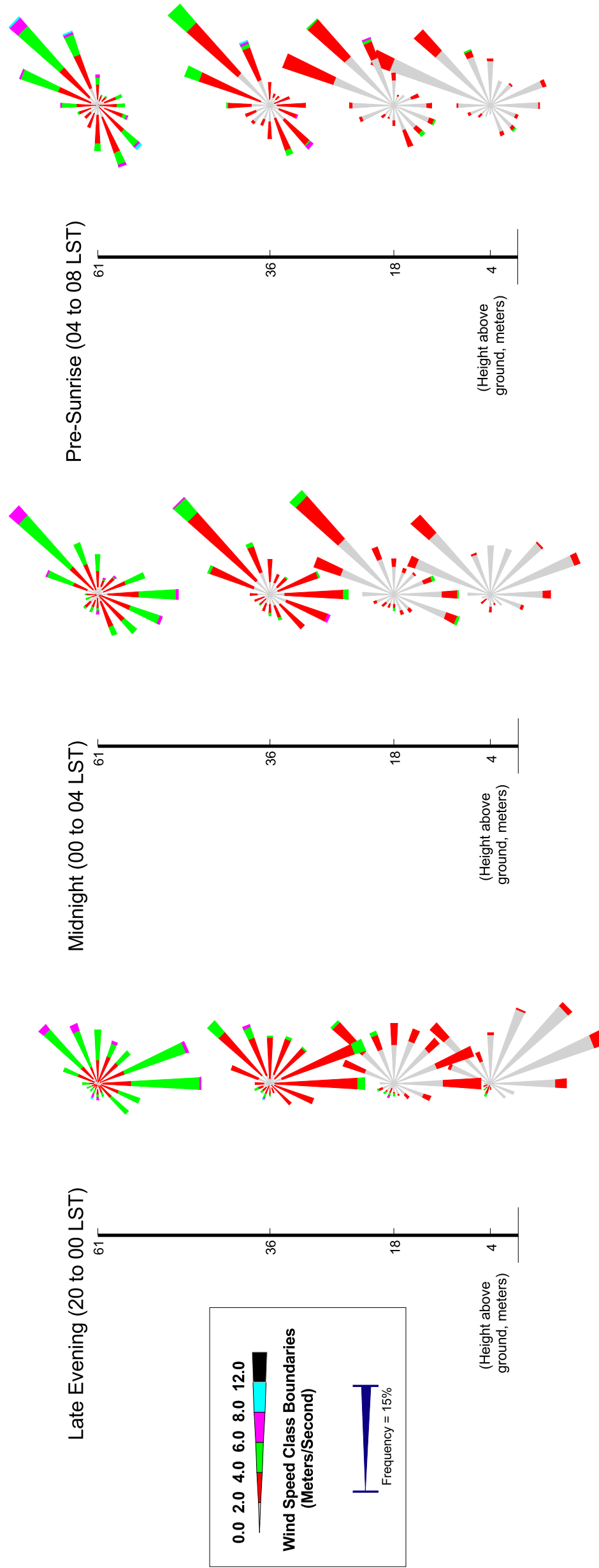
娄
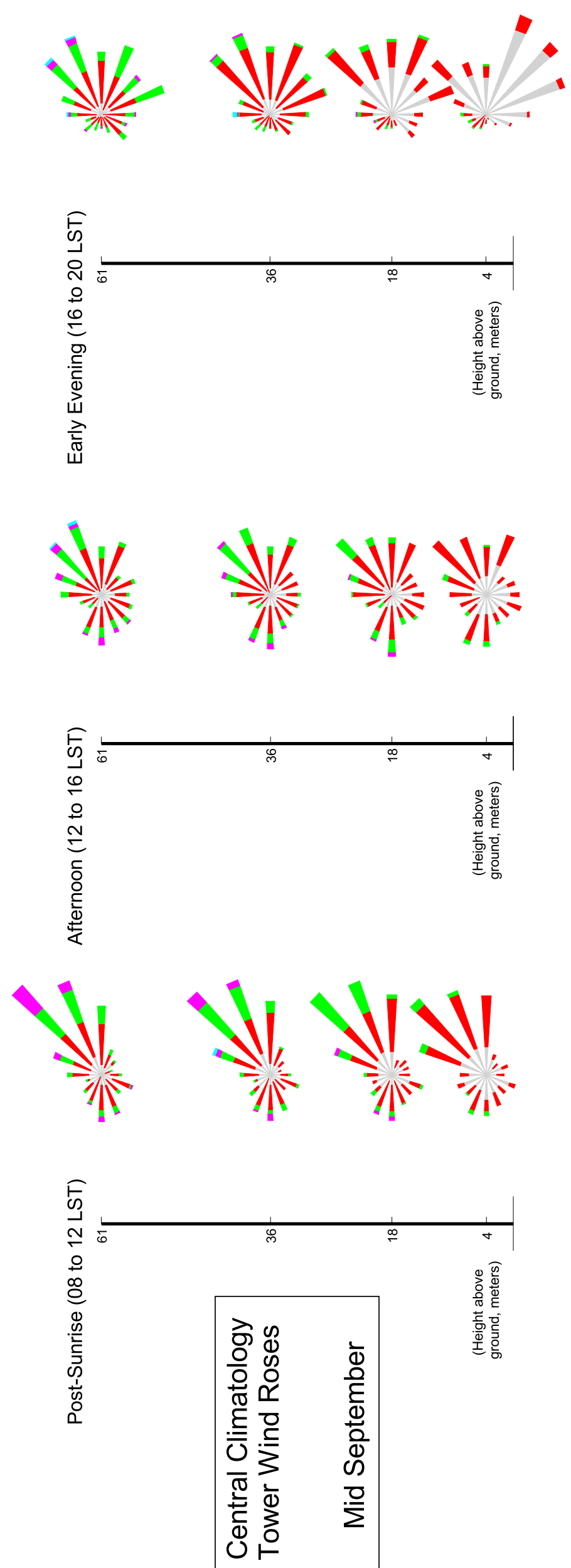
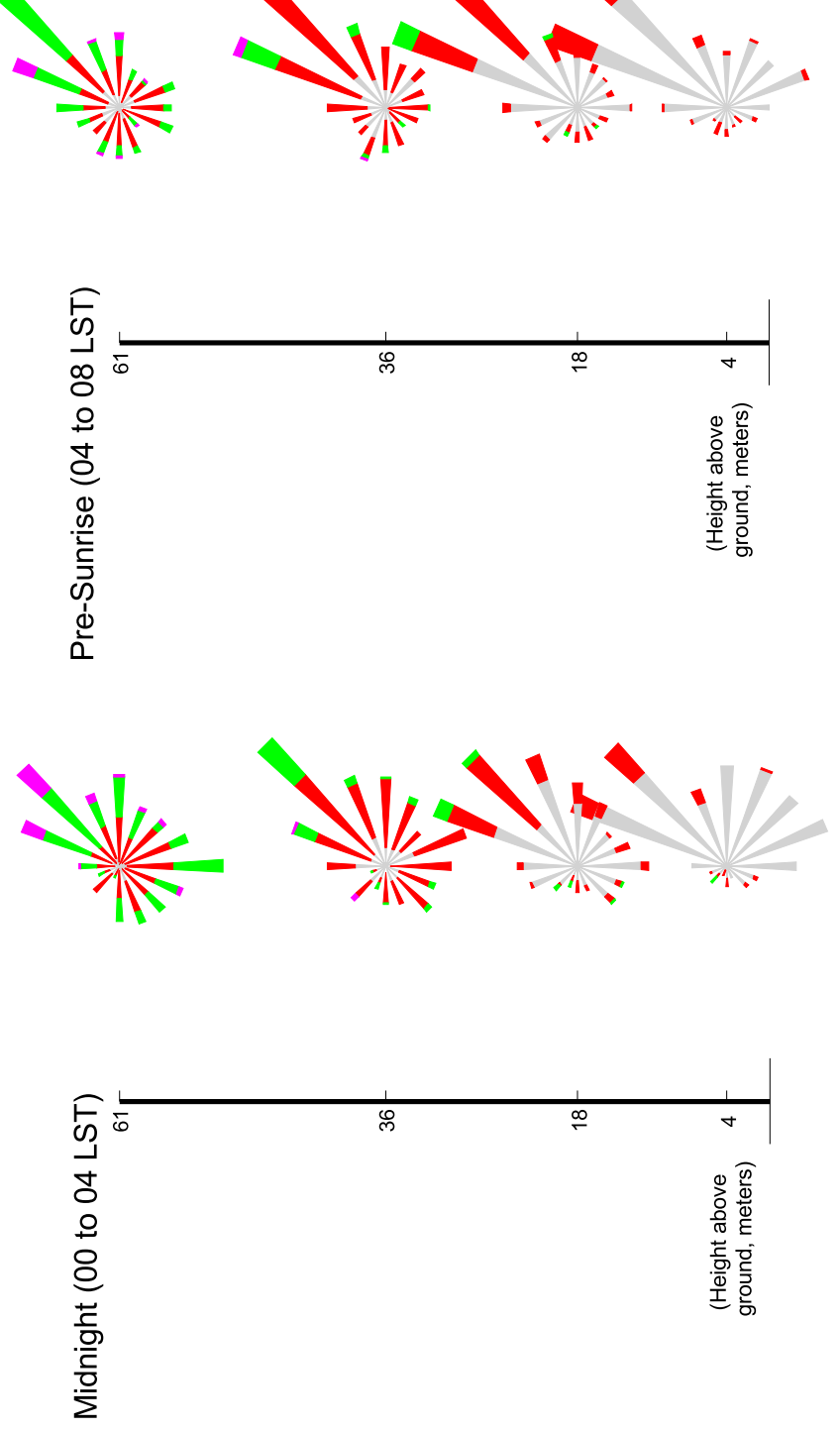

के
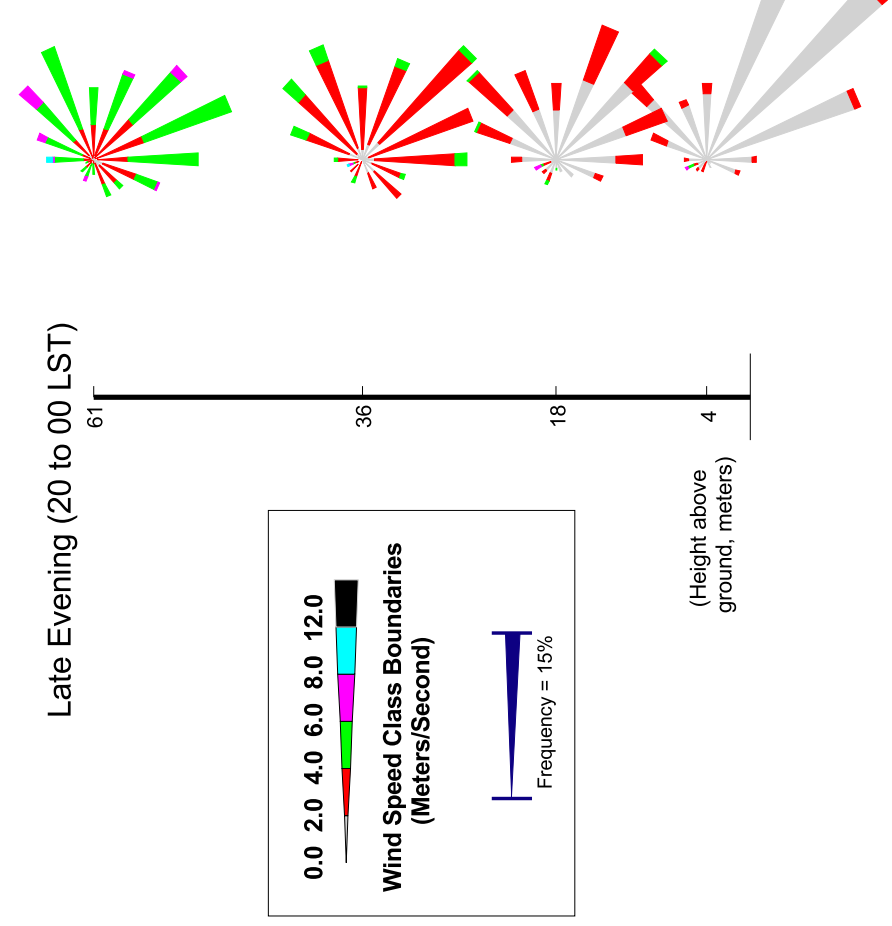

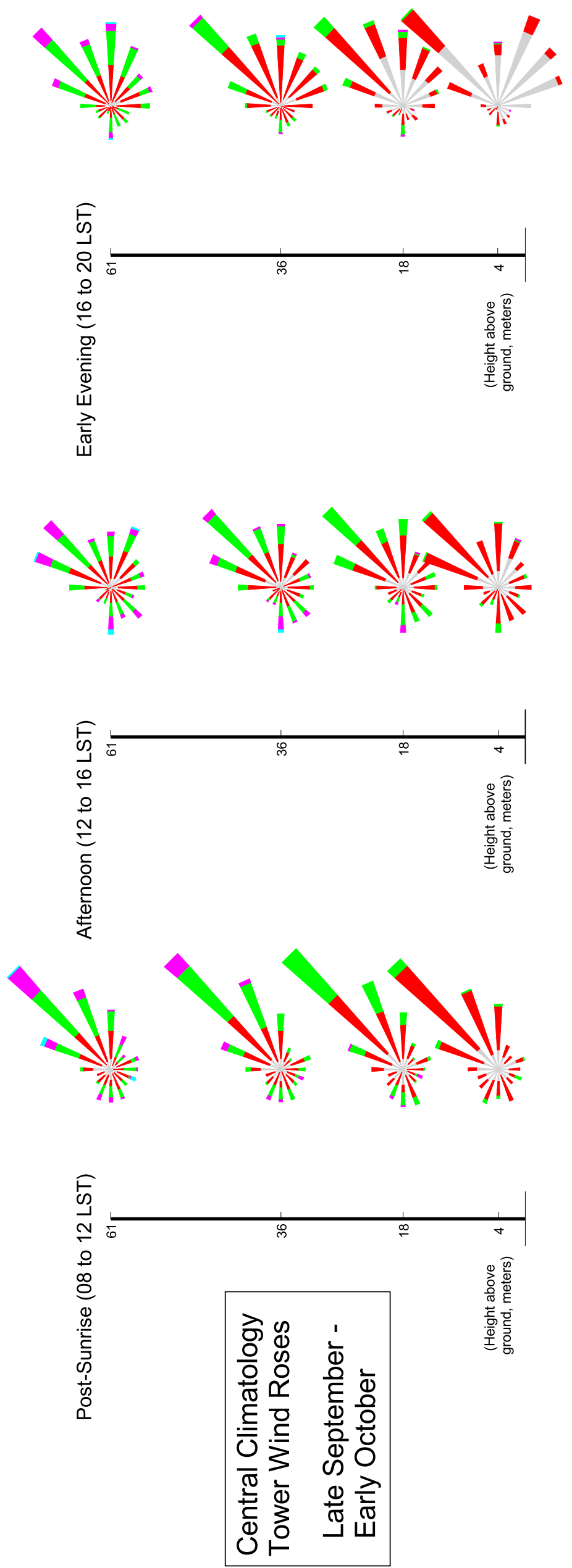
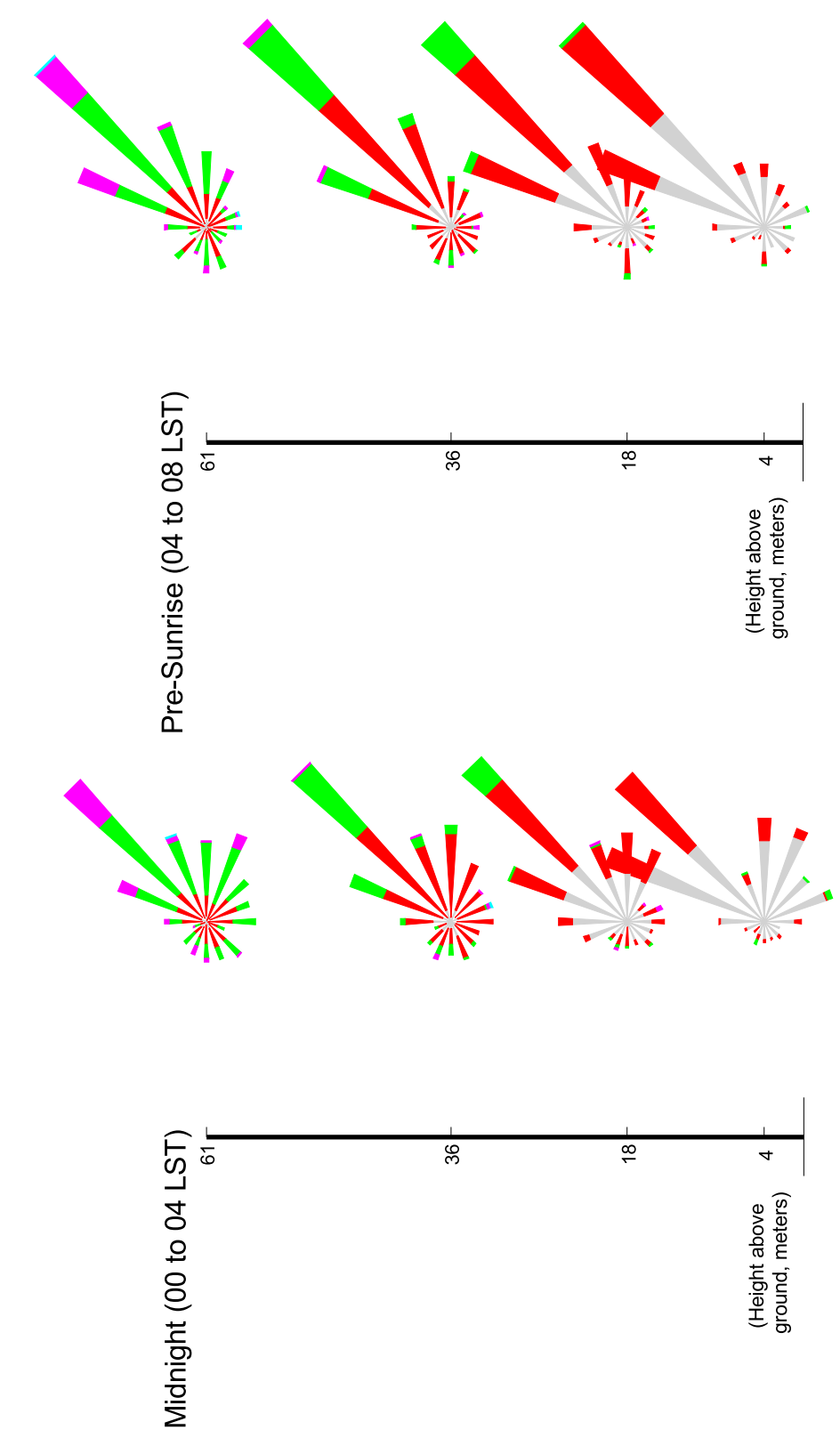

ㅇ
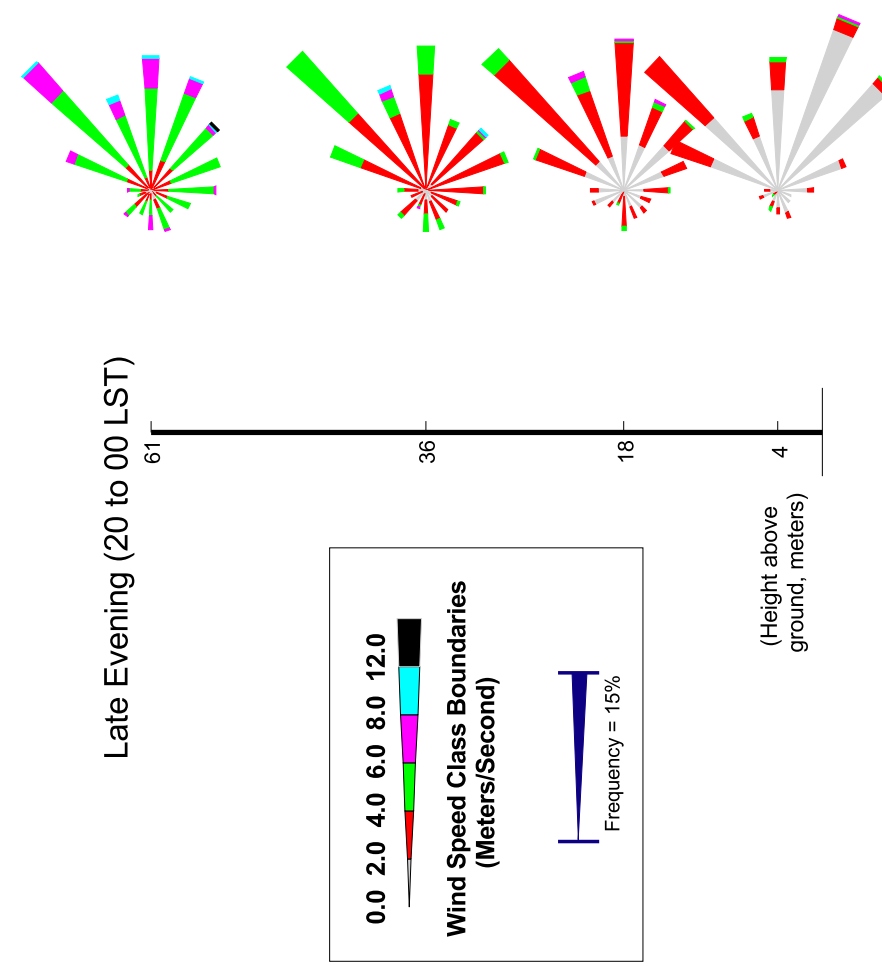

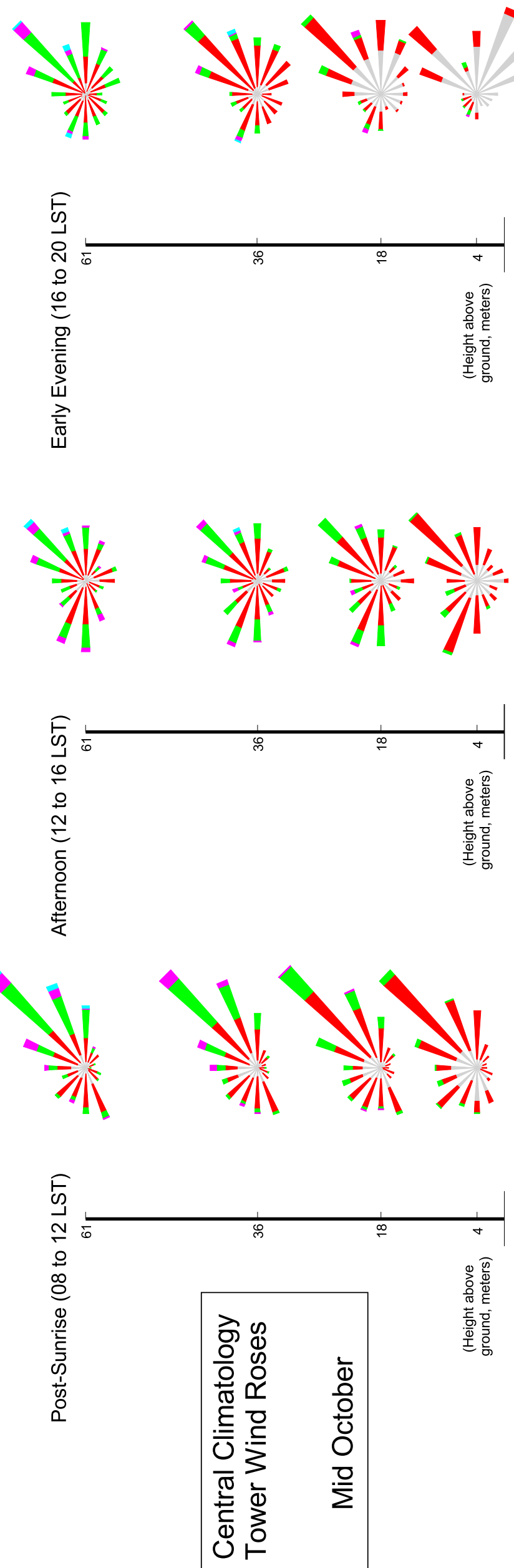
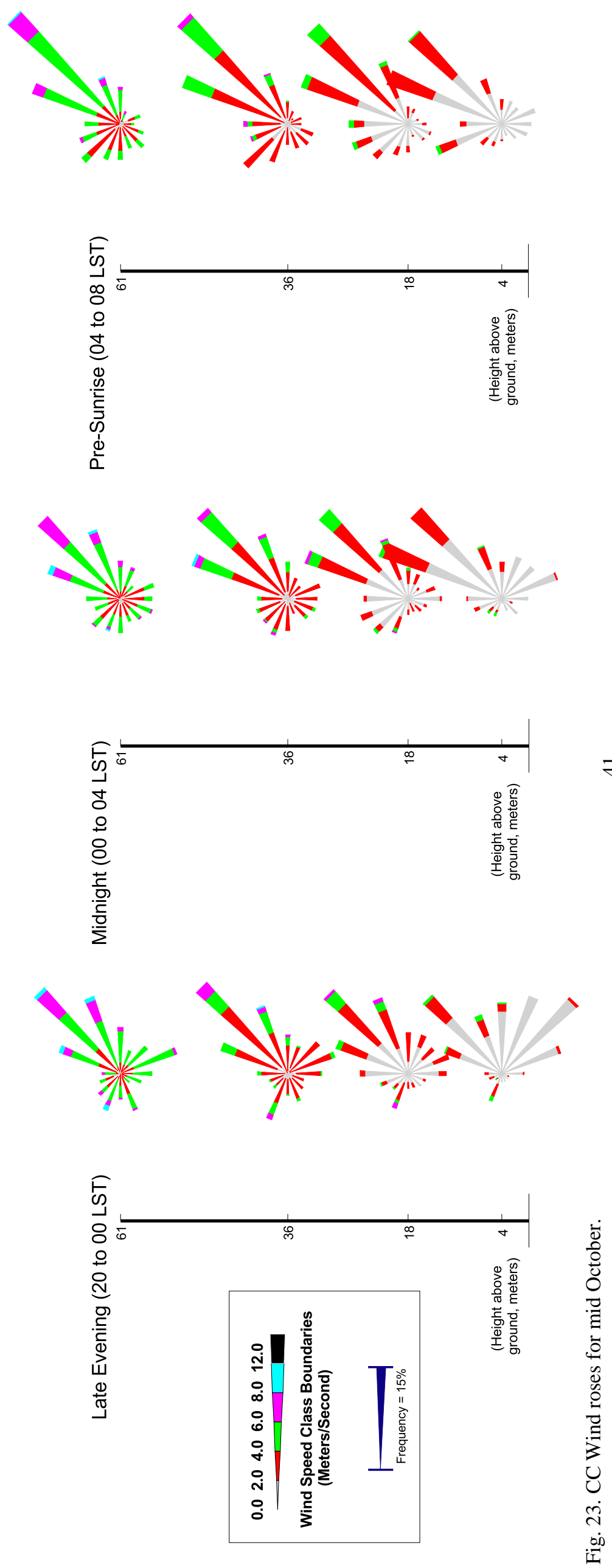

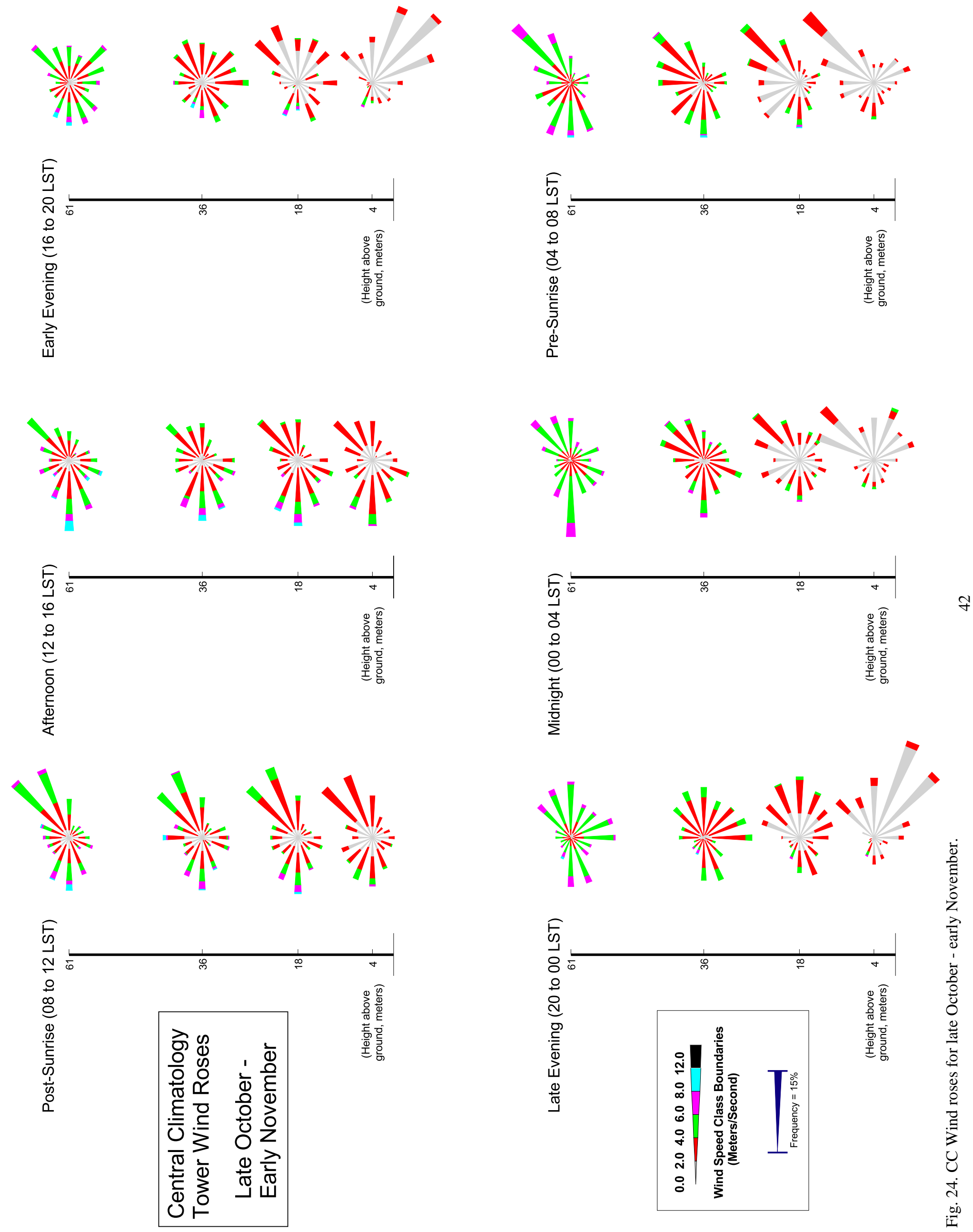


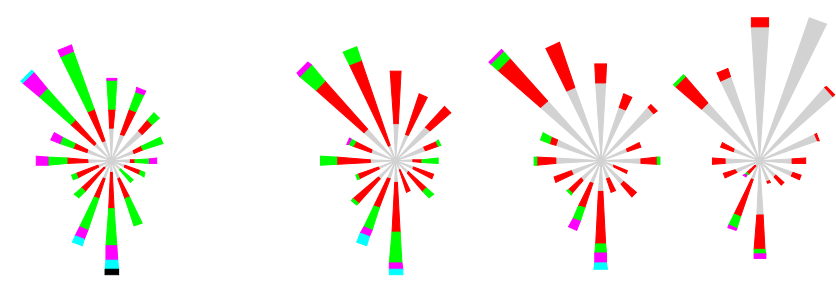
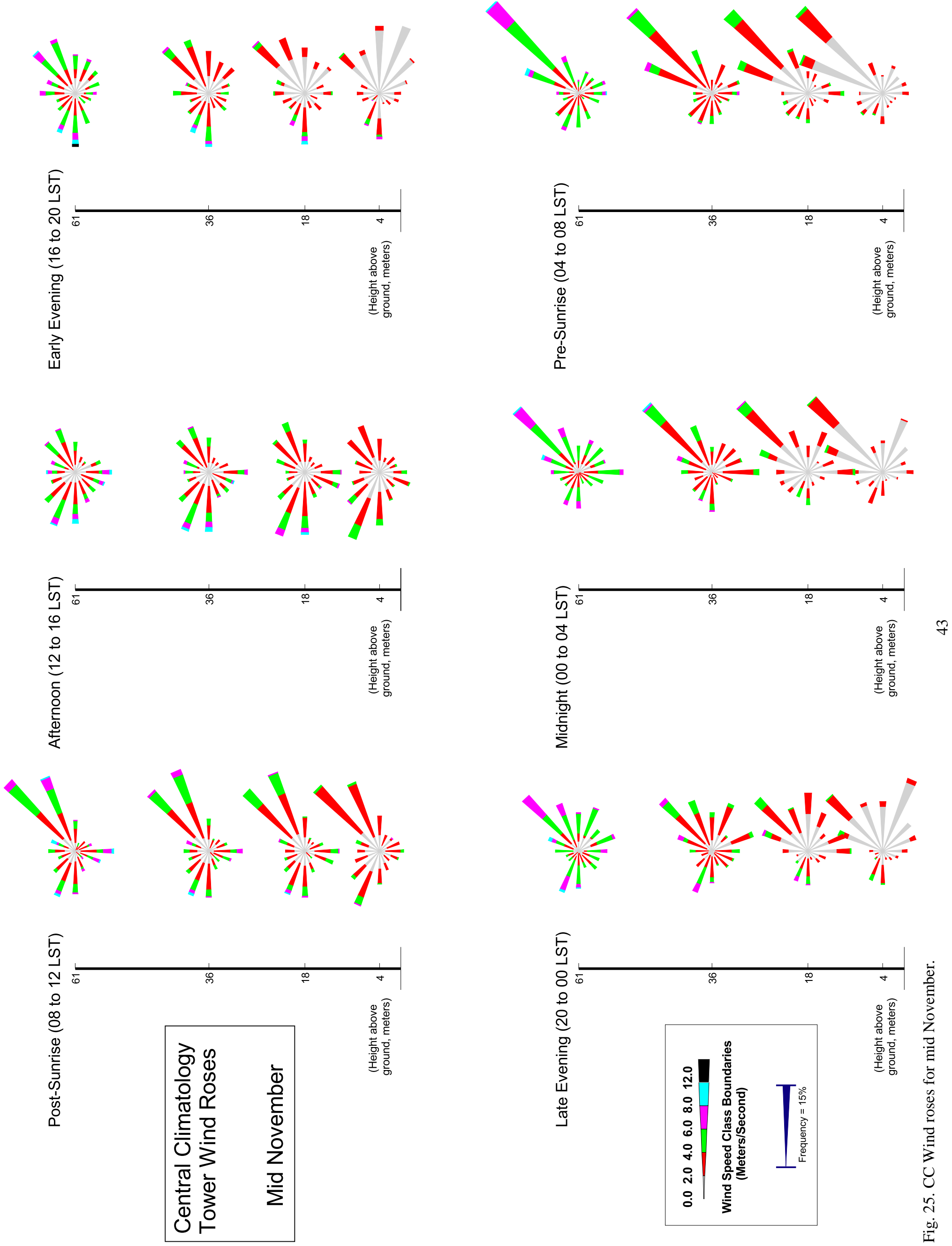


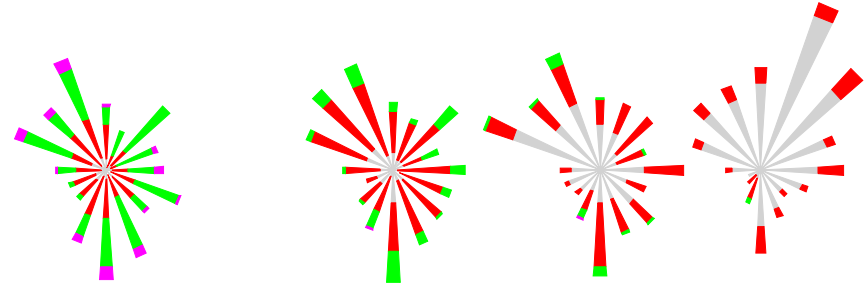
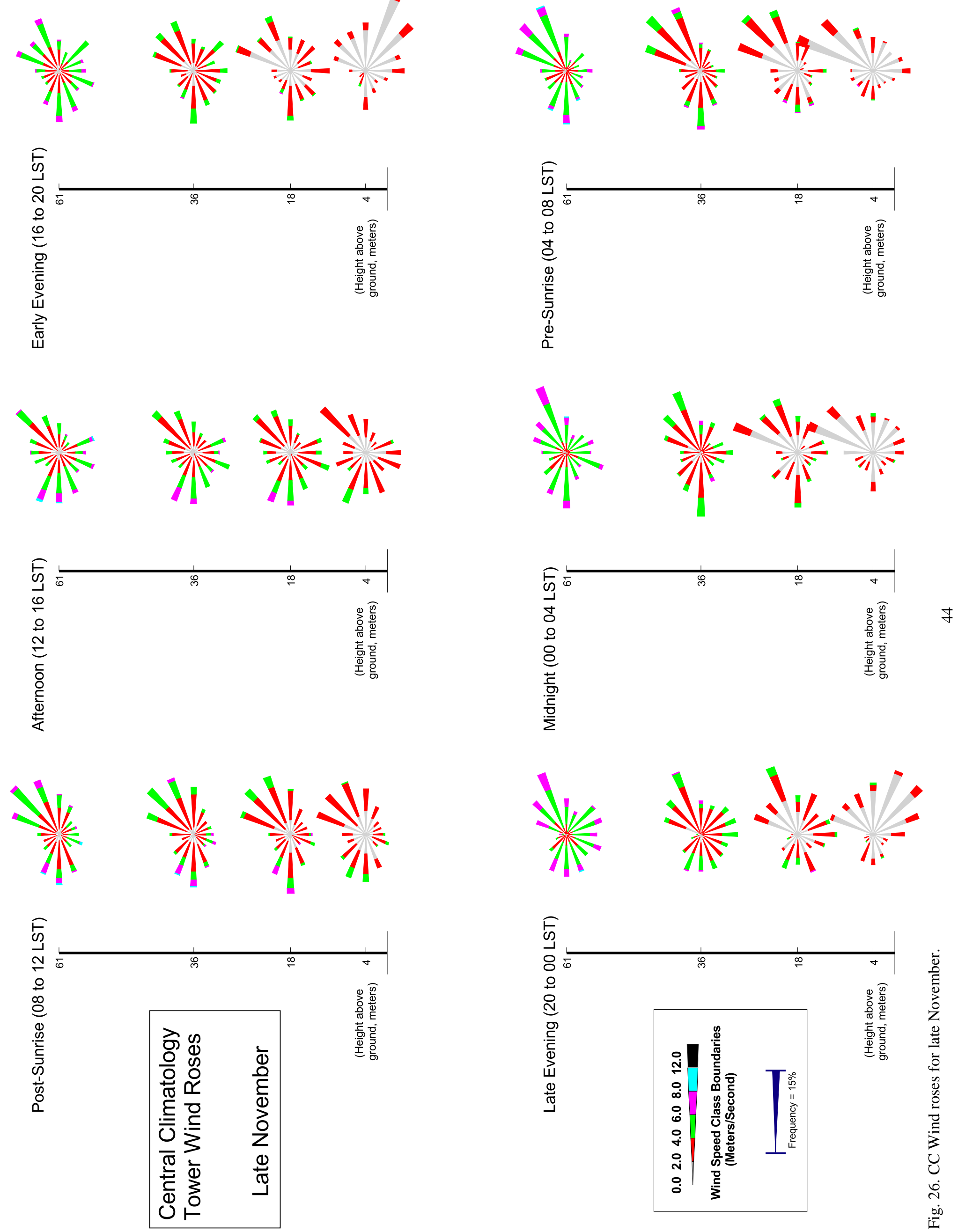


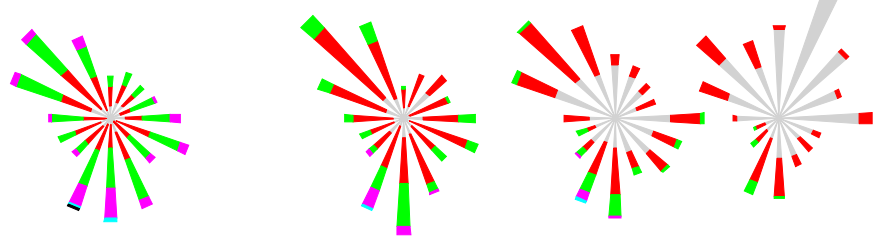
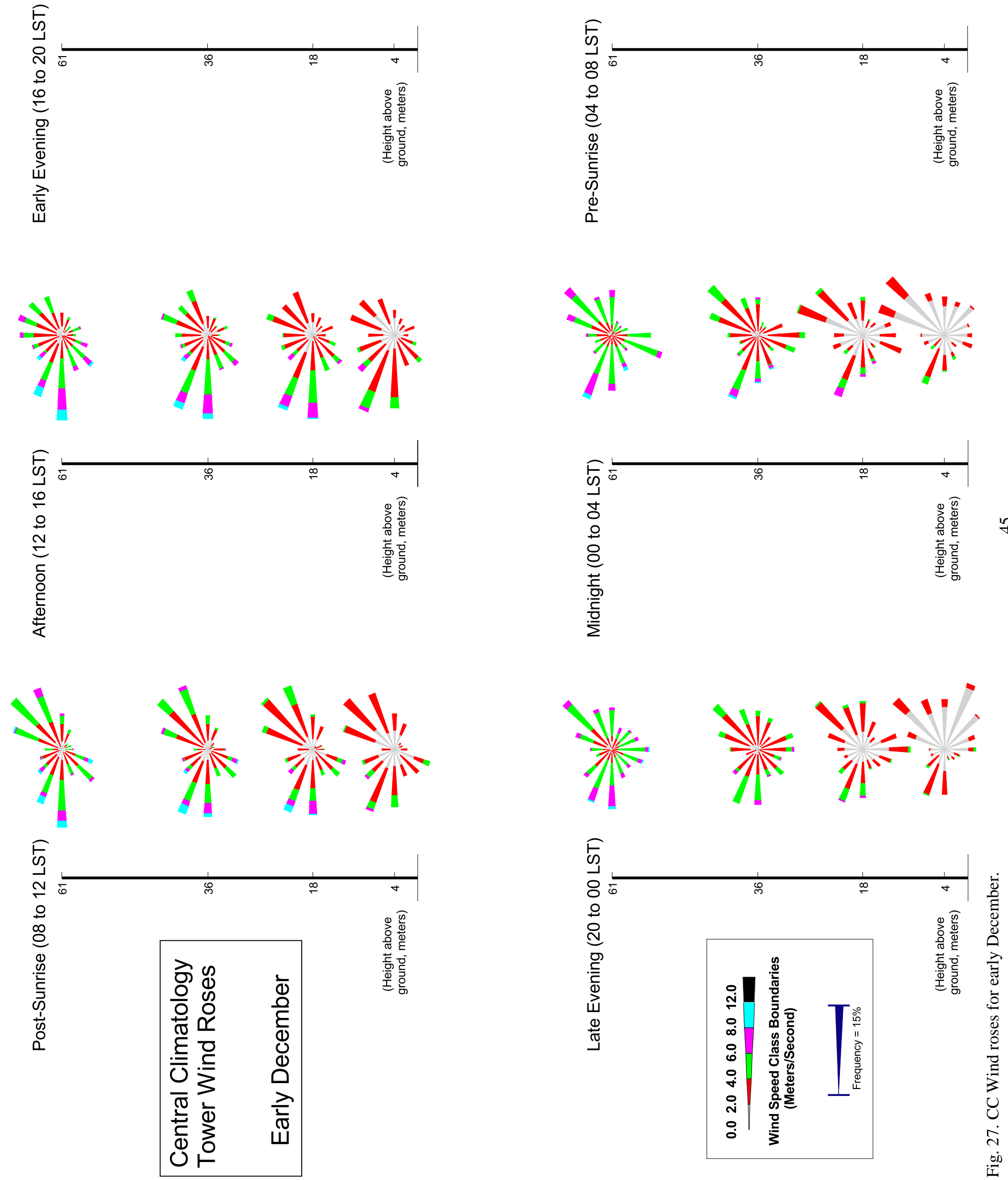

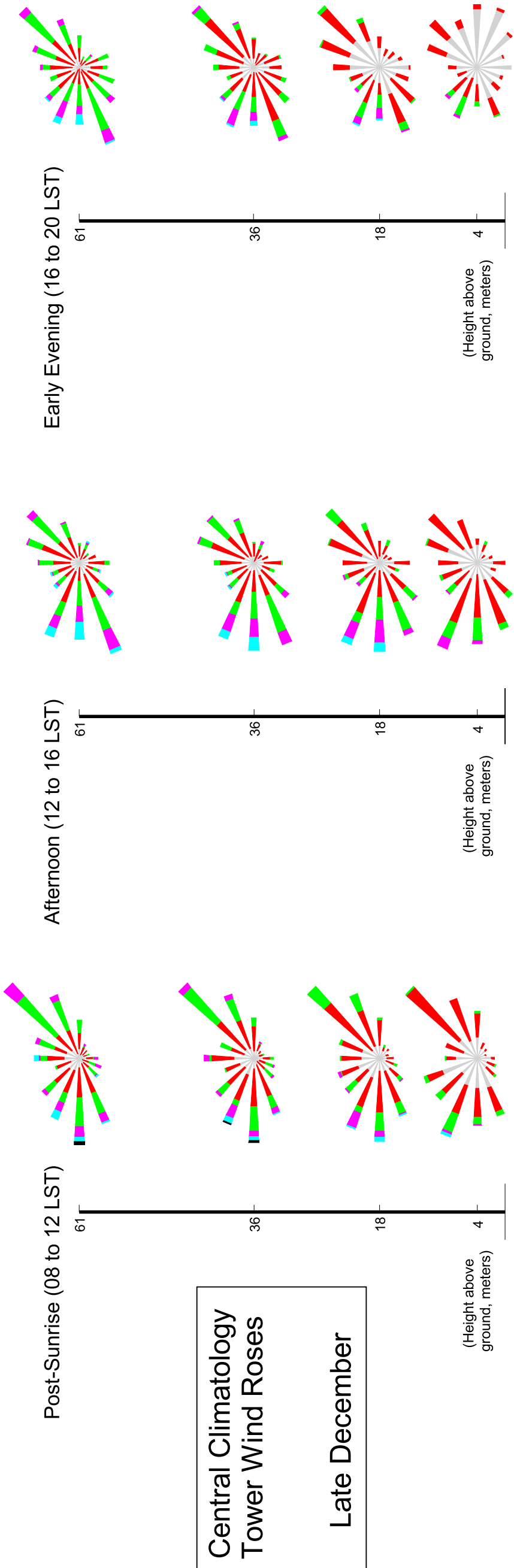
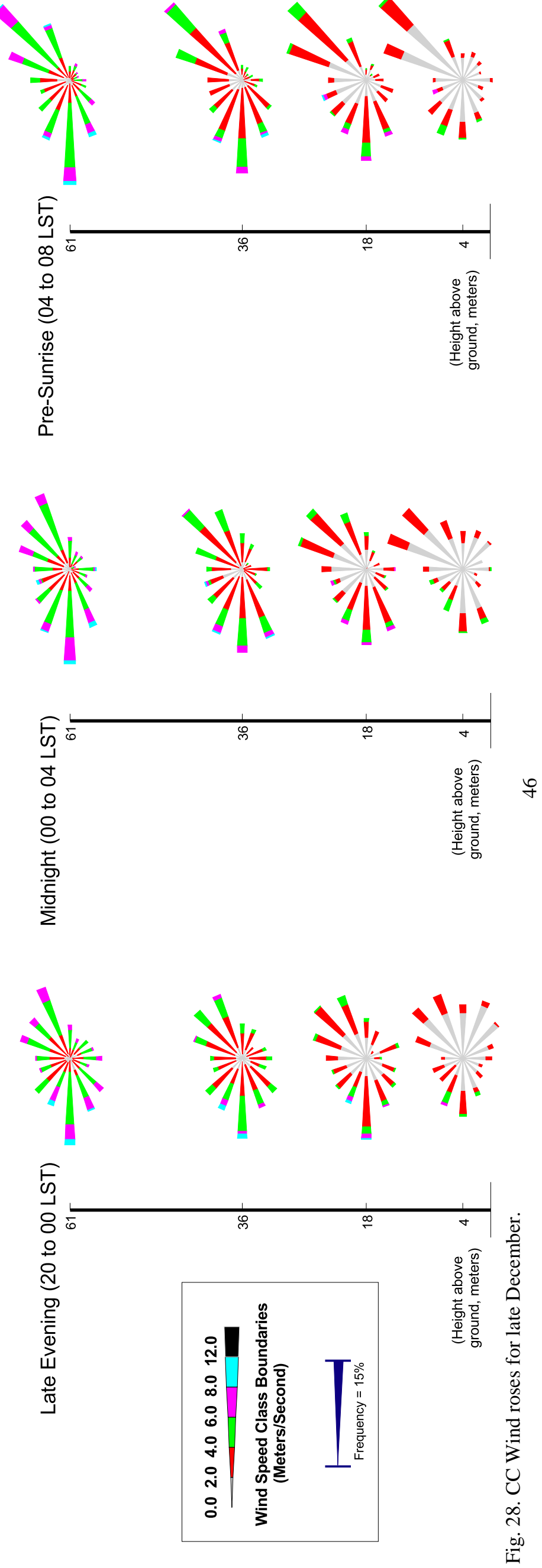

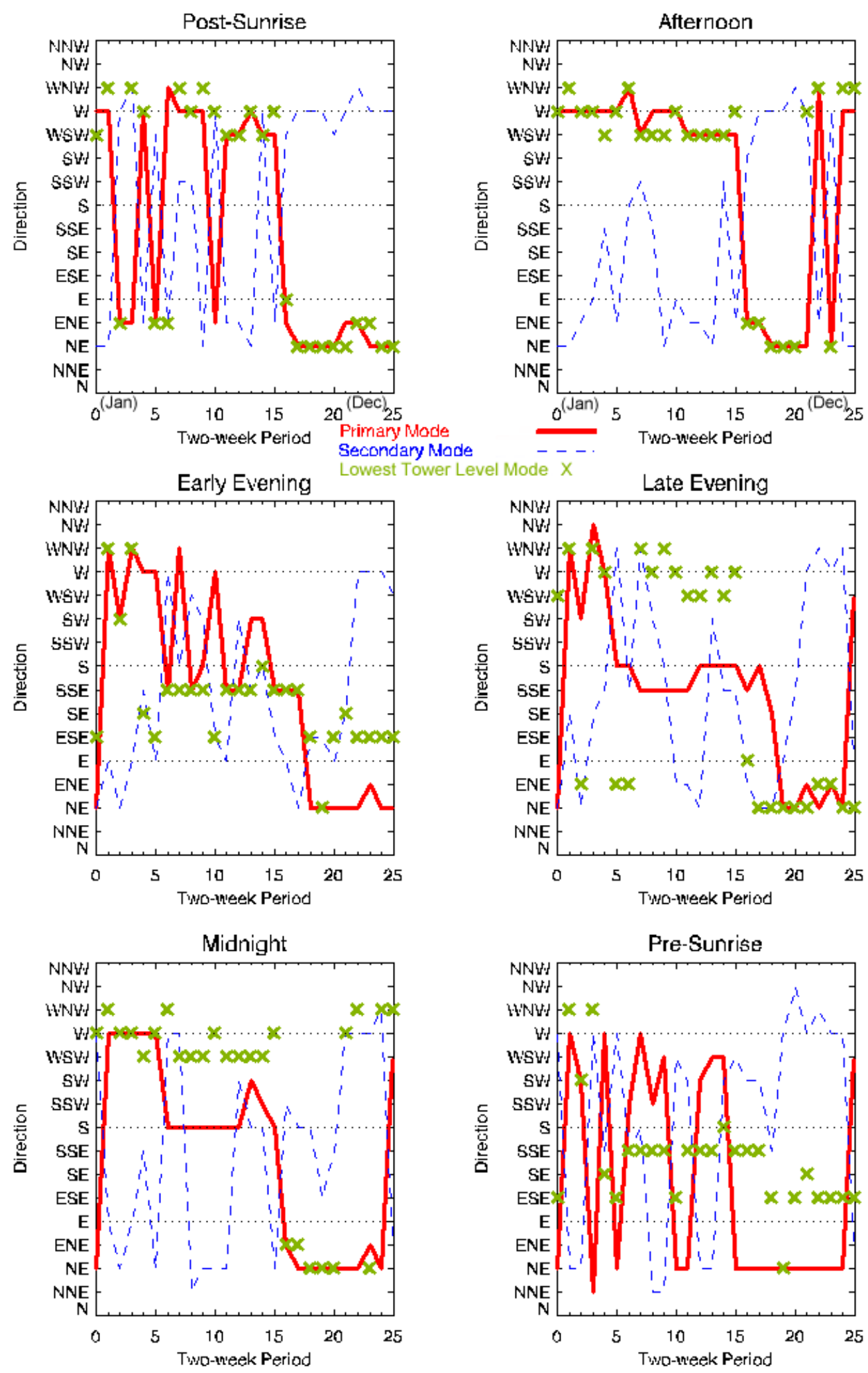

Figs. 29a-f. Wind direction modes for the 6 periods of the day over an entire year. The modes plotted in each figure are (1) primary mode: selected as representing the most frequent wind direction for the upper three levels of the tower, (2) secondary mode: selected as representing the second most frequent wind direction for the upper three levels of the tower, and (3) surface mode: selected as representing the most frequent wind direction for the lowest tower level. 


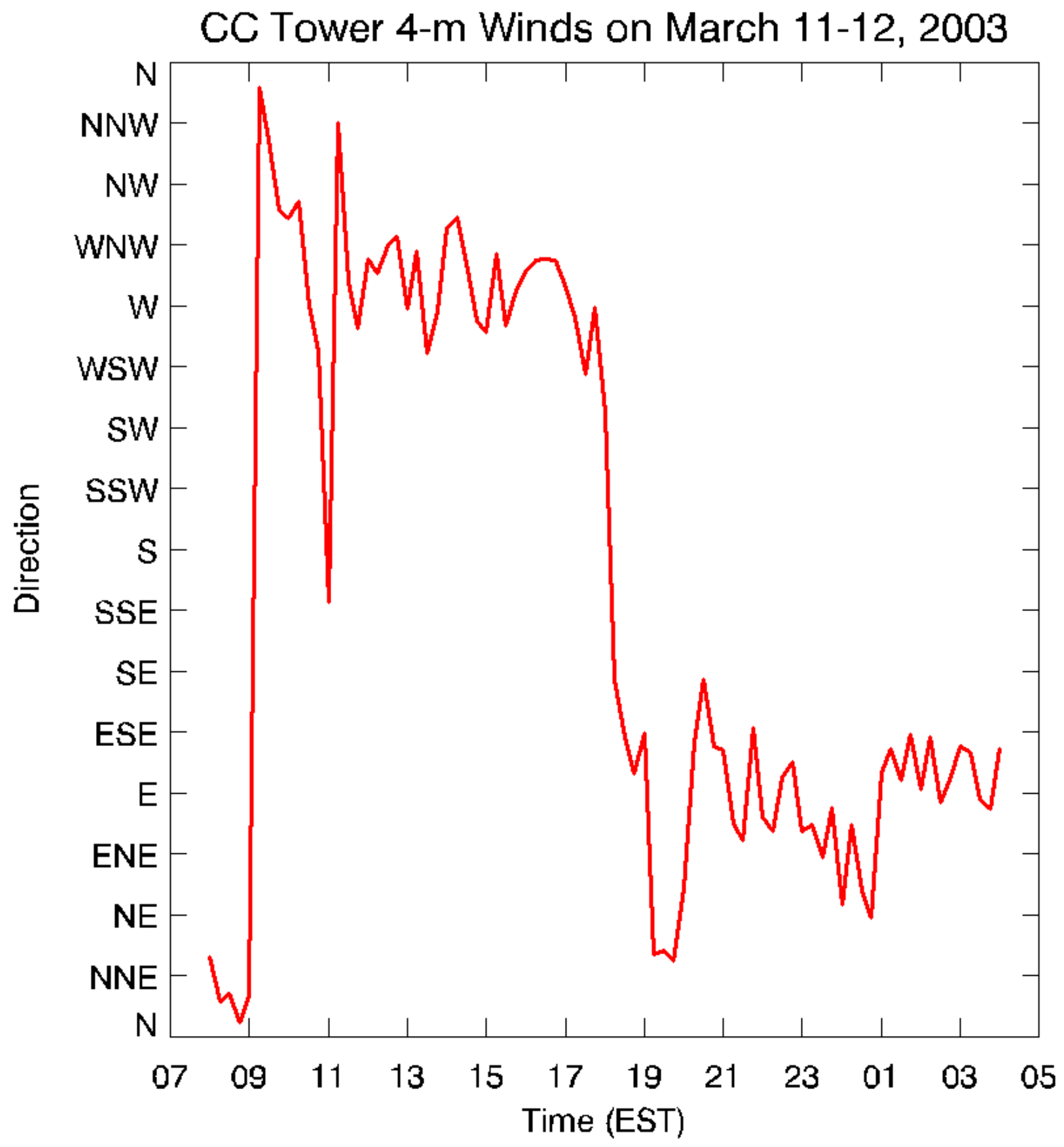

Fig. 30. A plot of the actual wind direction from the 4-m level of the CC Tower on March 11, 2003, during a controlled burn by the United States Forest Service at the SRS. This figure shows the switching of wind directions in light wind conditions from the west to the east-southeast as depicted in the wind rose plot of Fig. 8. 


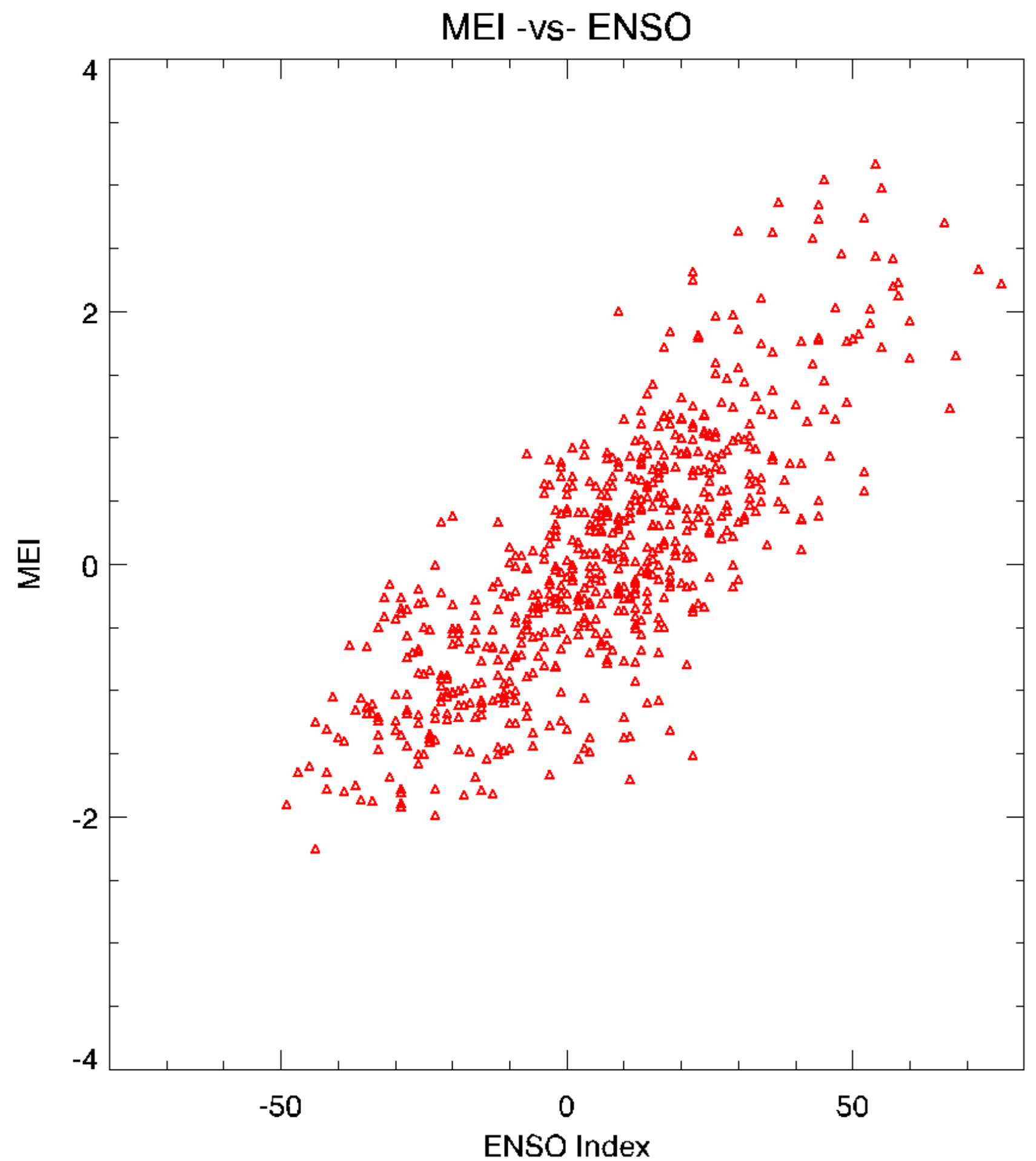

Fig. 31. A scatter plot of the MEI index versus the usual ENSO index (based on pressure differences). 


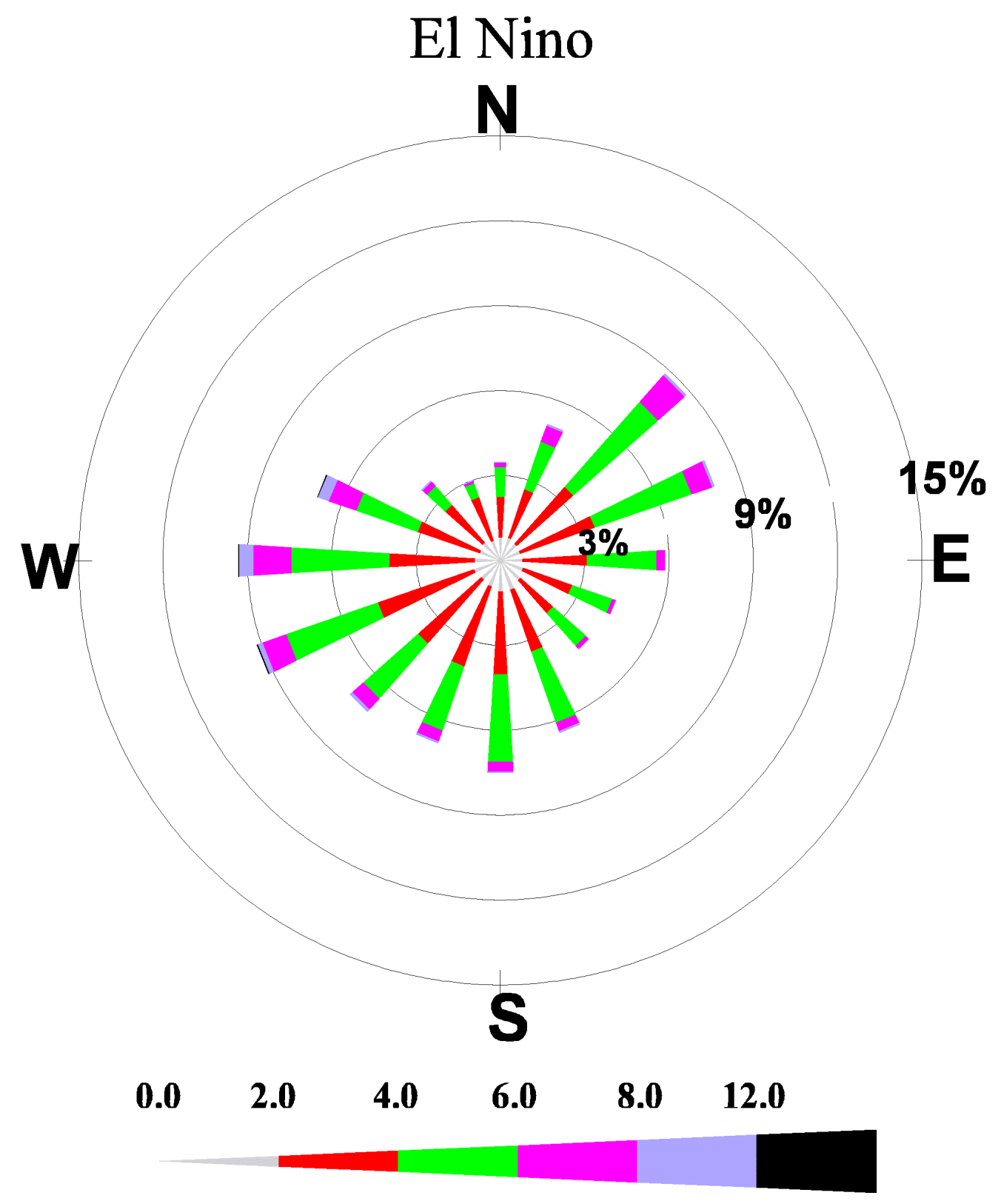

Wind Speed Class Boundaries

(Meters/Second)

Windrose plot depicts the frequency of the direction from which the wind is blowing and the wind speeds

Fig. 32. Wind rose description as in Fig. 2 for an individual level. This wind rose is for El Niño (MEI > 0.1) conditions over the 10-year period. 


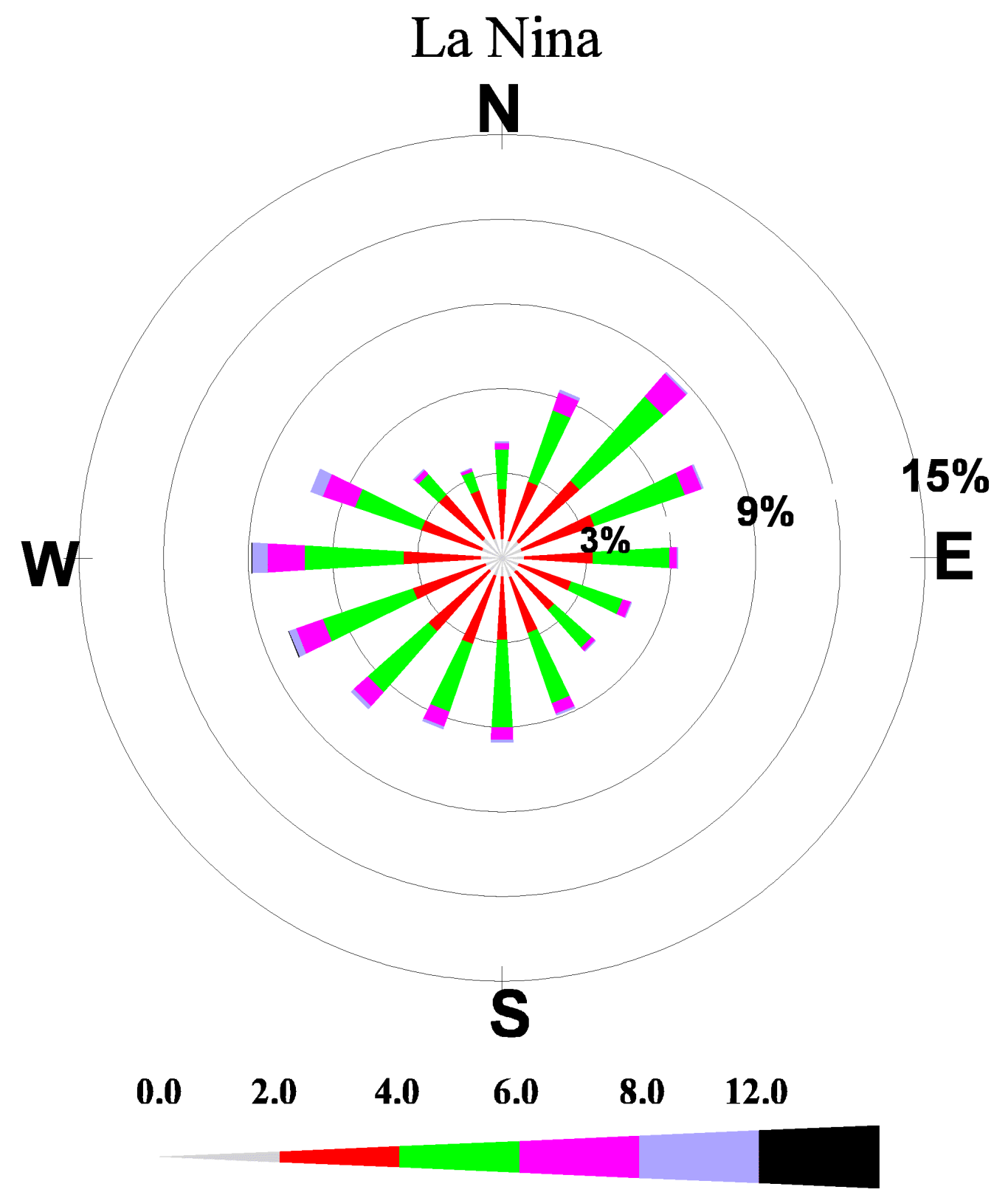

Wind Speed Class Boundaries

(Meters/Second)

Windrose plot depicts the frequency of the direction from which the wind is blowing and the wind speeds

Fig. 33. As in Fig. 31 except for La Niña (MEI <-0.1) conditions. 


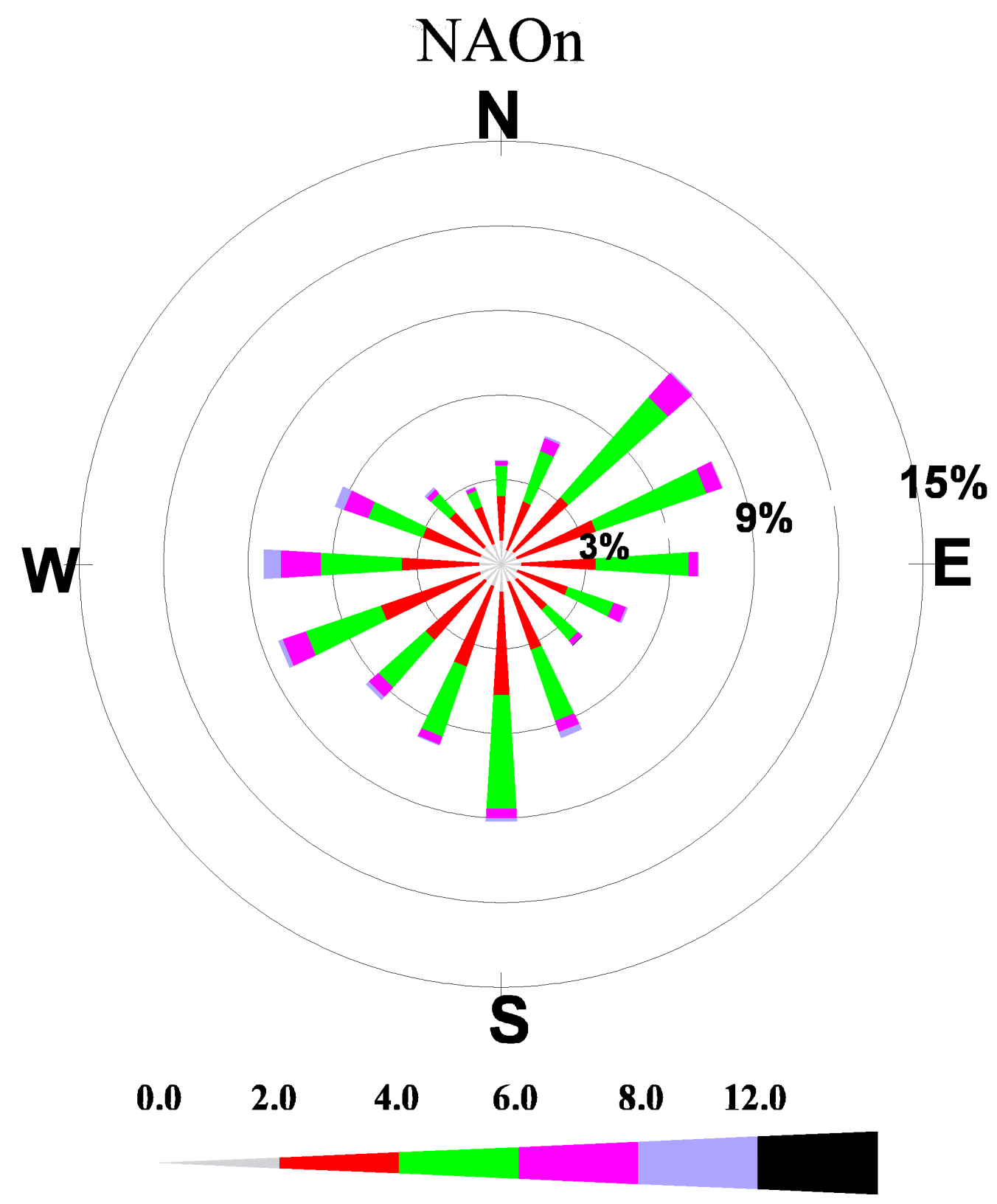

Wind Speed Class Boundaries

(Meters/Second)

Windrose plot depicts the frequency of the direction from which the wind is blowing and the wind speeds

Fig. 34. As in Fig. 31 except for neutral $(-0.1<\mathrm{MEI}<0.1)$ conditions. 


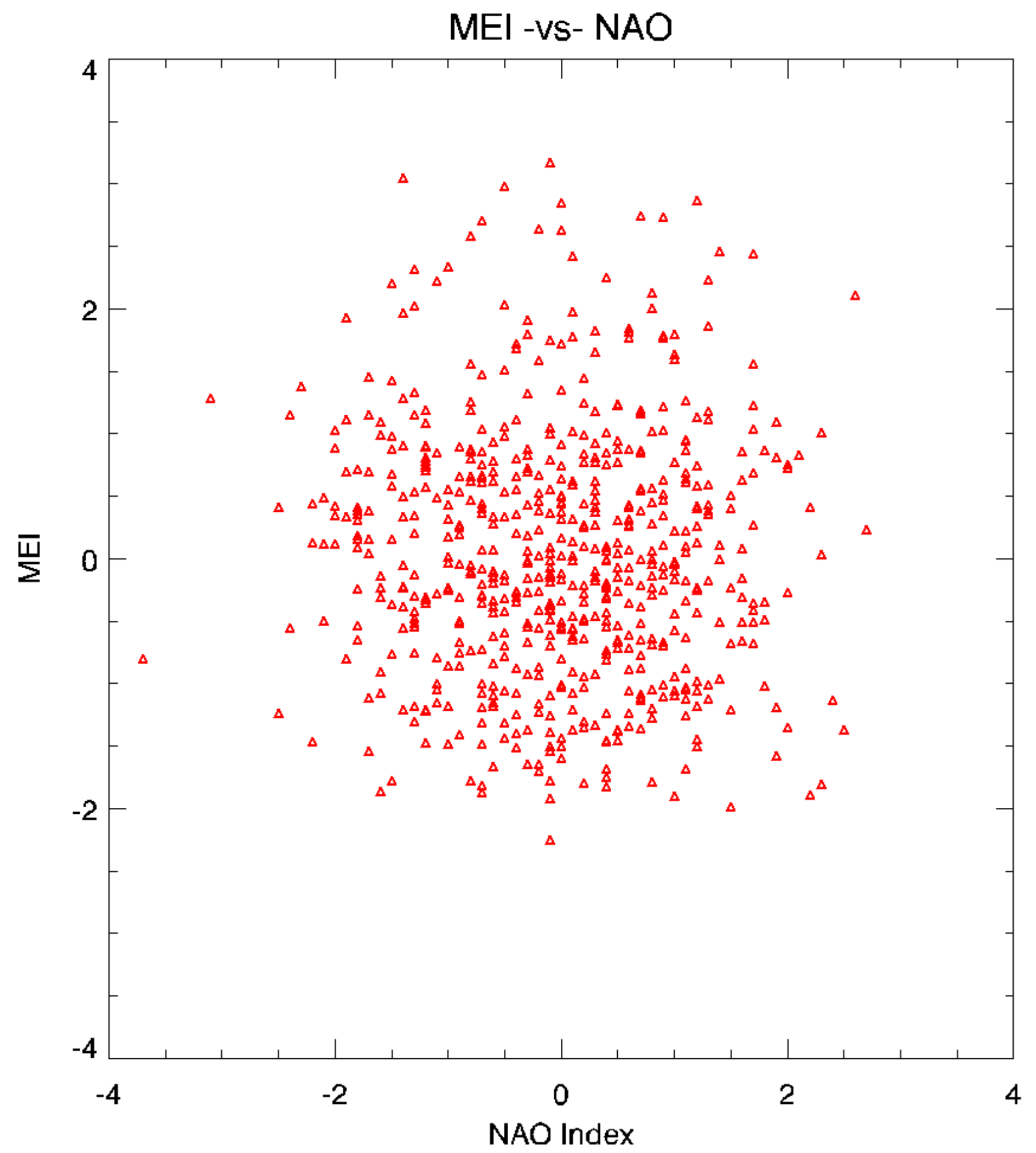

Fig. 35. A scatter plot of the NAO index versus the usual MEI index (based on pressure differences). 


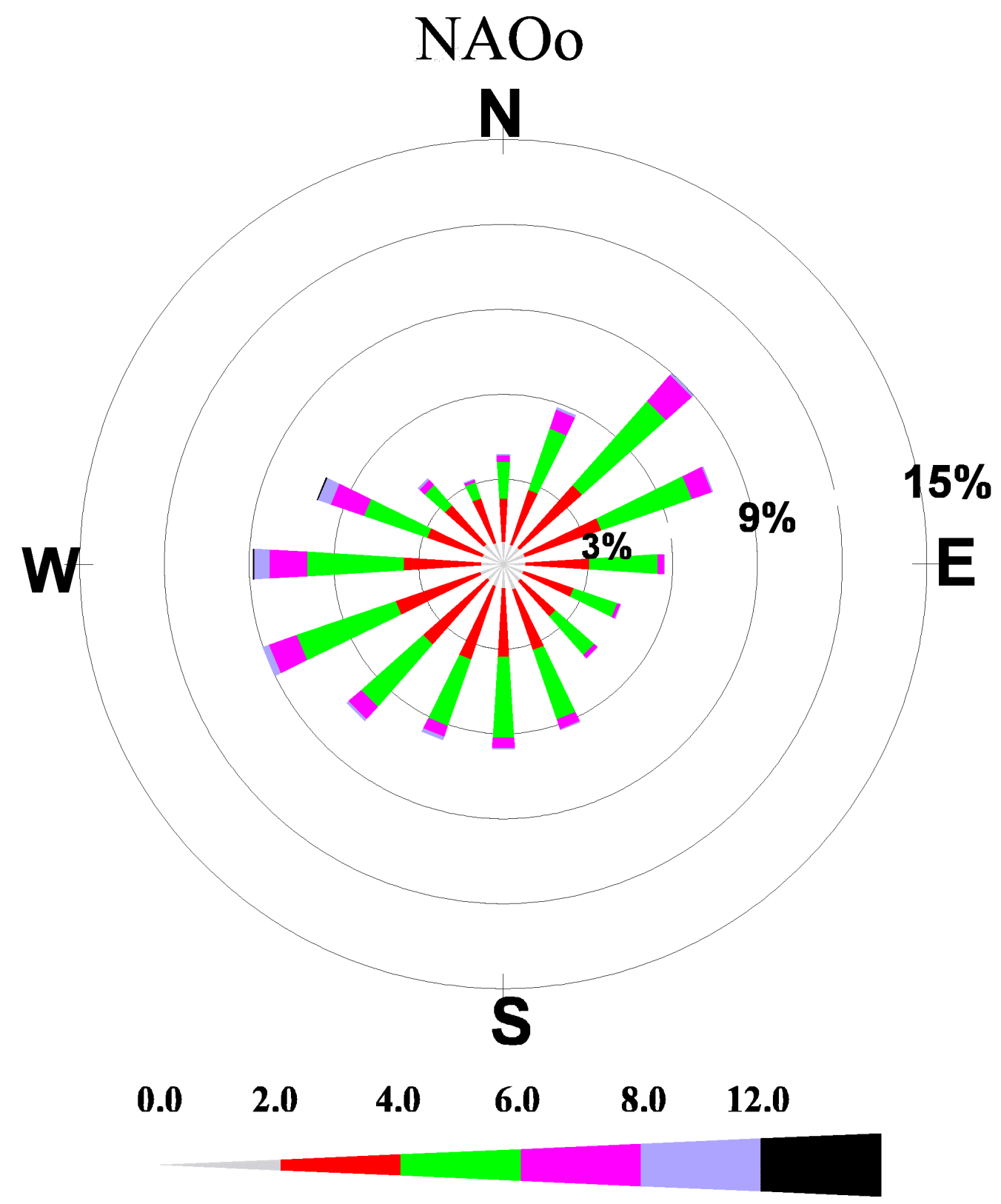

Wind Speed Class Boundaries

(Meters/Second)

Windrose plot depicts the frequency of the direction from which the wind is blowing and the wind speeds

Fig. 36. As in Fig. 31 except for NAOo (NAO> 0.1) conditions. 


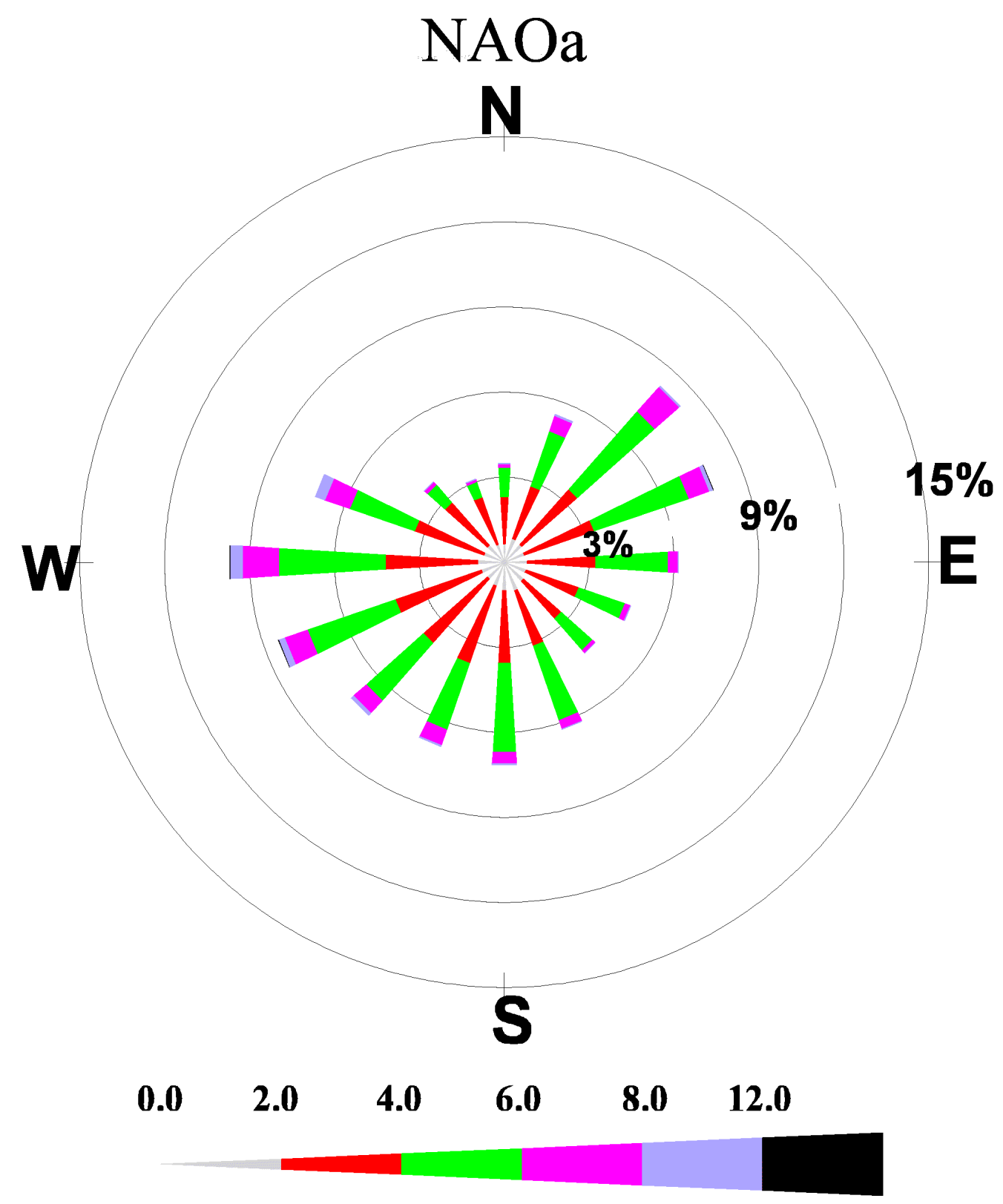

Wind Speed Class Boundaries

(Meters/Second)

Windrose plot depicts the frequency of the direction from which the wind is blowing and the wind speeds

Fig. 37. As in Fig. 31 except for NAOa (NAO<-0.1) conditions. 


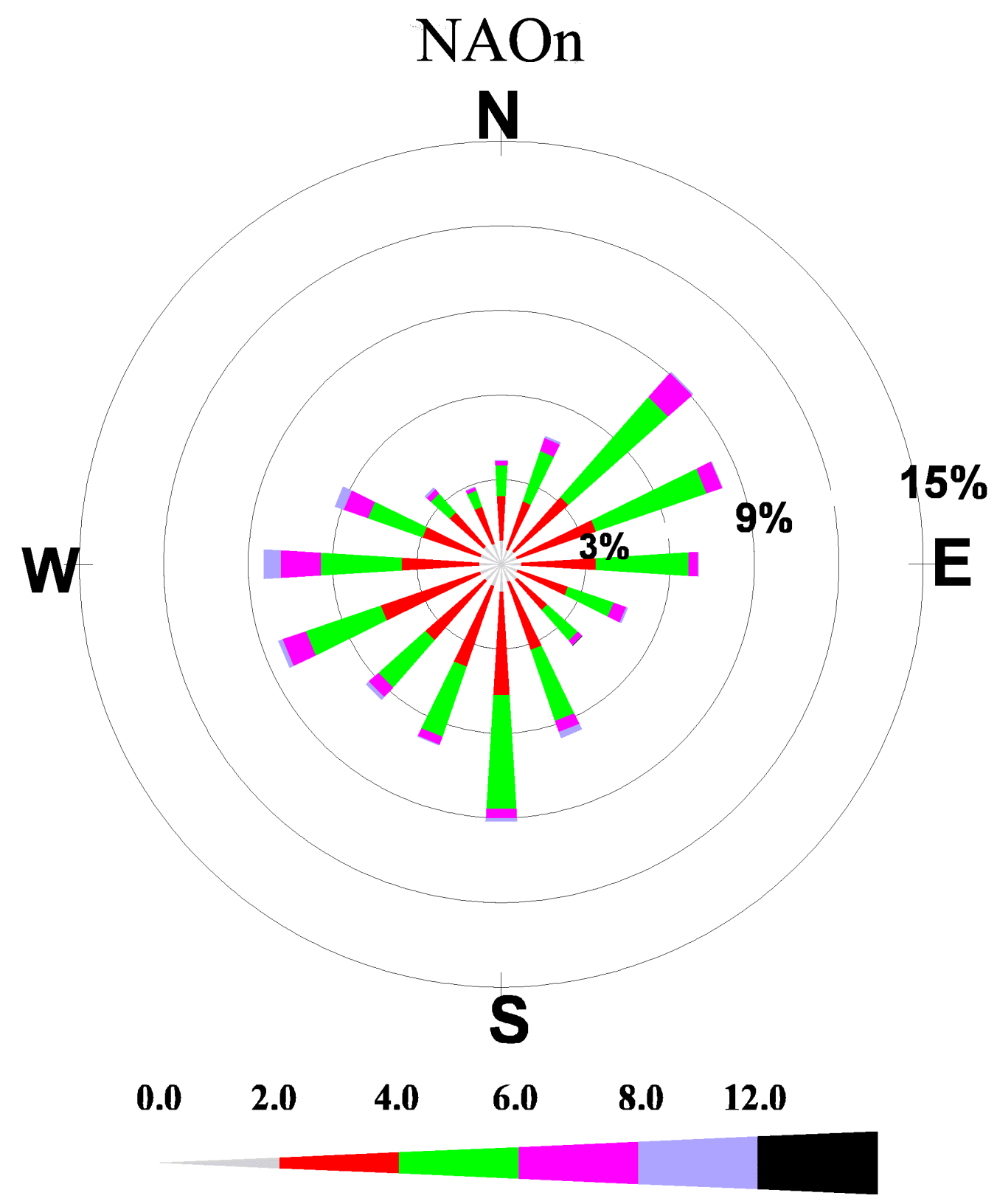

Wind Speed Class Boundaries

(Meters/Second)

Windrose plot depicts the frequency of the direction from which the wind is blowing and the wind speeds

Fig. 38. As in Fig. 31 except for NAOn $(-0.1<$ NAO $<0.1)$ conditions. 


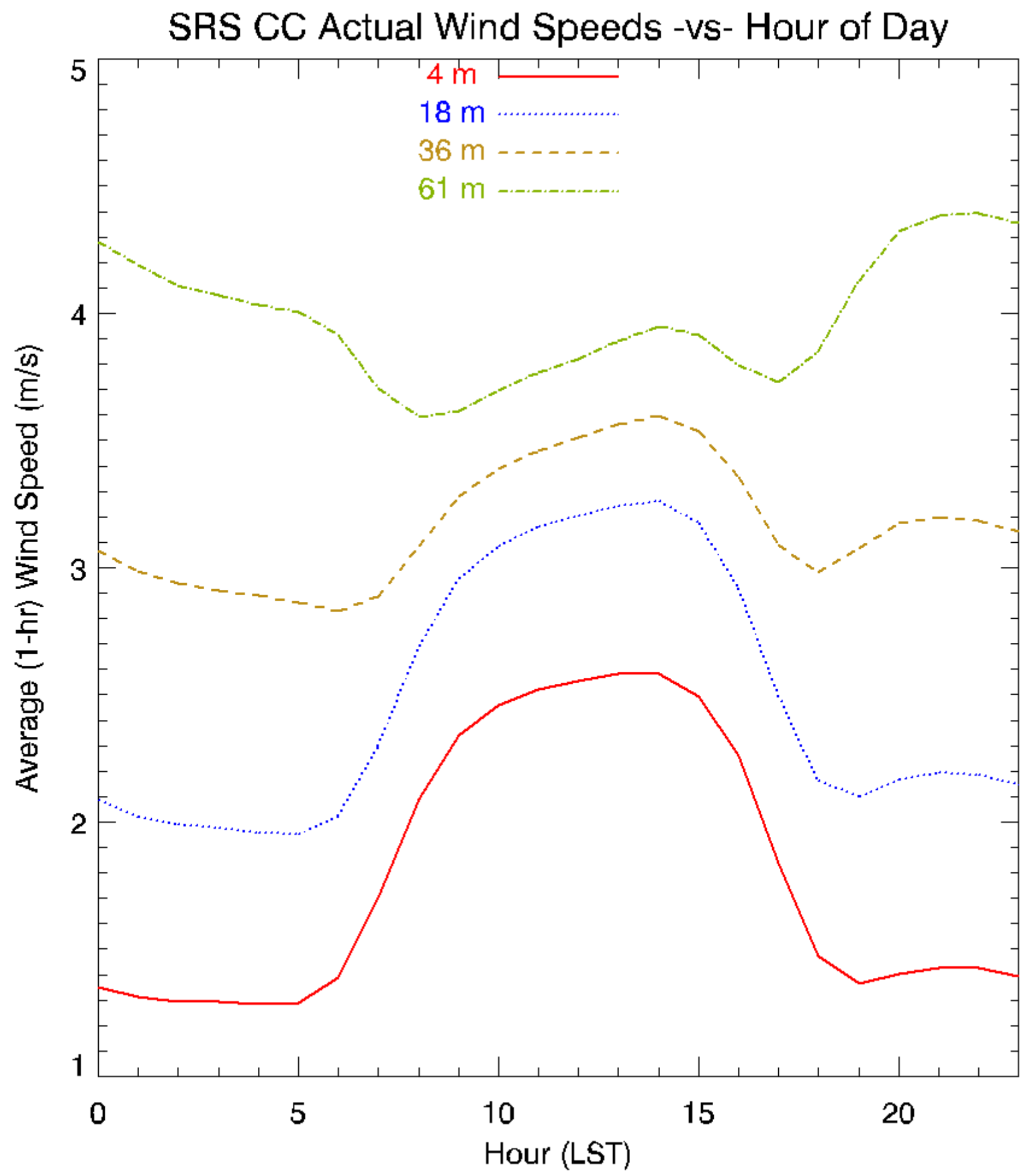

Fig. 39. Wind speeds averaged by LST hour for the entire 10-year data set (1991-2000) for the 2-4, 18, 36 and 61-m levels of the $\mathrm{CC}$ tower. 


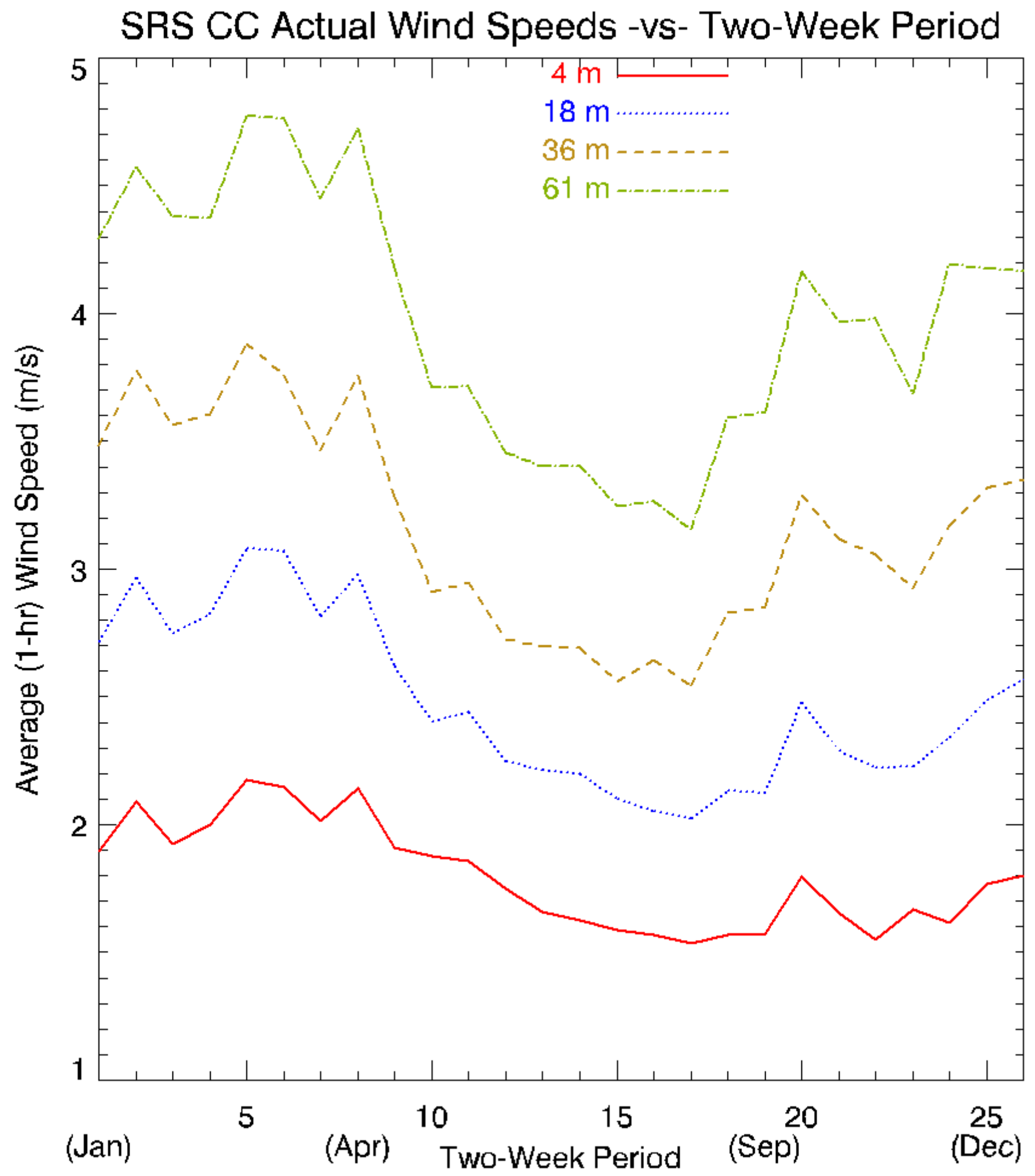

Fig. 40. Wind speeds averaged by two-week period for the entire 10-year data set (1991-2000) for the 2-4, 18, 36 and 61-m levels of the CC tower. (\#1 period is the first two weeks of January, \#2 period is the following two weeks, etc.,). 


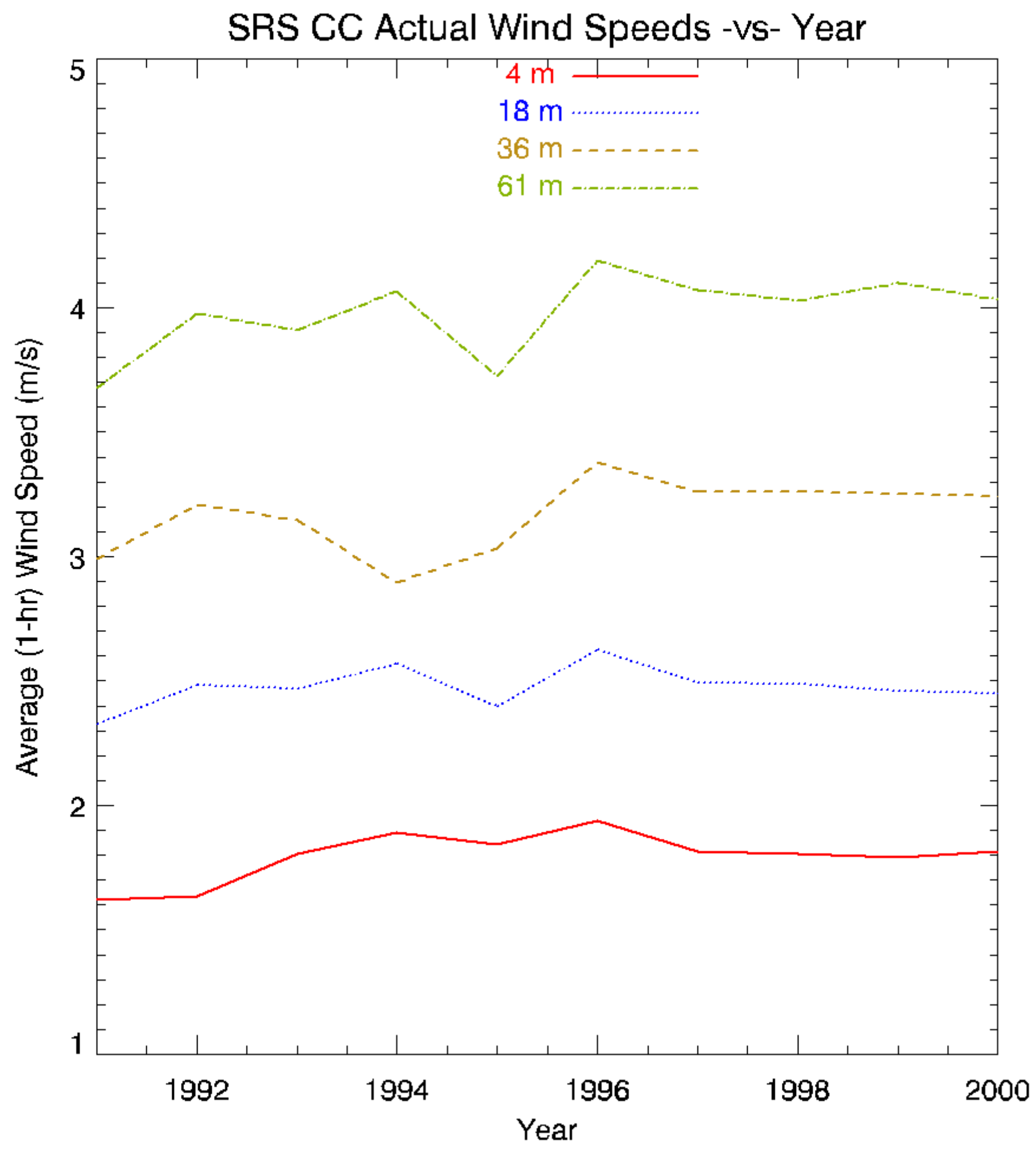

Fig. 41. Wind speeds averaged for each year of the 10-year data set (1991-2000) for the 2-4, 18, 36 and 61-m levels of the $\mathrm{CC}$ tower. 